Portland State University

PDXScholar

\title{
The Influence of Shared Mobility and Transportation Policies on Vehicle Ownership: Analysis of Multifamily Residents in Portland, Oregon
}

Edgar Bertini Ruas

Portland State University

Follow this and additional works at: https://pdxscholar.library.pdx.edu/open_access_etds

Part of the Transportation Commons

Let us know how access to this document benefits you.

Recommended Citation

Bertini Ruas, Edgar, "The Influence of Shared Mobility and Transportation Policies on Vehicle Ownership: Analysis of Multifamily Residents in Portland, Oregon" (2019). Dissertations and Theses. Paper 4842. https://doi.org/10.15760/etd.6718

This Thesis is brought to you for free and open access. It has been accepted for inclusion in Dissertations and Theses by an authorized administrator of PDXScholar. Please contact us if we can make this document more accessible: pdxscholar@pdx.edu. 
The Influence of Shared Mobility and

Transportation Policies on Vehicle Ownership:

Analysis of Multifamily Residents in Portland, Oregon

\author{
by
}

Edgar Bertini Ruas

A thesis submitted in partial fulfillment of the requirements for the degree of

Master of Science

in

Civil and Environmental Engineering

Thesis Committee:

Kelly Clifton, Chair

Christopher Monsere

Aaron Golub

João António de Abreu e Silva

Portland State University

2019 
(C) 2018 Edgar Bertini Ruas 


\begin{abstract}
Since the beginning of the $21^{\text {st }}$ Century, the world has seen the rapid development of the so-called "sharing economy" or collaborative consumption (Botsman, 2010). One of the first areas affected by the shared economy is vehicle ownership. With the emergence of several new providers of mobility services, such as Uber and car2go, there has been the promise of changes to the traditional way of owning and using a vehicle (Wong, Hensher, \& Mulley, 2017). One potential consequence of shared mobility services is the reduction in vehicle ownership. At the same time, cities are trying to anticipate these changes by reducing the amount of space dedicated to parking, including in parking requirements for residential developments.

This thesis aims to assess the extent to which new shared mobility services (specifically, carsharing, bikesharing, and ridehailing) and travel demand management strategies (especially parking requirements and transit pass availability) relate to vehicle ownership among residents of multifamily dwellings. To do this, we use a web-based survey targeted to residents of multifamily apartments from Portland, Oregon. With these data, we built a multinomial logistic of the number of the vehicles owned as a function of socio-demographics, built environment, parking supply, transit passes, and three forms of shared mobility services.
\end{abstract}


Results suggest that there is a strong association between shared mobility use and car ownership. However, it is not as significant as the effects of income, household size, distance to work, transit pass ownership, or even parking availability. Carshare use was negatively associated with the number of household vehicles, suggesting that it may be a useful tool in reducing car ownership. For respondents with higher education and income levels, increased carshare use was associated with fewer cars. Ridehail use, however, was not as clearly associated with reducing vehicle ownership and the effect was much smaller than that of carsharing. Parking availability in the building also has a significant and positive association with vehicle ownership. In sites with no parking available, there is an increased chance of the household owning less than two or more vehicles. However, this effect seems to disappear with the increased use of shared mobility. For all income levels, monthly use of ridehail and carshare between two and three times may decrease the odds of owning two or more vehicles.

The use of both options, relaxing parking requirements and shared mobility availability, seems the best strategy to reduce vehicle ownership. In the short term, it is an alternative to those residents that decide to get rid of one of all cars but still are not ready to give up using cars. For the long term, a new relationship with vehicle ownership can be built now for the younger generation. 


\section{Acknowledgments}

Thank you Dr. Kelly Clifton for motivation, encouragement, and support before, during, and after the many iterations of this thesis. Thank you Dr. Chris Monsere, Dr. Aaron Golub and Dr. João António de Abreu e Silva for your reviews and assistance as committee members. Thank you family, friends old and new, and colleagues for support throughout my US adventures. Thank you, Linnea Spitzer, for patiently showing me what academic writing is (someday I will learn that too...). Additionally, I gratefully acknowledge the National Institute for Transportation and Communities (NITC), for funding the project from which this research originates. 


\section{Table of Contents}

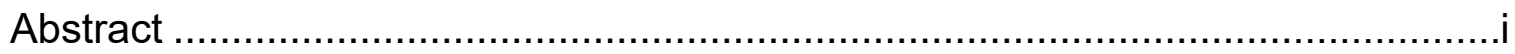

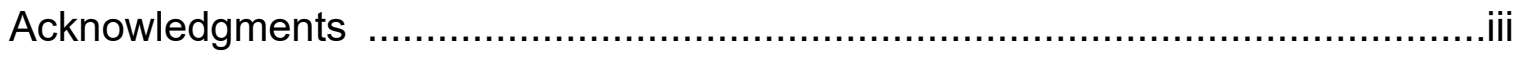

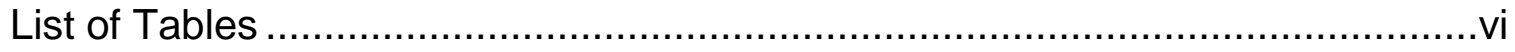

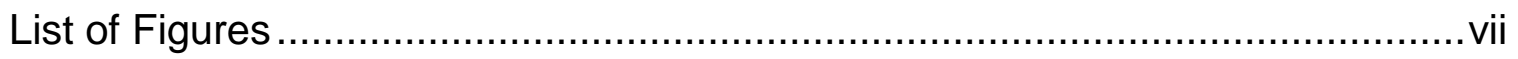

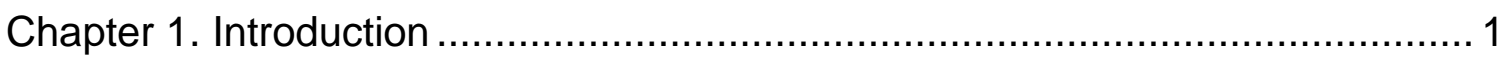

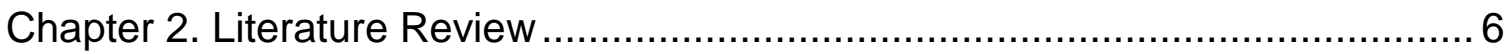

2.1 Demographics and Built Environment............................................... 7

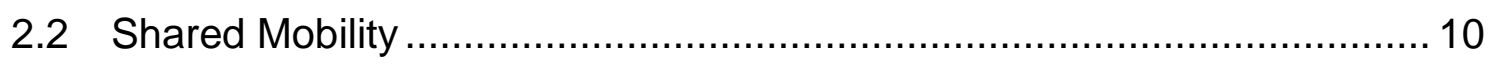

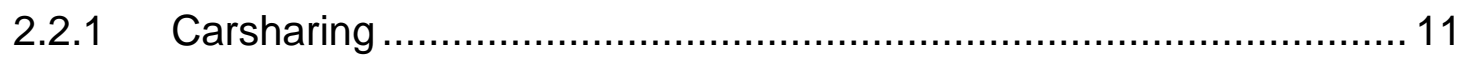

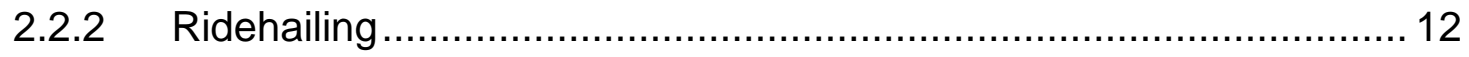

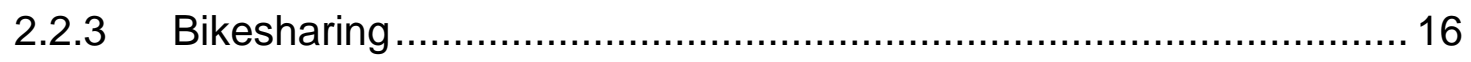

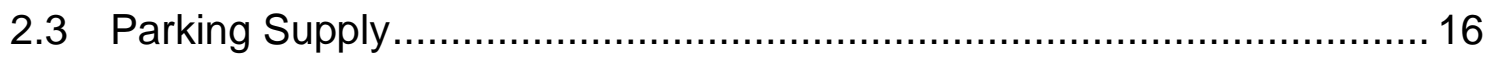

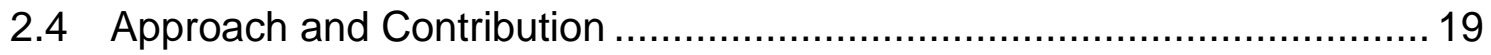

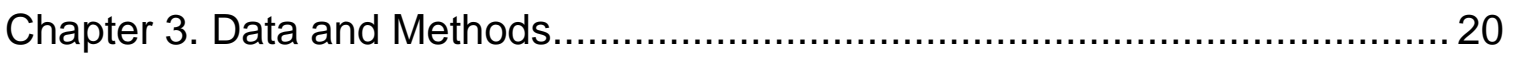

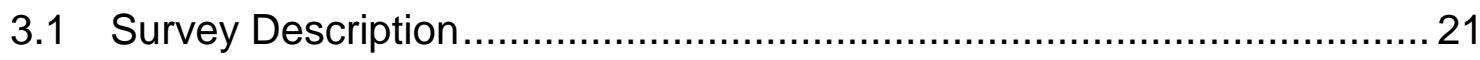

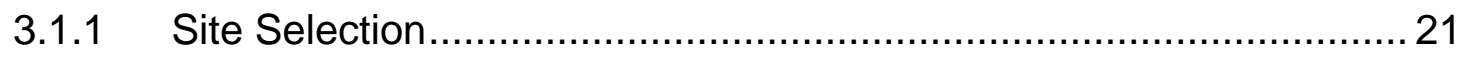

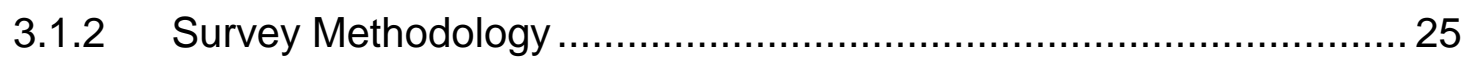

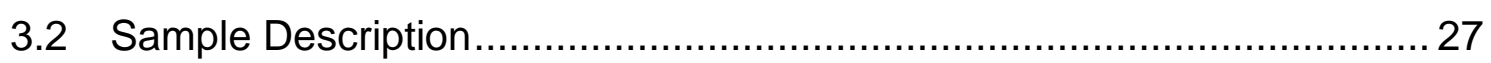

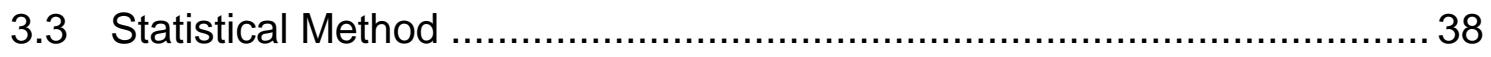

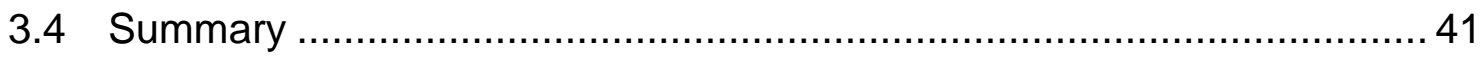

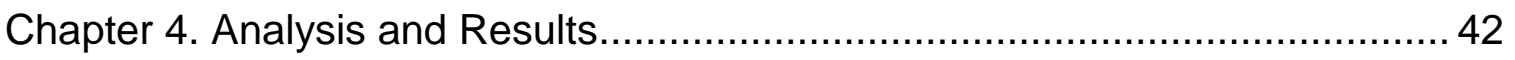

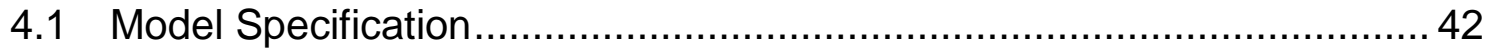

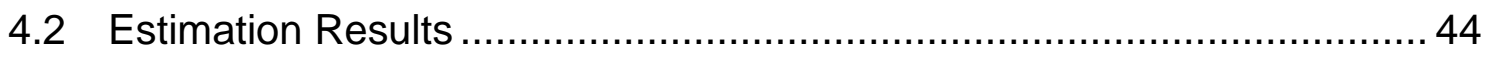

4.3 Goodness of Fit and Model Stability .................................................... 49

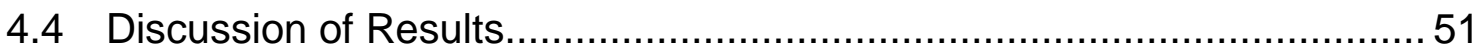

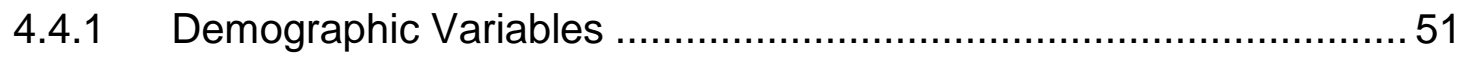


4.4.2 Built Environment Variables........................................................... 53

4.4.3 Transportation Policy Variables .................................................... 55

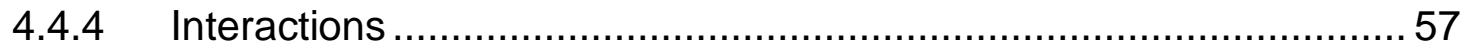

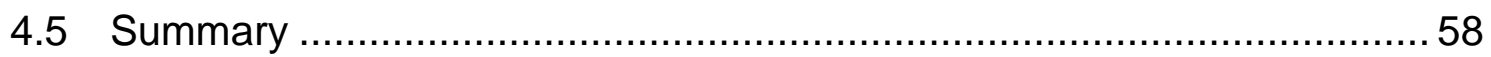

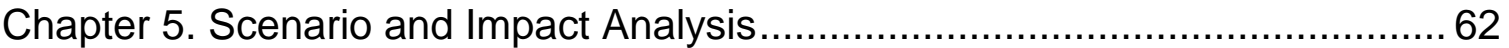

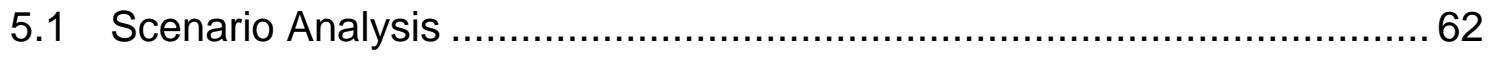

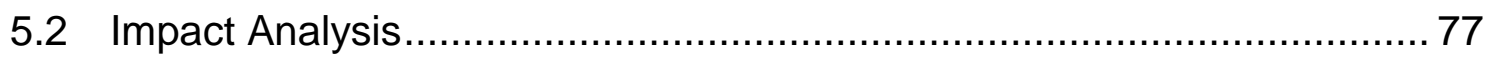

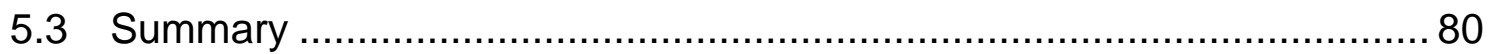

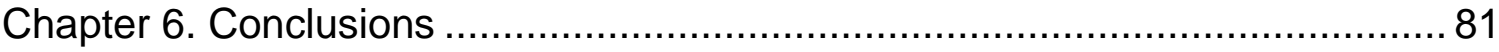

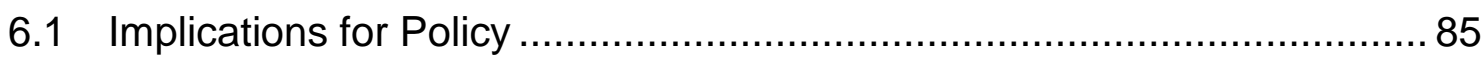

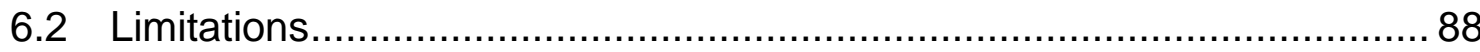

6.3 Recommendations and Future Research ........................................... 88

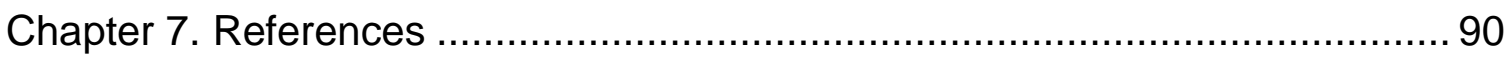

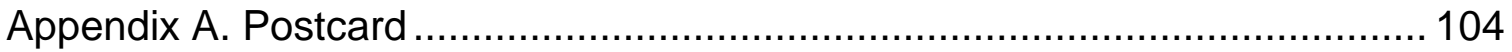

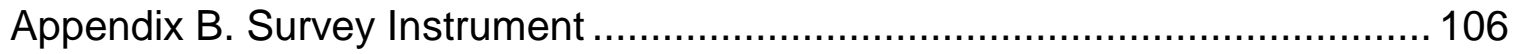

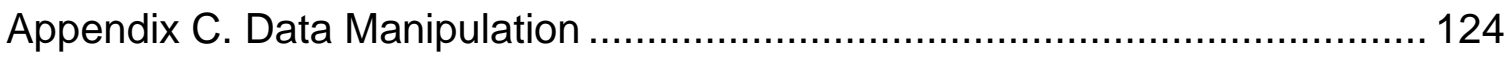




\section{List of Tables}

Table 3-1 Response Rate for the Online Survey ......................................... 23

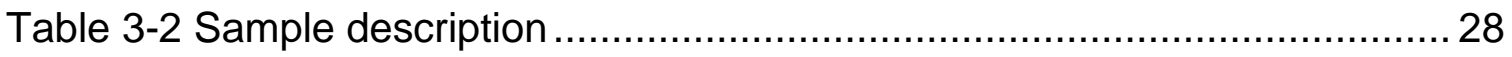

Table 3-3 Individual and Household Characteristics - continuous variables .......31

Table 3-4 Individual and Household Characteristics - categorical variables ...... 32

Table 3-5 Built Environment Measures and Sources....................................... 33

Table 3-6 Built Environment Characteristics................................................... 34

Table 3-7 Transportation Policy Options - binary variables ............................ 37

Table 3-8 Transportation Policy Options - continuous variables ....................... 37

Table 3-9 Types of Carshare Membership .................................................... 38

Table 4-1 Parameter for the three models .................................................... 45

Table 4-2 Likelihood Ratios of the variables used in the models ...................... 48

Table 4-3 Comparison of Goodness of Fit Measures between the Models ........ 50

Table 4-4 Summary of model three results without interactions ......................60

Table 5-1 Comparison of Four Scenarios of Vehicle Ownership ..................... 80

Table 6-1 Significant differences between ridehail and carshare users and not

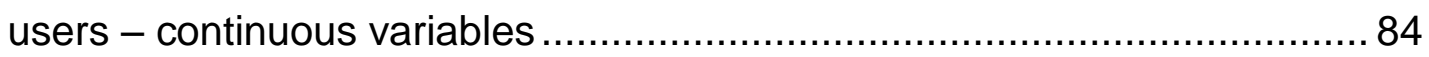

Table 6-2 Significant differences between ridehail and carshare users and not

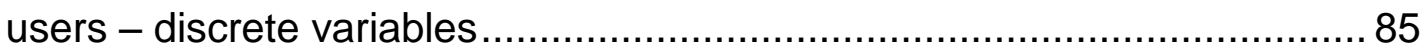




\section{List of Figures}

Figure 3-1 Distribution of Responses per Building....................................... 24

Figure 3-2 Location of all mailed sites with responses available ...................... 24

Figure 5-1 Vehicle ownership probabilities varying shared mobility use for "The

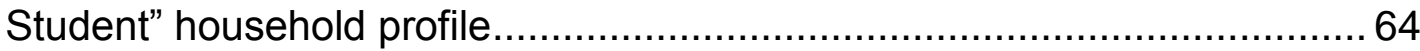

Figure 5-2 Vehicle ownership probabilities varying shared mobility use for "The

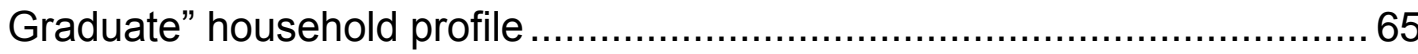

Figure 5-3 Probability of owning zero vehicle for different levels of education and

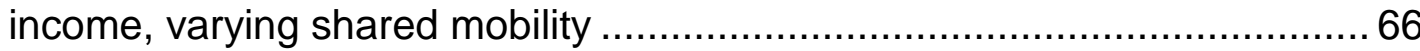

Figure 5-4 Vehicle ownership probabilities varying shared mobility use for "New

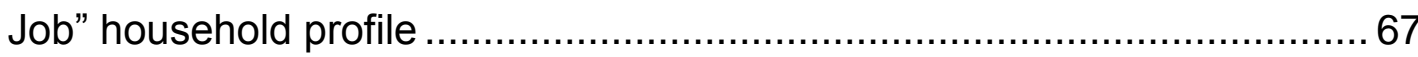

Figure 5-5 Vehicle ownership probabilities varying shared mobility use for

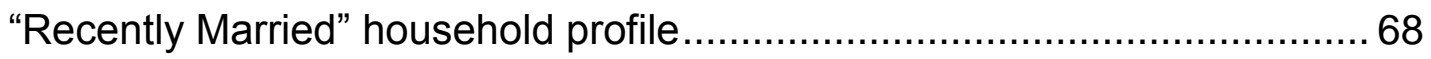

Figure 5-6 Probability of owning one vehicle for different levels of parking and

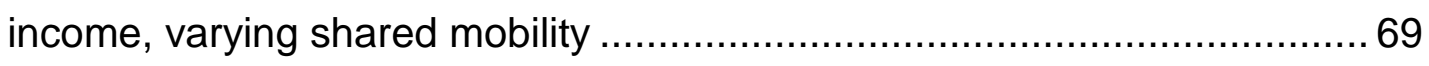

Figure 5-7 Probability of owning one car for different levels of education and income, varying ridehail use

Figure 5-8 Vehicle ownership probabilities varying shared mobility use for "Ex-

Millennial" household profile 71

Figure 5-9 Vehicle ownership probabilities varying shared mobility use for

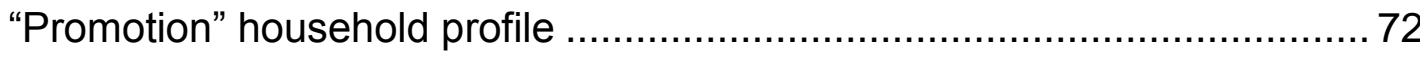


Figure 5-10 Probability of owning one vehicle for different levels of transit pass availability and income, varying shared mobility use

Figure 5-11 Vehicle ownership probabilities varying shared mobility use for "New Family" household profile 74

Figure 5-12 Probability of owning one car for different levels of household size and income, varying shared mobility use

Figure 5-13 Probability of owning one vehicle for different levels of houehold size and income, varying ridehail use 76 


\section{Chapter 1. Introduction}

Since the beginning of the $20^{\text {th }}$ Century, the automobile has been a transforming force for western societies in the way people move, live, work, consume energy and relate to the environment. Cars have become an essential part of the family, many of which until recently cannot even think or imagine living without it. To have access to a car, the family or individual would have to buy one or know someone who did. However, that premise is changing.

In last two decades, the world has seen the rapid development of the socalled collaborative consumption or the "sharing economy" (Botsman, 2010), in which people offer and share underutilized resources usually through a webbased application and provider. The sharing economy is challenging the traditional thinking about how resources can and should be provided and consumed. One of the first areas affected by the shared economy is vehicle ownership, with the emergence of several new providers of mobility services that has a direct impact on the traditional way of owning and using a vehicle. These providers can be identified as ridehailing, like Uber or lyft, carsharing, as car2go or Zipcar, and bikeshare, as Biketown in Portland, Oregon. Throughout this thesis, the term shared mobility services or just shared mobility will be used referring to carsharing, ridehailing and bikesharing together. 
For a long time, there were several stakeholders using vehicle ownership in their models to predict vehicle use for various reasons, such as regional planning, transportation policies, environmental impact, and economic development. A considerable amount of literature has been published to help understand and better predict the number of vehicles owned (Anowar, Eluru, \& Miranda-Moreno, 2014; de Jong, Fox, Daly, Pieters, \& Smit, 2004; Potoglou \& Susilo, 2008; Whelan, 2007). These studies found several factors to be influencing vehicle ownership, that can be either classified in socio-demographics (e.g., income, age, gender) (Bhat \& Pulugurta, 1998; Train, 1986) and land use or built environment (e.g. employment and population density and transit accessibility) (Ewing \& Cervero, 2010; Hess \& Ong, 2002).

There is a growing body of literature that recognizes the influence of shared mobility in changing the travel behavior of individuals. Extensive research has been done to assess the impact of carsharing in vehicle ownership, as shown in works by (Cervero, Golub, \& Nee, 2007; Martin \& Shaheen, 2011; Namazu \& Dowlatabadi, 2018 ). In contrast to carsharing, there is much less information about the effects of ridehailing on travel behavior, mainly due to the novelty of the theme and scarcity of publicly available data. The most recent and comprehensive work about the topic can be found in (Circella, Alemi, Tiedeman, Handy, \& Mokhtarian, 2018; Gehrke, Felix, \& Reardon, 2018; SFCTA, 2017; Shaheen \& Cohen, 2018). In contrast to carsharing and ridehailing, there is even 
greater lack of information about the relationship of shared mobility (or combining carsharing, ridehailing, and bikesharing use) in the number of vehicles owned by households.

In addition to the small number of studies about shared mobility and vehicle ownership, a search of the literature revealed even fewer studies that combines the effect of travel demand management such as parking supply and transit passes availability with shared mobility. Parking requirements are receiving growing attention by city planners, as a way of reducing the growing costs of housing in the US. Residential parking requirements and their effects on vehicle ownership were the subjects of a few studies (Guo Z. , 2013; Weinberger, 2012; Weinberger, Seaman, Johnson, \& Kaehny, 2008), following the seminal work by Shoup (2005) about the cost of free parking. However, we found only a few studies combining carshare services rather than shared mobility to parking supply and vehicle ownership, with mixed results (Engel-Yan \& Passmore, 2013;

Rivasplata, Guo, Lee, \& Keyon, 2013; Schure, Napolitan, \& Hutchinson, 2012). To our knowledge, no studies have tried to jointly study the effects of shared mobility and parking availability on vehicle ownership and who is being more affected by these policies.

To address this gap in research, this thesis intends to assess the extent to which new mobility services (or shared mobility) and travel demand management (especially parking requirements and transit pass availability) relates to vehicle 
ownership among residents of multifamily dwellings. To do this, we use a webbased survey targeted to residents of multifamily apartments from Portland, Oregon. With these data, we built a multinomial logistic regression model of the number of the vehicles owned as a function of socio-demographics, built environment, parking supply, transit passes and three forms of shared mobility services. To date, these transportation policies (transit passes, parking supply and shared mobility) have not been used together to assess their impacts vehicle ownership. The demand for shared mobility is considered in this thesis as a proxy to level of service or the shared mobility supply availability.

The results of this study are relevant for cities trying to lower or eliminate parking requirements for new development and reduce car ownership. Parking requirements can distort the real estate market, either by lowering the supply of housing units in favor of parking spaces or by increasing the cost of the planned development to accommodate the required parking minimum. For example, Portland, Oregon is currently supporting the development of new multifamily housing along high-frequency transit corridors by eliminating parking requirements. These housing units may also have additional on or near the site vehicle sharing (automobile and bicycle) and transportation demand policy strategies, such as free transit passes to residents. How to model and estimate the impacts of such policies in travel behavior requires as an input variable the 
number of vehicles per household, and this study provides a model to determine vehicle ownership in the household.

This thesis is structured in this general outline. Chapter 2 reviews related literature from vehicle ownership, shared mobility and parking requirements to identify the contribution of this study. Chapter 3 describes the data from a 2017 web survey in Portland, Oregon and the multiple regression method used in the analysis. Chapter 4 presents the analysis models and results. Chapter 5 summarizes the main takeaways and their implications for policy. The thesis concludes by discussing the limitations and offering recommendations for future work. 


\section{Chapter 2. Literature Review}

Vehicle ownership has been studied through multiple perspectives, such as regional planning, transportation policies, environmental impact, and economic development (Yagi \& Managi, 2016). Most of the studies are interested in mitigating the consequences of auto dependence on modern society, such as air pollution, climate change, obesity and more recently, housing prices, as car ownership influences modal split. Over the last twenty years, the understanding of the correlates with travel demand and car ownership has evolved significantly. Recently, new mobility options have emerged (as shared mobility) and urban challenges have intensified (as the soaring housing prices), which pose new demands for the various stakeholders interested in forecasting vehicle ownership.

The focus of this review will be to inform various aspects of this study. The first section is devoted to outlining the approaches to modeling vehicle ownership with demographics and built environment data, then highlights the impacts of shared mobility services such as ridehailing, carsharing and bikesharing in car ownership. Section 2.3 will briefly cover the influence of parking on vehicle ownership, and lastly, we will explain our research approach and contribution. 


\subsection{Demographics and Built Environment}

The early studies of vehicle ownership used aggregate data at local or regional level (de Jong, Fox, Daly, Pieters, \& Smit, 2004; Whelan, 2007). Since the availability of household travel surveys and detailed built environment data, most studies have focused on disaggregate models because of their superior ability to identify causal relationships (Anowar, Eluru, \& Miranda-Moreno, 2014; Potoglou \& Susilo, 2008). These disaggregate models use the household as the decision-making unit. In line with the recent literature and as a more relevant instrument to policymakers, this research will use disaggregate models.

Several variables have been consistently found to be correlated with vehicle ownership. In the work by Cirillo and Liu (2013), the attributes of car ownership and type are summarized into four categories: (1) information on the household, (2) information on the household head or primary driver, (3) land use or built environment factors, and (4) car attributes. We are using the term demographics to refer to categories 1 and 2 combined, and we are not considering car attributes, as it is not of our current interest to estimate the type (i.e., SUV, sedan) of the vehicle.

Demographic traits are fundamental predictors of vehicle ownership and have been associated with car ownership at least since 1967 (Kain, 1967). The most important demographic features found in the literature related to vehicle ownership are household characteristics and income. Kain found that family size 
and labor force participation had the strongest statistical relationships with density and vehicle ownership. Other household characteristics as number of children, adults, workers, or licensed drivers were later included and found to be significant (Bhat, Sen, \& Eluru, 2009). Another significant predictor of car ownership and use is income. For instance, in an influential longitudinal review of cars and their usage from 1958 to 1980 in 19 countries, Tanner (1983) found that "among the clearest and strongest influences are those of income levels on the number of cars, and of petrol prices on the sizes of cars and hence how much petrol they use". The consensus is that the number of vehicles tends to increase as any of these variables increases (Bhat \& Pulugurta, 1998; Potoglou \& Susilo, 2008).

A more recently included set of key explanatory variables are built environment attributes, which range from simple binary indicators (e.g., urban vs. suburban) to detailed area characteristics (e.g., population density, transit frequency). In the last twenty years, the literature dealing with the relationships between built environment and travel-related behavior focused on the five types of "D variables" - density, diversity, design, destination accessibility, and distance to transit (Cervero \& Kockelman, 1997; Ewing \& Cervero, 2010). These studies have hypothesized that households who live in denser or more mixeduse areas can access a significantly higher number of activity locations by walking, biking, or taking public transit, reducing the need to own one (or more) 
vehicles. In general, empirical results in the literature support this hypothesis. For example, considering density, increased population and residential density are associated with reduced car ownership (Hess \& Ong, 2002; Holtzclaw, Clear, Dittmar, Goldstein, \& Haas, 2002). However, the influence of compact development on changes in vehicle ownership is relatively low (Cirillo \& Liu, 2013). If we consider diversity, car ownership tends to decrease when the landuse mix increases (Chu, 2002; Potoglou \& Susilo, 2008). An example of pedestrian-oriented designed streets reducing vehicle ownership can be found in the work by Frank et al. (2006). Some examples of destination accessibility can be found on Schimek (1996) and Bento et al. (2005), which demonstrated that fewer vehicles were owned the closer to the city center a household resided. Another critical determinant of vehicle ownership is the transit accessibility. It is typically measured as the proximity to transit stations, transit supply, and jobs accessibility by a certain commute period. Increased transit access and high quality of transit service have a significant adverse effect on the number of automobiles owned (Bento, Cropper, Mobarak, \& Vinha, 2005; Potoglou \& Susilo, 2008).

As a summary of this section, vehicle ownership tends to decrease as the first four Ds (density, diversity, design, and destination accessibility) increase and the fifth (distance to transit) decreases. To conclude this section, we cite the findings of Bhat and Guo (2007, p. 524), that in the context of car ownership 
decisions, both household demographics and built environmental characteristics are influential. However, household demographics have a more dominant effect. The next section will analyze the literature concerning shared mobility (ridehailing, carsharing and bikesharing) and vehicle ownership.

\subsection{Shared Mobility}

The combination of Information and Communications Technologies (ICT) and the sharing economy has had profound impacts in several economic sectors, such as hospitality (Airbnb), education (Italki), financing (Kickstarter), the labor market (TaskRabbit) and property (BRICKX) (Wong, Hensher, \& Mulley, 2017). The transportation sector was not immune to this global trend: thanks to increased online connectivity and associated changes in individual lifestyles, the emergence of new transportation services gained traction in the early 2000s (Shaheen, Cohen, Zohdy, \& Kock, 2016). Shared-mobility services range from carsharing services, including fleet-based (as car2go) or peer-to-peer services (as getAround), to ridehail services, comprising dynamic carpooling such as Carma or BlaBla Car in Europe and on-demand ride services such as Uber and Lyft, and bikesharing services, such as Biketown in Portland, Oregon (Shaheen, Cohen, \& Zohdy, 2016).

So far, the studies on shared mobility services have shown that most users are Millennials (especially those highly-educated) and residents living in 
dense central parts of cities. The Pew Research Center (2018) defines

"Millennials" as the individuals born between 1981 and 1997. One possible reason for younger generations' early adoption of shared mobility services is their familiarity with digital platforms, a pre-requisite in almost all shared services.

Residents living in dense, central parts of the city, have greater availability of new mobility options and are more encouraged to adopt these services (as they already don't own a car) (Alemi, Circella, Handy, \& Mokhtarian, 2018; Alemi, Circella, Mokhtarian, \& Handy, 2018; Circella, et al., 2017; Circella, et al., 2016; Taylor, et al., 2015). In the next subsections, a brief review of the literature on carsharing, ridehailing, and bikesharing will be presented.

\subsubsection{Carsharing}

Martin, Shaheen and Lidicker (2010) broadly define carsharing as a mobility service in which multiple individuals share access to and use of a pool of vehicles. Since the beginning of the recent spread of modern carsharing systems in North America during the mid-90s, their business and operational models have evolved significantly. Carsharing operation can be found in two general operational models: (1) two-way or round-trip carsharing; and (2) one-way carsharing (also known as free-floating or station-based). As of January 2017, there were over 1.9 million two- and one-way carsharing users in North America sharing 24,629 vehicles, across 39 operators. If we include peer to peer 
carsharing (over 2.9 million individuals and over 131,336 cars, among six operators), total carsharing activity is estimated at over 4.8 million members and 155,965 vehicles, across 45 operators, in North America (Shaheen, Martin, \& Bansal, 2018).

Carshare can potentially impact vehicle ownership in several ways. Both one and two-way carsharing allows individuals to access a vehicle when needed without bearing the associated fixed costs, e.g., insurance, maintenance, and long-term parking (Circella, Alemi, Tiedeman, Handy, \& Mokhtarian, 2018). It also lessens the need to own multiple cars among those that already possess a vehicle (or more). Thus, carsharing may help to reduce vehicle ownership, allowing, at least, a portion of their users to get rid of one (or all) of their vehicles. As shown by Namazu and Dowlatabadi (2018), several early studies empirically demonstrated that in most cities where car sharing has been offered, members reduced private vehicle ownership by using carsharing vehicles. Other studied consequences of carsharing are the increased use of public transit, walking, and biking (Cervero, Golub, \& Nee, 2007; Martin \& Shaheen, 2011; Mishra, Clewlow, \& Mokhtarian, 2015).

\subsubsection{Ridehailing}

Perhaps no shared mobility services are more controversial and disruptive as on-demand ride services or ridehailing, such as Uber and Lyft. They are also 
the newest and fastest growing industries in mobility services. On-demand ride services primarily resemble traditional taxi services and differ from conventional rideshare in that they connect travelers with the pool of available drivers through a smartphone application. There are two types of drivers reflecting the nature of ridehail services: one is dedicated to driving the passenger exclusively to his destination (services such as UberX) and the second is already going to a destination that matches the new passenger desire (such as UberPool or BlaBlaCar).

As of November 2017, Uber operated in more than 700 cities (expanded into about 80 countries); Lyft operates mainly in the U.S. market, providing rides in more than 300 cities (Shaheen, Totte, \& Stocker, 2018). As the popularity and availability of ridehail services increases, their impacts on travel behaviors become apparent. Approximately $15 \%(170,000)$ of all trips on a typical weekday inside the city of San Francisco was made by ridehail companies (SFCTA, 2017).

There are not many studies investigating the factors influencing the frequency of using ridehail services. A survey by Rayle et al. (2014) showed that frequent users of on-demand ride services in San Francisco are mainly highly educated young adults. Another study by the Pew Research Center (2016) reported that out of the $15 \%$ of respondents using ridehail $(\mathrm{N}=4,787)$, only $3 \%$ and $12 \%$ said to use on a daily and weekly basis, respectively. The research confirmed that younger adults tend to use on-demand ride services more 
frequently. Accordingly to Feigon and Murphy (2016), the most frequent users of ridehail live in middle-income households (annual incomes of $\$ 50$ to $75 \mathrm{~K}$ ). These three studies agreed that regular ridehail users are more likely to live in households with a lower-than-average number of vehicles and tend to be multimodal, using more public transit or active modes.

Recent studies have identified three different types of ridehail users (Alemi, 2018; Circella, Alemi, Tiedeman, Handy, \& Mokhtarian, 2018): 1. Highereducated independent millennials who live in more urban locations that make more long-distance leisure trips and are more frequent users of ICT and smartphone apps; 2. Affluent older Generation X and dependent Millennials living with their families, who make more long-distance trips for business purposes, have higher income and use ICT more often (the Pew Research Center (2018) defines "Generation X" as the individuals born between 1965 and 1980); 3. Rural dwellers and individuals with low education and who live in low-income households.

Accordingly to Taylor et al. (2015), ridehailing may affect activity patterns, mode choice, vehicle ownership, and vehicle miles traveled. Nevertheless, the impact of ridehail services on other means of transportation varies based on the type of services available, the local context, and the characteristics of the users. For example, around $30 \%$ of Millennials and $50 \%$ of Generation X would have driven a car and would have taken a taxi in the absence of Uber and Lyft (Alemi, 
Circella, Handy, \& Mokhtarian, 2017). There are impacts of ridehail in active modes too. A report by Feigon and Murphy (2018) showed that average Uber/Lyft trips are between 2 to 4 miles long in five metropolitan regions of the US, potentially capturing walk and bike trips. The study by Hampshire et al. (2017) in the city of Austin, TX found that the suspension of Uber/Lyft led to a small increase around $2.5 \%$ in the use of active modes, supporting the substitution effect of ridehailing on walking and biking.

The association between ridehailing and vehicle ownership has also been highlighted by recent studies. A Reuters/lpsos opinion poll in 2017 (Henderson, 2017) revealed that $9 \%$ of Uber and Lyft users plan to get rid of their vehicles and turn to ridehail services instead. In Austin, 17\% of Uber and Lyft users were considering purchasing a car or purchased a vehicle due to the suspension of ridehail services (Hampshire, Simek, Fabusuyi, Di, \& Chen, 2017). Accordingly to rough estimations of Davidson and Webber (2017), it is possible that for $25 \%$ of Americans, using ridehailing would be more cost-effective than owning a car. If we consider autonomous vehicles, this proportion could increase significantly. As drivers are the main costs of ridehail services, creating a fleet of autonomous vehicles that eliminates the need for a driver would reduce the costs of ridehail trips significantly. 


\subsubsection{Bikesharing}

Bikesharing provides users with on-demand access to bicycles for shortdistance trips that seem too long for walking, usually in urban areas. Like carsharing, there are many business and operational models for bikesharing, such as dock-based, dockless, GPS based systems, and peer-to-peer. As of 2015, there were 61 bike-sharing programs in more than 85 cities in the U.S., with approximately 30,750 bikes and 3,200 stations (Shaheen, Chan, Bansal, \& Cohen, 2015).

Bikesharing has been associated with an increase in mobility and may increase transit use with the coupling of bikesharing, and transit stops (Nair, Miller-Hooks, Hampshire, \& Busic, 2013). Bikesharing programs have also reduced driving and vehicle ownership in almost every city in which they are available. In a study of four bike-sharing programs in the US and Canada, Shaheen et al. (2014) found that half of all bike-sharing members reported reducing their personal automobile use. They also found that approximately $2 \%$ of the respondents stated that bikeshare was somewhat to very important in their decision to sell or donate a private vehicle.

\subsection{Parking Supply}

Almost all major cities have some parking requirements for new developments in each land use type. Usually, the requirements consist of a 
minimum amount of parking spaces, with a few exceptions so far, as found in London (Guo \& Ren, 2012) or Buffalo, NY (Hess D. B., 2017). There are at least two undesirable effects of providing minimum parking requirements. One is the distortion caused in the housing market, altering the values of the houses and land usage. As is stated by Manville (2013, p. 1):

When local governments require on-site parking for new housing, the cost of housing rises and the price of driving falls. The cost of parking, which drivers should arguably pay at the end of their trips, is instead paid by developers at the start of their projects. The final cost of driving becomes an up-front cost of property development.

More studies confirm this effect (Gabbe \& Pierce, 2016; Jia \& Wachs, 1999; Litman, 2010; McDonnell, Madar, \& Been, 2011). For San Francisco, Jia and Wachs (1999) estimated a $10 \%$ increase in the value of single-family houses and condominiums that had off-street parking. Using data from the American Housing Survey, Gabbe and Pierce (2016) estimated that an additional $\$ 1,700$ per year or $17 \%$ increase in rent is due to minimum parking requirements.

Unbundling parking from the apartment is an alternative some cities are pursuing to reduce housing costs. Allowing developers to decide the amount of 
parking to be built and not bundling its offer to the apartments can reduce rental costs and promote car-free households (Durning, 2013). Besides, the area before reserved for parking can be converted to new housing units thus increasing the supply of housing units.

The second undesirable effect of minimum parking regulations is the increase in car ownership and use. It is rare to find literature discussing car ownership and use explicitly considering the effects of parking availability at home (Guo Z. , 2013). This is likely because the data available for off-street parking for residential units are more difficult to obtain, fewer studies were made that explicitly recognizes the parking availability at home as a predictor for car ownership. A few recent studies confirm how the influence of parking availability at home significantly increases the likelihood of car ownership and use (Guo Z. , 2013; Weinberger, 2012; Weinberger, Seaman, Johnson, \& Kaehny, 2008). For example, Guo (2013) found that 1 in 11 cars in a suburb of New York could be explained by the availability of free on-street parking.

Even fewer studies have investigated the influence on car ownership of the use or availability of shared mobility options and the existence or not of residential parking. To our knowledge, only the effects of carsharing programs on residential parking requirements were studied. (Engel-Yan \& Passmore, 2013; Rivasplata, Guo, Lee, \& Keyon, 2013; Schure, Napolitan, \& Hutchinson, 2012). The results of these studies did not confirm but suggested a trend of reducing 
vehicle ownership for multifamily developments with carsharing services and reduced parking requirements.

\subsection{Approach and Contribution}

As guided by existing literature, this study examines vehicle ownership at the household level through the estimation of a multinomial logistic model that will be explained in the following chapters. We will control for individual and household demographics, such as income, age, education and household size,

and built environment, with population density, employment density, intersection density.

What is new in this research is the inclusion of transportation policy variables in the model, with a specific focus of the suite of new shared mobility services. In this study, we analyze the association of parking availability at the residence, transit pass availability, and the use of carsharing, bikesharing, and ridehailing. These variables have not been combined to evaluate their association with vehicle ownership, especially for the population of this study: residents of multifamily dwellings. The data and analysis methods are presented in the next chapter. 


\section{Chapter 3. Data and Methods}

This research proposes to understand the influence of emerging mobility services (such as ridehailing and carsharing) and transportation policy measures (as reduced parking and transit passes) on household vehicle ownership of multifamily dwellers while controlling for socio-demographics and the built environment. There are four main themes to be studied. First, the characteristics of the individuals living in households owning fewer cars. Then, we are interested in the magnitude of the effects of both shared mobility services and transportation policies on the number of household vehicles. We are also interested in the profile of the mobility services being used and the people using shared mobility. To accomplish this, data from a 2017 online travel survey targeted to residents of multifamily apartments from Portland, Oregon are used, augmented with archived spatial data.

In this chapter, an overview of the data collection process and a summary of the data will be provided. The first section describes the site selection and survey methodology. Section 3.2 gives a demographic description of the sample, divided by individual and household characteristics, built environment and transportation options. Section 3.3 provides an overview of the statistical method used in the analysis. Lastly, a summary of the data collection process and data are presented. 


\subsection{Survey Description}

\subsubsection{Site Selection}

The sampling frame for this study was multifamily residential sites in the City of Portland, Oregon. Since 2002, Portland has been encouraging the development of new multifamily housing with no parking, unbundled parking, or with less supply than parking standards would allow along high-frequency transit corridors (City of Portland, 2018, pp. 266-3). These housing developments may also have additional transportation demand management strategies (TDM) on or near the site, such as transit passes provided by the building and on- or off-site vehicle sharing (automobile and bicycle). The survey was conceived to be able to test the impacts of these transportation options as well as the impact of various built environment measures. A stratified sampling frame was developed to target multifamily developments that were: a) sites with zero or reduced parking (the policy group), and b) other sites that have parking, do not have TDM programs but are similarly situated regarding accessibility (the control group).

A total of 304 multifamily developments were selected, based on information provided by the City of Portland and onsite visits done by the research team. For the policy group, we selected some sites that have been built since 2002 when the reduced parking policies when into effect as well as a few developments constructed before World War II with no parking that were in or 
near the city center. The control group was then selected based upon sites that were similarly situated to the policy group but that had on-site parking available (see Figure 3-2).

We identified 11,610 individual unit addresses from the 304 sites. Between June and September of 2017, they were mailed a postcard, inviting residents to participate in a 15-minute online survey about a neighborhood transportation study. In the letter, the web address of the study and personal code to allow access to the survey site were provided. Participants were offered the opportunity to voluntarily enter themselves in a raffle of five US\$50 gift cards at the completion of the survey. A copy of the postcard can be found in Appendix A.

The postcards were first sent to a pilot group of 350 apartments in five sites, to test the survey administration process. After small adjustments to the survey, the remaining 11,260 postcards were sent in four different waves. Due to a low initial response rate in the first four waves (3.5\%), a reminder postcard was sent to the addresses of the first three waves to increase the sample. The final valid response rate, excluding those units where postcards were returned as undeliverable and respondents, who entered wrong codes or left too many blank answers was $4.6 \%$, as can be seen from Table 3-1 below. Although the response rate was low, this is similar to other studies using a similar technique in Oregon (Clifton, Gehrke, \& Currans, 2015). 
Table 3-1 Response Rate for the Online Survey

\begin{tabular}{|c|c|c|c|c|c|}
\hline \multirow{2}{*}{$\begin{array}{l}\text { Survey } \\
\text { Wave }\end{array}$} & \multirow{2}{*}{ Sent } & \multicolumn{3}{|c|}{ Responses } & \multirow{2}{*}{$\begin{array}{c}\text { Response } \\
\text { Rate }\end{array}$} \\
\hline & & 1st Mailing & Reminders & TOTAL & \\
\hline PILOT & 350 & 29 & 3 & 32 & $9.1 \%$ \\
\hline 1 & 1012 & 36 & 24 & 60 & $5.9 \%$ \\
\hline 2 & 3422 & 80 & 32 & 112 & $3.3 \%$ \\
\hline 3 & 1851 & 84 & 62 & 146 & $7.9 \%$ \\
\hline 4 & 3802 & 185 & & 185 & $4.9 \%$ \\
\hline TOTAL & 11610 & 414 & 121 & 535 & $4.6 \%$ \\
\hline
\end{tabular}

The 535 valid responses came from 169 of the total 304 sites identified (56\% of the sites). The average response rate per building was $6.4 \%$ (or 3.16 responses), ranging from $0.4 \%$ (1 response from a 228 -unit building) to $67 \%$ (2 replies from a 3-unit building). The distribution of the responses per building can be seen in Figure 3-1 below, with the maximum amount of answers being 32, for a development of 654 units (4.9\% response rate). Figure 3-2 shows the location of the sites that received the postcard but did not answer (dark purple) and the sites that participated in the survey (light yellow). 


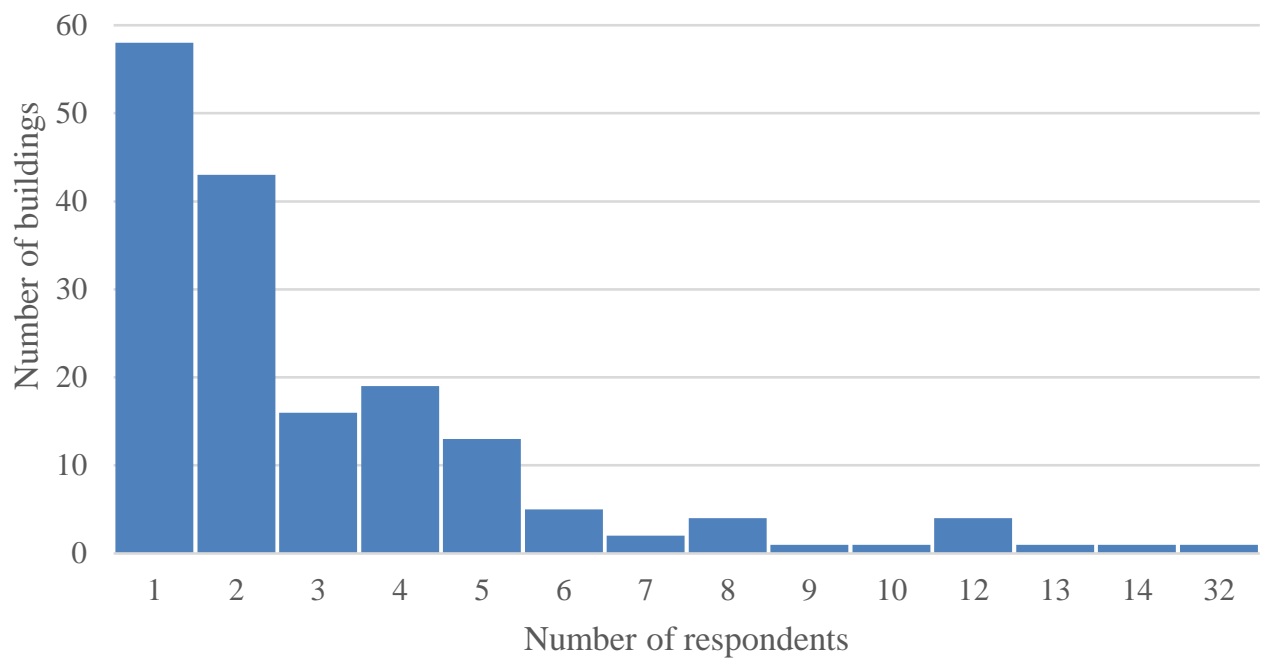

Figure 3-1 Distribution of Responses per Building

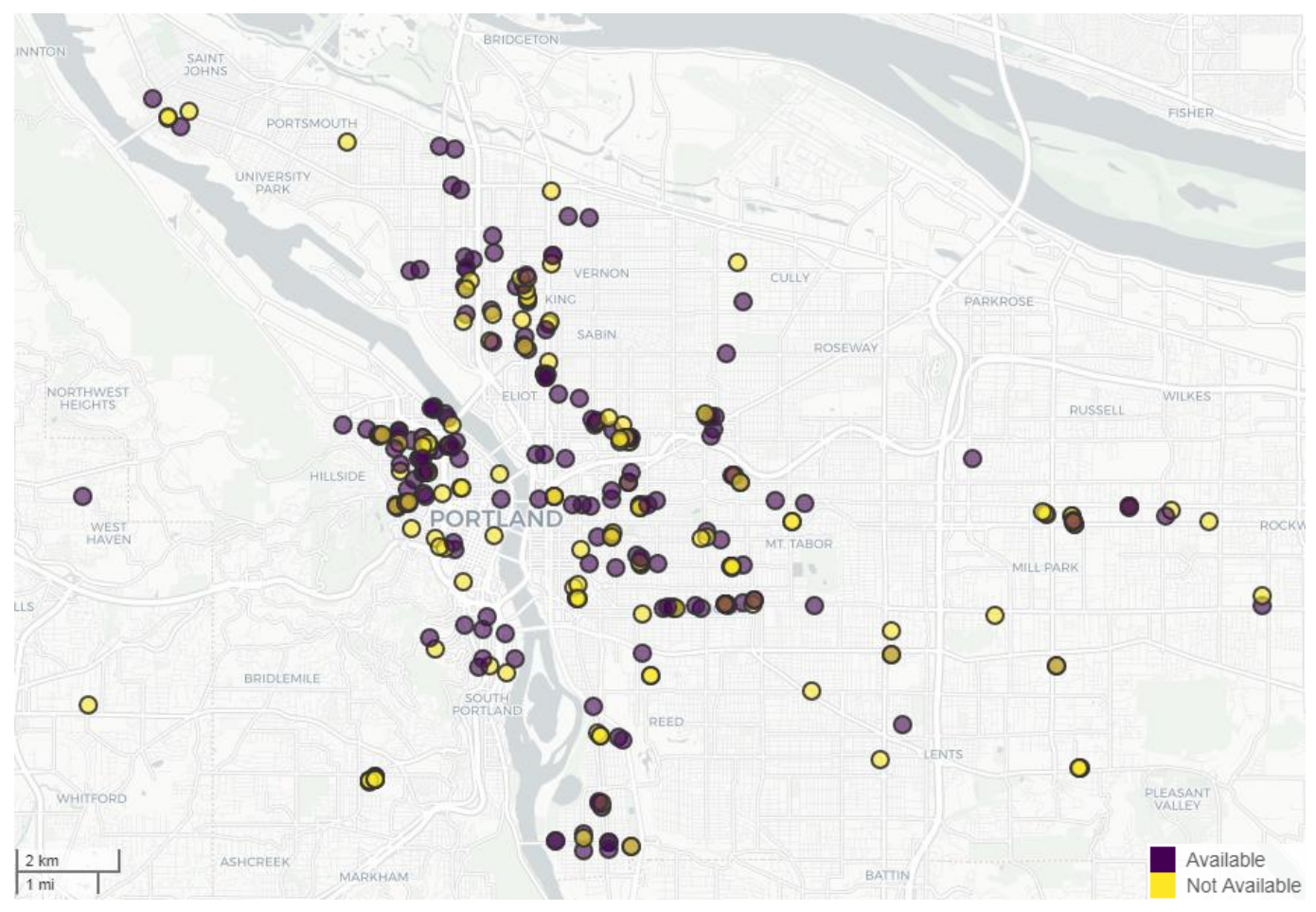

Figure 3-2 Location of all mailed sites with responses available 


\subsubsection{Survey Methodology}

The online survey was designed and administered using the software Qualtrics, which was available free for researchers at Portland State University. One of the original objectives of the survey was to test a new and lower cost methodology of collecting trip generation and vehicle miles traveled data instead of the resource and time-consuming traditional intercept count surveys for a building. Given the low response rate, the online survey was not appropriate for replacing or characterizing a development's trip generation pattern. On the other hand, it provided valuable insights to describe the residents and their habits if the sample is considered.

One might also argue that an online survey may exclude parts of the population that do not have access to or do not know how to access a webenabled device. However, $98.7 \%$ of the inhabitants in Portland have wired broadband internet access available (BroadbandNow, 2017). One of the topics of this research, the use of shared mobility options such as Uber or Car2go, also requires internet access to be able to use these services, implying that the targeted respondent of this survey is familiar and have access to a web-enabled device. We hypothesize the number of respondents that may not be able to answer would not significantly compromise or bias the research. 
The survey consisted of 45 questions, divided into seven blocks. An overview of the survey instrument can be found in Appendix B and below is a brief overview of only those data and blocks used in this study:

- Household and Current Residence

These questions comprise the characteristics of the household, such as the number of people aged under and above 16 years of age, type of household (i.e., family, single person, couple) and the apartment characteristics, such as ownership, rent, size and number of bedrooms. Variables could be either categorical or continuous.

\section{- Transportation Resources}

This section is devoted to the transportation options available to the respondents. The survey asked the number of automobiles and bicycles owned, and membership in ridehailing, carsharing, bikesharing, and transit passes, besides how these memberships are paid.

\section{- Transportation Use}

The survey asked about which mode the respondent uses to commute, the distance and frequency. The monthly use of ridehail and carshare are obtained in this section. 
- Parking

All the information relating to parking is asked in this block. The respondent answered if they have parking. Despite all the efforts to be as clear and concise as possible in the questions, with a simple and continuous flow of questions to know the availability, quantity, and price of the parking available only for the respondent, many respondents reported the total number of parking spots instead of their personal use.

\section{- Personal Information}

The last section of the survey collected demographic information about the respondent and their household to allow for comparison to other studies and the census data. These questions are sometimes categorical, and sometimes have units of years, miles or minutes. The units for these variables either are given or can be easily inferred.

\subsection{Sample Description}

The data used in this study are summarized in Table 3-2. For details on how the data were prepared for analysis, see Appendix C. Despite the valid 535 responses received, only 481 were used in the study. The primary cause was the removal of all the pilot data collected, as new questions/variables of interest were added to the survey that excluded the 32 responses received. 
Table 3-2 Sample description

\begin{tabular}{|c|c|c|c|c|}
\hline & $\begin{array}{c}\text { Sample } \\
\text { Size }\end{array}$ & (\%) & Avg. & $\begin{array}{l}\text { Std. } \\
\text { Dev. }\end{array}$ \\
\hline \multicolumn{5}{|l|}{ Dependent Variable } \\
\hline \multicolumn{5}{|l|}{ Household vehicles } \\
\hline 2 or more & 103 & $21 \%$ & & \\
\hline 1 vehicle & 278 & $58 \%$ & & \\
\hline 0 vehicle & 100 & $21 \%$ & & \\
\hline \multicolumn{5}{|l|}{ Demographics } \\
\hline \multicolumn{5}{|l|}{ Income } \\
\hline Refused / Unknown & 32 & $7 \%$ & & \\
\hline More than $\$ 75,000$ & 129 & $27 \%$ & & \\
\hline$\$ 50,000$ to $\$ 74,999$ & 117 & $24 \%$ & & \\
\hline Less than $\$ 50,000$ & 203 & $42 \%$ & & \\
\hline \multicolumn{5}{|l|}{ Household size } \\
\hline $3+$ Persons & 30 & $6 \%$ & & \\
\hline 2 Persons & 221 & $46 \%$ & & \\
\hline 1 Person & 230 & $48 \%$ & & \\
\hline \multicolumn{5}{|l|}{ Education } \\
\hline Lower than BA & 93 & $19 \%$ & & \\
\hline BA and higher & 388 & $81 \%$ & & \\
\hline \multicolumn{5}{|l|}{ Age } \\
\hline More than 35 & 212 & $44 \%$ & & \\
\hline 18 to 35 & 269 & $56 \%$ & & \\
\hline \multicolumn{5}{|l|}{ Built Environment } \\
\hline \multicolumn{5}{|l|}{ Distance to Work } \\
\hline Not Working / Unknown & 140 & $29 \%$ & & \\
\hline More than 10 miles & 54 & $11 \%$ & & \\
\hline Between 2 and 10 miles & 149 & $31 \%$ & & \\
\hline Less than 2 miles & 138 & $29 \%$ & & \\
\hline Pop. Density (People/Acre) & 481 & & 17.3 & 15.0 \\
\hline Emp. Density (Jobs/Acre) & 481 & & 20.2 & 22.4 \\
\hline Ped. Or. Inter. per acre*100 & 481 & & 16.0 & 9.3 \\
\hline Transportation Policy & & & & \\
\hline
\end{tabular}




\begin{tabular}{lrrrr}
\hline & $\begin{array}{c}\text { Sample } \\
\text { Size }\end{array}$ & (\%) & Avg. & $\begin{array}{c}\text { Std. } \\
\text { Dev. }\end{array}$ \\
\hline $\begin{array}{l}\text { Reported Parking } \\
\quad \text { Yes }\end{array}$ & 337 & $70 \%$ & & \\
$\quad$ No & 144 & $30 \%$ & & \\
Transit Pass & & & & \\
$\quad$ Yes & 171 & $36 \%$ & & \\
$\quad$ No & 310 & $64 \%$ & & \\
Bikeshare Membership & & & & \\
$\quad$ Yes & 67 & $14 \%$ & & \\
$\quad$ No & 414 & $86 \%$ & & \\
Freq. Carshare per month & 481 & & 0.6 & 2.3 \\
Freq. Ridehail per month & 481 & & 1.6 & 2.7 \\
\hline
\end{tabular}

There are three categories for Household Vehicles: zero vehicles, one vehicle and two or more vehicles. As there were only 12 respondents with three or more vehicles available in the household, they were added to the two or more vehicles category. There are 34 respondents with no private car, but at least one car in the household. Overall, there are 1.1 vehicles per household, and $21 \%$ of the households do not own a car, both figures below the Portland area average (1.5 cars per household and $14 \%$ of households have no cars) (ACS 2016). The figures of Portland includes single and multifamily residences.

There are $56 \%$ of the overall respondents with less than 35 years old. If we consider only households with 2 or more vehicles, that percentage rises to $76 \%$. One explanation might be the proportion of households defined as roommates with two cars. A small share of the households identified as two 
persons comprised of roommates (20 or $10 \%$ of the sample). The other hypotheses might be newly formed couples, who just joined their vehicles and might not yet have decided to sell one. As found by Clark (2012, p. 183), there is an average of three years before the newly formed family of two cars chooses to get rid of one.

The average personal income was US $\$ 57,745$, and in line with the literature, households with zero vehicles tend to earn less. It is important to note that the question asked about personal income, not household income. For households with two or more persons, which are the majority for two vehicle households (65\% of the 103 total households against $24 \%$ of zero-vehicle household), the income might be higher than reported, as the second member of the household might also generate income. Table 3-3 gives more details about these individual and household characteristics. 
Table 3-3 Individual and Household Characteristics - continuous variables

\begin{tabular}{|c|c|c|c|c|c|c|}
\hline & HH Vehicles & $\mathbf{N}$ & Mean & S.D. & Min & Max \\
\hline \multirow{4}{*}{$\begin{array}{l}\text { Household } \\
\text { size }\end{array}$} & 0 Vehicle & 100 & 1.4 & 0.6 & 1.0 & 4.0 \\
\hline & 1 Vehicle & 278 & 1.5 & 0.7 & 1.0 & 5.0 \\
\hline & 2 or more & 103 & 2.1 & 0.8 & 1.0 & 5.0 \\
\hline & TOTAL & 481 & 1.6 & 0.8 & 1.0 & 5.0 \\
\hline \multirow{4}{*}{ Age } & 0 Vehicle & 100 & 39.8 & 13.8 & 21.0 & 88.0 \\
\hline & 1 Vehicle & 278 & 39.1 & 14.5 & 18.0 & 85.0 \\
\hline & 2 or more & 103 & 33.4 & 12.1 & 18.0 & 72.0 \\
\hline & TOTAL & 481 & 38.0 & 14.1 & 18.0 & 88.0 \\
\hline \multirow{4}{*}{$\begin{array}{l}\text { Personal } \\
\text { income } \\
\text { (USD) }\end{array}$} & 0 Vehicle & 100 & $\$ 51,667$ & $\$ 35,375$ & $\$ 5,000$ & $\$ 137,500$ \\
\hline & 1 Vehicle & 278 & $\$ 61,139$ & $\$ 34,265$ & $\$ 5,000$ & $\$ 137,500$ \\
\hline & 2 or more & 103 & $\$ 54,425$ & $\$ 34,566$ & $\$ 5,000$ & $\$ 137,500$ \\
\hline & TOTAL & 481 & $\$ 57,745$ & $\$ 34,718$ & $\$ 5,000$ & $\$ 137,500$ \\
\hline
\end{tabular}

One-third of the sample has a bachelor's degree or higher, significantly more than the $23 \%$ of residents of Portland (ACS 2017). This group of highly educated persons is more likely to be living in one-vehicle households, with $40 \%$ of the 278 households falling into this category. In contrast, there is a disproportionate concentration of persons without a bachelor's degree living in zero vehicles households (37\%) compared to the total share (19\%). The distance to work shows that households with no vehicles tend to work closer to their homes or not work at all. There were $39 \%$ of zero vehicles households that commuted less than 2 miles or telecommuted, compared to the $29 \%$ of the total 
sample. In addition, for those individuals that do not work (25\%) or did not answer the commute distance (4\%), a combined total of $29 \%$, the proportion of households with zero vehicles is higher, $34 \%$ of the 100 households. More than half of those not working (53\%) are retired or disabled. More details can be seen in Table 3-4.

Table 3-4 Individual and Household Characteristics - categorical variables

\begin{tabular}{llrrrr}
\hline & & \multicolumn{4}{c}{ Household Vehicles } \\
\cline { 3 - 6 } & S Vehicle & 1 Vehicle & 2 or more & TOTAL \\
\hline \multirow{5}{*}{ Education } & Lample Size & 100 & 278 & 103 & 481 \\
& Lower than BA & $37 \%$ & $14 \%$ & $17 \%$ & $19 \%$ \\
& Higher than BA & $37 \%$ & $47 \%$ & $60 \%$ & $48 \%$ \\
& Homework & $26 \%$ & $40 \%$ & $22 \%$ & $33 \%$ \\
& Less than 2 miles & $4 \%$ & $5 \%$ & $5 \%$ & $5 \%$ \\
Distance & Between 2 and 10 miles & $35 \%$ & $22 \%$ & $17 \%$ & $24 \%$ \\
to Work & More than 10 miles & $4 \%$ & $33 \%$ & $32 \%$ & $31 \%$ \\
& Not working & $31 \%$ & $11 \%$ & $19 \%$ & $11 \%$ \\
& Unknown & $3 \%$ & $4 \%$ & $22 \%$ & $25 \%$ \\
& & & & $4 \%$ & $4 \%$ \\
\hline
\end{tabular}

Several built environment features that have been identified in the literature review as influential in travel choice and in-vehicle ownership were considered in the analysis (Bhat, Sen, \& Eluru, 2009; Cirillo \& Liu, 2013; Potoglou \& Susilo, 2008). The data were collected from archived data sources, using as reference the Census Block Group where the site is located. A 
description of the built environment variables and their sources is shown in Table 3-5 below.

Table 3-5 Built Environment Measures and Sources

\begin{tabular}{|c|c|c|}
\hline $\begin{array}{l}\text { Variable } \\
\text { Description }\end{array}$ & Units & Data Source \\
\hline Population Density & $\begin{array}{l}\text { Residents per acre by } \\
\text { Census Block Group }\end{array}$ & $\begin{array}{l}2016 \text { ACS (5-year) B01003 Total } \\
\text { Population (block group); Divided } \\
\text { by Census Block Group area }\end{array}$ \\
\hline Employment Density & $\begin{array}{l}\text { Jobs per acre by Census } \\
\text { Block Group }\end{array}$ & $\begin{array}{l}2015 \text { LEHD Workplace Area } \\
\text { Characteristics (WAC) All Jobs } \\
\text { (JT00), Total Jobs (S000), Total } \\
\text { Number of Jobs (C000); Divided } \\
\text { by Census Block Group area }\end{array}$ \\
\hline $\begin{array}{l}\text { Jobs accessible by } \\
30 \text { min. transit } \\
\text { commute }{ }^{1}\end{array}$ & Number of Jobs & $\begin{array}{l}\text { Accessibility Observatory of the } \\
\text { University of Minnesota (2018) }\end{array}$ \\
\hline $\begin{array}{l}\text { Pedestrian } \\
\text { Intersection Density }\end{array}$ & $\begin{array}{l}\text { Pedestrian Oriented } \\
\text { Intersections (four-way or } \\
\text { more) per acre }\end{array}$ & $\begin{array}{l}\text { Smart Location Database } \\
\text { (Ramsey \& Bell, 2014); Variable } \\
\text { D3bpo4: Intersection density } \\
\text { regarding pedestrian-oriented } \\
\text { intersections having four or more } \\
\text { legs per acre using } \\
\text { NAVSTREETS }\end{array}$ \\
\hline \multicolumn{3}{|c|}{$\begin{array}{l}{ }^{1} \text { These variables were tested in our analysis but did not make a significant contribution } \\
\text { to explaining trip generation. }\end{array}$} \\
\hline \multicolumn{3}{|c|}{ Table 3-6 below shows the descriptions for all the built environment } \\
\hline \multicolumn{3}{|c|}{ measures presented. Confirming the findings of previous research (Bhat, Sen, \& } \\
\hline \multicolumn{3}{|c|}{ Eluru, 2009), households with zero vehicles tend to live in denser areas, both in } \\
\hline
\end{tabular}


employment density (32\% more than the global average). These households also are better served by transit (12\% more jobs accessible by transit than the global average) and active mode infrastructure (17\% more pedestrian-oriented intersections than the global average).

Table 3-6 Built Environment Characteristics

\begin{tabular}{|c|c|c|c|c|c|c|}
\hline & HH Vehicles & $\mathbf{N}$ & Mean & S.D. & Min & Max \\
\hline \multirow{4}{*}{$\begin{array}{l}\text { Population Density } \\
\text { (pop./acre) }\end{array}$} & 0 Vehicle & 100 & 21.0 & 19.4 & 3.8 & 94.8 \\
\hline & 1 Vehicle & 278 & 16.5 & 13.4 & 3.8 & 94.8 \\
\hline & 2 or more & 103 & 15.6 & 13.5 & 3.8 & 87.7 \\
\hline & TOTAL & 481 & 17.3 & 15.0 & 3.8 & 94.8 \\
\hline \multirow{4}{*}{$\begin{array}{c}\text { Employment } \\
\text { Density (job/acre) }\end{array}$} & 0 Vehicle & 100 & 26.5 & 28.3 & 2.1 & 105.5 \\
\hline & 1 Vehicle & 278 & 19.6 & 21.2 & 0.5 & 99.5 \\
\hline & 2 or more & 103 & 15.7 & 17.5 & 0.5 & 99.5 \\
\hline & TOTAL & 481 & 20.2 & 22.4 & 0.5 & 105.5 \\
\hline \multirow{4}{*}{$\begin{array}{c}\text { Activity Density } \\
\text { (number/acre) }\end{array}$} & 0 Vehicle & 100 & 48 & 35 & 12 & 133 \\
\hline & 1 Vehicle & 278 & 36 & 24 & 7 & 121 \\
\hline & 2 or more & 103 & 31 & 21 & 7 & 106 \\
\hline & TOTAL & 481 & 37 & 27 & 7 & 133 \\
\hline \multirow{4}{*}{$\begin{array}{l}\text { Jobs by } 30 \mathrm{~min} . \\
\text { commute }(000 \mathrm{~s})\end{array}$} & 0 Vehicle & 100 & 135 & 63 & 14 & 243 \\
\hline & 1 Vehicle & 278 & 120 & 61 & 1 & 242 \\
\hline & 2 or more & 103 & 109 & 64 & 1 & 242 \\
\hline & TOTAL & 481 & 121 & 63 & 1 & 243 \\
\hline \multirow{4}{*}{$\begin{array}{l}\text { Ped. Inter. Density } \\
\text { (number/acre)*100 }\end{array}$} & 0 Vehicle & 100 & 18.7 & 9.2 & 0.6 & 41.9 \\
\hline & 1 Vehicle & 278 & 16.0 & 9.5 & 0.0 & 41.9 \\
\hline & 2 or more & 103 & 13.6 & 8.4 & 0.0 & 36.9 \\
\hline & TOTAL & 481 & 16.0 & 9.3 & 0.0 & 41.9 \\
\hline
\end{tabular}


Table 3-7 and Table 3-8 present more details about the transportation policy options. Households with two or more vehicles tend to live in multifamily developments with more parking available ( $83 \%$ of the households), compared with zero and one vehicle households (63\% and $68 \%$, respectively). Despite only $23 \%$ of the sample being carshare members, a higher proportion zero vehicles households (41\%) are registered to use either one-way carshare companies (car2go, Reach now) or two-way (ZipCar, getaround). Households with zero vehicles also presented the higher amount of carshare use per month, significantly different from the total average (1.5 times per month vs. 0.6$)$. It is important to note that all the nonmembers and members that do not use carshare had a zero-frequency use, lowering the average. If we consider the monthly use of only those 110 respondents that are members, the general average would be 2.8 times per month and for zero vehicle household, the use of carshare per month would be 3.7 or almost once per week. Of all the members of carshare, $84 \%$ were members of Car2go or ReachNow and $41 \%$ were members of Zipcar or Getaround.

Respondents living in with zero vehicles had a significantly higher proportion of transit passes available, $62 \%$ against the sample average of $36 \%$.It is interesting to note that membership levels of ridehail companies does not vary with vehicle ownership. The number of households with ridehail membership $(58 \%)$ is higher than those households with transit passes (36\%). There is no 
barrier to be a member of Uber and lyft, it requires downloading and configuring the app, and possession of a credit card. There is no membership fee and the payment is only for the trip you make. But there is a cost to purchase a transit pass, even if you are not using it. Intuitively, it is much easier to be a ridehail company member than own a transit pass, even if the cost of use both services are very different. However, even for zero-vehicle households, the proportions of ridehail members and transit pass owners are very similar, suggesting no interest to use regularly ridehail due to cost, lack of information or other reason. Table 3-8 shows that there is no significant difference in the use of ridehail between the households, with zero vehicles households using ridehail per month slightly more than the average (2.1 vs. 1.6). As it happened with carshare data, all the nonmembers and members that do not use ridehail had a zero-frequency use, lowering the average. If we consider the monthly use of only those 278 respondents that are members, the general average would be 2.5 times per month. For zero vehicle household, the use of ridehail per month would be 3.2 times, slightly lower than the average monthly use of carsharing by carshare members (3.7 times). 
Table 3-7 Transportation Policy Options - binary variables

\begin{tabular}{lcccc}
\hline \multirow{2}{*}{ Variable } & \multicolumn{3}{c}{ Household Vehicles } & \\
\cline { 2 - 4 } & 0 Vehicle & $\mathbf{1}$ Vehicle & 2 or more & TOTAL \\
\hline Sample Size & 100 & 278 & 103 & 481 \\
Parking available & $63 \%$ & $68 \%$ & $83 \%$ & $70 \%$ \\
Carshare Membership & $41 \%$ & $19 \%$ & $17 \%$ & $23 \%$ \\
Ridehail Membership & $57 \%$ & $56 \%$ & $62 \%$ & $58 \%$ \\
Bikeshare Membership & $19 \%$ & $11 \%$ & $17 \%$ & $14 \%$ \\
Transit Pass available & $62 \%$ & $31 \%$ & $22 \%$ & $36 \%$ \\
\hline
\end{tabular}

Table 3-8 Transportation Policy Options - continuous variables

\begin{tabular}{|c|c|c|c|c|c|c|}
\hline & $\begin{array}{c}\text { HH } \\
\text { Vehicles }\end{array}$ & $\mathbf{N}$ & Mean & S.D. & Min & Max \\
\hline \multirow{4}{*}{$\begin{array}{l}\text { Freq. Carshare } \\
\text { per month }\end{array}$} & 0 Vehicle & 100 & 1.5 & 3.5 & - & 20.0 \\
\hline & 1 Vehicle & 278 & 0.4 & 1.8 & - & 15.0 \\
\hline & 2 or more & 103 & 0.4 & 1.9 & - & 15.0 \\
\hline & TOTAL & 481 & 0.6 & 2.3 & - & 20.0 \\
\hline \multirow{4}{*}{$\begin{array}{l}\text { Freq. Ridehail } \\
\text { per month }\end{array}$} & 0 Vehicle & 100 & 2.1 & 3.2 & - & 16.0 \\
\hline & 1 Vehicle & 278 & 1.5 & 2.6 & - & 18.0 \\
\hline & 2 or more & 103 & 1.5 & 2.3 & - & 10.0 \\
\hline & TOTAL & 481 & 1.6 & 2.7 & - & 18.0 \\
\hline
\end{tabular}

There are differences in the membership type and use of carshare by its members. For two-way carshare programs, even being available in the market for more time (Zipcar started in Portland in 2007, and car2go began in 2012 (Njus, 2017) - both are the first services available in the market), they are not as 
popular as one-way carshare programs. A simple ANOVA test between the three groups of carshare membership (only one-way, only two-way and both) and household vehicle ownership revealed no significant difference in the means, $F(2,106)=1.75$, n.s. However, the frequency of use by carshare membership type presented a significant difference between different types of membership, $F$ $(2,106)=4.56, p<0.05$. Residents that are members for both kinds of carshare services use the service more ( 4.25 times per month) than one-way members (2.4 times per month) and two-way members (0.85 times per month). Table 3-9 below provides an overview of the membership distribution for carshare services:

Table 3-9 Types of Carshare Membership

\begin{tabular}{lrrr}
\hline \multicolumn{1}{c}{ Type } & Sample & Proportion & \multicolumn{2}{c}{$\begin{array}{c}\text { Use per } \\
\text { Month }\end{array}$} \\
\hline Only Two-Way (ZipCar, getAround) & 17 & $15 \%$ & 0.8 \\
Only One-Way (car2go, ReachNow) & 55 & $50 \%$ & 2.4 \\
Both One and Two-Way & 37 & $35 \%$ & 4.2 \\
TOTAL & $\mathbf{1 0 9}$ & $\mathbf{1 0 0 \%}$ & $\mathbf{2 . 8}$ \\
\hline
\end{tabular}

\subsection{Statistical Method}

As the selected dependent (or outcome variable), household vehicle ownership is discrete and assumes the values of zero vehicles, one vehicle, and two or more vehicles. Two different types of models are appropriate in dealing with discrete-choice outcomes. The first is the ordered response models, which 
assumes a natural order or hierarchy in the outcome, such as response outcomes never, sometimes and a lot. In ordered models, the choice of the outcome variable arises from a unidimensional latent variable that reflects the propensity of choosing each outcome. The second type of models are the unordered response models, which assume there is no apparent order in the outcome, such as response outcomes blue, red or yellow. For more information about discrete choice models, see (Agresti, 2013; Kromrey \& Rendina-Gobioff, 2002; Long, 1997). Both types of models can be used to evaluate vehicle ownership levels as a dependent variable, as has been done in practice. For the use of ordered response models to model vehicle ownership, see Bhat (1993) and Cao, Mokhtarian \& Handy (2007). For the use of unordered response models, see Purvis (1994), Agostino (1996) and Whelan (2007).

Both types of models have advantages and disadvantages in the estimation of vehicle ownership. An article by Bhat and Pulugurta (1998) and later by Potoglou and Susilo (2008) found unordered models to be superior to ordered models in several aspects, such as nonnested hypothesis tests, the average probability of correct prediction, and predictive adjusted likelihood ratio index. Still, ordered models presented reasonable estimates with a more parsimonious outcome.

For this analysis, the unordered model is adopted. Specifically, the multinomial logistic regression (MLR) is selected as our estimation technique 
because the underlying factors associated with vehicle ownership may differ depending upon the number of vehicles owned. To confirm this hypothesis, the models presented in the next chapter were tested for the parallel regression assumption or proportional odds (Brant, 1990), a prerequisite for ordered models. The parallel regression assumption assumes that the relationship between all pairs of groups is the same. Therefore, there is only one set of coefficients (only one model). All the models failed the parallel assumption test. Thus, the MLR model was chosen as the preferred estimation technique. However, there are still some risks in choosing MLR over more sophisticated discrete choice methodologies, such as Nested Logit or Linear Combination Multinomial Models. The endogeneity bias occurs when some explanatory variables are correlated with the error term of an econometric model due to, among other things, omitted attributes, measurement or specification errors, simultaneous determination or self-selection (Guevara, 2015). It is not well treated in simple MLR model, but due to the exploratory nature of this research and the more parsimonious approach of MLR compared to the other models, besides the acceptable results shown in the literature (Cirillo, Liu, \& Tremblay, 2017), reinforced our decision to use MLR. 


\subsection{Summary}

This chapter outlined the data collected from 535 residents of multifamily apartments from 169 developments in Portland, Oregon. Despite the low response rate of $4.6 \%$, the sample was large enough to be statistically significant.

In the next chapter, the results of the analysis of the data, in the form of a Multinomial Logistic Regression (MLR) as presented in section 3.3, will be developed. 


\section{Chapter 4. Analysis and Results}

In this chapter, the three groups of variables collected in the survey and presented in the previous chapter will be used to model household vehicle ownership levels. The variables identified as individual and household characteristics, built environment, and transportation policy and their relationship with the number of household vehicles will be used to generate three different Multinomial Logistic Regression (MLR). Then the models will be compared, to understand the policy implications of the relationships that are revealed by the statistical analysis of the models. The first section introduces the model specifications, and the next part shows a comparison of the estimation results, and the last section summarizes the results.

\subsection{Model Specification}

The MLR employs the following specification:

$$
\begin{aligned}
& P_{i}=f(\text { Demographics, Built Environment, Transportation Policy }) \\
& \qquad P_{i}=\frac{e^{V_{i}}}{\sum_{j=0,1,2+} e^{V_{j}}}
\end{aligned}
$$

Where $P_{i}=$ probability of owning the number of vehicles owned by the household $(0,1,2$ or more), as a function of demographics, built environment 
and transportation policy variables. The terms $V_{i}$ and $V_{j}$ refers to the utility of each vehicle ownership level:

$$
V_{i}=V_{j}=\beta_{0}+\beta_{1} \cdot \text { Dem }+\beta_{2} \cdot B E+\beta_{3} \cdot \text { Trans }+\beta_{4} \cdot \text { Inter }+\varepsilon(3)
$$

where the $\beta s$ are coefficients representing the magnitude and direction of the association between each of the variable(s) and the utility of the number of vehicles owned. Demographics $(D e m)$, built environment $(B E)$, transportation policy (Trans), interactions (Inter) can represent single variables or vectors, and $\varepsilon$ is the error term representing the net impact on vehicle ownership of all unobserved variables and error. In our context, the outcome of interest is a discrete measure (vehicle ownership), the utility in the equation can be directly a dependent variable. In our context, the outcome of interest is a discrete measure (vehicle ownership), hence the utility in the equation represents the utility of a given alternative (a specific number of vehicles), and the $\beta s$ differ by each alternative (relative to a base case). In our study, the base case will be owning zero vehicles and all of the parameter estimates should be interpreted relative to this case. 


\subsection{Estimation Results}

In this section, the process of testing the associations between vehicle ownership and the three sets of independent variables is as follows. First, all of the independent variables were tested for correlation, and none was found to have an absolute value of the Pearson Correlation Index greater than 0.4. Then the MLR estimated a model using only the sets of demographic and built environment variables, as these have been previously examined in the literature. Then, the transportation policy variables were added to the model to test for model stability and to assess their contribution to model fit. Finally, interaction terms were added and evaluated in the final model. These estimation results are shown in Table 4-1 below. 
Table 4-1 Parameter for the three models

\begin{tabular}{|c|c|c|c|c|c|c|c|c|c|}
\hline & \multicolumn{3}{|c|}{$\begin{array}{l}\text { Model } 1 \\
\text { Dem. + BE }\end{array}$} & \multicolumn{3}{|c|}{$\begin{array}{c}\text { Model } 2 \\
\text { Model } 1+\text { Trans. }\end{array}$} & \multicolumn{3}{|c|}{$\begin{array}{c}\text { Model } 3 \\
\text { Model } 2+\text { Inter. }\end{array}$} \\
\hline & B & OR & & B & OR & & B & OR & \\
\hline \multicolumn{10}{|l|}{ Demographics } \\
\hline \multicolumn{10}{|c|}{ Income (Less than $\$ 50,000)$} \\
\hline \multicolumn{10}{|l|}{ Refused / Unknown } \\
\hline 2 or more vehicles & -1.77 & 0.17 & $* *$ & -1.73 & 0.18 & $* *$ & -1.80 & 0.17 & $* *$ \\
\hline 1 vehicle & -0.33 & 0.72 & & -0.21 & 0.81 & & -0.29 & 0.75 & \\
\hline \multicolumn{10}{|l|}{ More than $\$ 75,000$} \\
\hline 2 or more vehicles & 0.20 & 1.23 & & 0.65 & 1.91 & & 1.47 & 4.35 & $* * *$ \\
\hline 1 vehicle & 0.47 & 1.60 & & 0.77 & 2.16 & $* *$ & 1.43 & 4.17 & $* * * *$ \\
\hline \multicolumn{10}{|l|}{$\$ 50,000$ to $\$ 74,999$} \\
\hline 2 or more vehicles & 0.49 & 1.63 & & 1.04 & 2.84 & $* *$ & 1.53 & 4.60 & $* * *$ \\
\hline 1 vehicle & 0.64 & 1.90 & $*$ & 1.02 & 2.77 & $* *$ & 1.14 & 3.11 & $* *$ \\
\hline \multicolumn{10}{|c|}{ Household size (1 Person) } \\
\hline \multicolumn{10}{|l|}{ 3+ Persons } \\
\hline 2 or more vehicles & 2.40 & 11.07 & $* * * *$ & 2.48 & 12.00 & $* * * *$ & 1.79 & 5.97 & * \\
\hline 1 vehicle & -0.14 & 0.87 & & -0.14 & 0.87 & & 0.01 & 1.01 & \\
\hline \multicolumn{10}{|l|}{2 Persons } \\
\hline 2 or more vehicles & 2.79 & 16.27 & $* * * *$ & 3.20 & 24.55 & $* * * *$ & 2.60 & 13.44 & $* * * *$ \\
\hline 1 vehicle & 0.65 & 1.91 & $* *$ & 0.92 & 2.52 & $* * *$ & 0.32 & 1.37 & \\
\hline \multicolumn{10}{|c|}{ Education (BA and higher) } \\
\hline 2 or more vehicles & 1.10 & 3.02 & $* * *$ & 0.96 & 2.60 & $* *$ & 0.91 & 2.48 & \\
\hline 1 vehicle & 1.33 & 3.77 & $* * * *$ & 1.25 & 3.50 & $* * * *$ & 1.39 & 4.02 & $* * * *$ \\
\hline \multicolumn{10}{|l|}{ Age (More than 35) } \\
\hline 2 or more vehicles & -0.87 & 0.42 & $* *$ & -1.15 & 0.32 & $* * *$ & -1.43 & 0.24 & $* * *$ \\
\hline 1 vehicle & -0.10 & 0.91 & & -0.28 & 0.76 & & -0.40 & 0.67 & \\
\hline \multicolumn{10}{|l|}{ Built Environment } \\
\hline \multicolumn{10}{|c|}{ Distance to Work (Less than 2 miles) } \\
\hline \multicolumn{10}{|c|}{ Not Working / Unknown } \\
\hline 2 or more vehicles & 0.61 & 1.85 & & 0.28 & 1.32 & & 0.32 & 1.38 & \\
\hline 1 vehicle & 0.41 & 1.51 & & 0.24 & 1.28 & & 0.23 & 1.26 & \\
\hline
\end{tabular}




\begin{tabular}{|c|c|c|c|c|c|c|c|c|c|}
\hline & \multicolumn{3}{|c|}{$\begin{array}{l}\text { Model } 1 \\
\text { Dem. + BE }\end{array}$} & \multicolumn{3}{|c|}{$\begin{array}{c}\text { Model } 2 \\
\text { Model } 1+\text { Trans. }\end{array}$} & \multicolumn{3}{|c|}{$\begin{array}{c}\text { Model } 3 \\
\text { Model } 2+\text { Inter. }\end{array}$} \\
\hline & B & OR & & B & OR & & B & OR & \\
\hline \multicolumn{10}{|l|}{ More than 10 miles } \\
\hline 2 or more vehicles & 2.15 & 8.56 & $* * *$ & 2.51 & 12.32 & $* * * *$ & 2.68 & 14.59 & $* * * *$ \\
\hline 1 vehicle & 1.23 & 3.43 & $* *$ & 1.45 & 4.24 & $* *$ & 1.41 & 4.09 & $* *$ \\
\hline \multicolumn{10}{|c|}{ Between 2 and 10 miles } \\
\hline 2 or more vehicles & 0.64 & 1.90 & & 0.92 & 2.50 & $*$ & 0.95 & 2.59 & * \\
\hline 1 vehicle & 0.65 & 1.91 & $* *$ & 0.89 & 2.44 & $* *$ & 0.91 & 2.48 & $* *$ \\
\hline \multicolumn{10}{|c|}{ Pop Density (People/Acre) } \\
\hline 2 or more vehicles & -0.015 & 0.99 & & -0.014 & 0.99 & & -0.014 & 0.99 & \\
\hline 1 vehicle & -0.012 & 0.99 & & -0.017 & 0.98 & $*$ & -0.019 & 0.98 & * \\
\hline \multicolumn{10}{|c|}{ Emp. Density (Jobs/Acre) } \\
\hline 2 or more vehicles & -0.016 & 0.98 & $* *$ & -0.016 & 0.98 & $*$ & -0.030 & 0.97 & $* * *$ \\
\hline 1 vehicle & -0.013 & 0.99 & $* *$ & -0.006 & 0.99 & & -0.012 & 0.99 & * \\
\hline \multicolumn{10}{|c|}{ Ped. Or. Inter. per acre*100 } \\
\hline 2 or more vehicles & -6.33 & 0.00 & $* * * *$ & -6.05 & 0.00 & $* * *$ & -5.45 & 0.00 & $* *$ \\
\hline 1 vehicle & -3.22 & 0.04 & $* *$ & -3.31 & 0.04 & $* *$ & -3.32 & 0.04 & $* *$ \\
\hline \multicolumn{10}{|l|}{ Transportation Policy } \\
\hline \multicolumn{10}{|l|}{ Reported Parking (Yes) } \\
\hline 2 or more vehicles & & & & 1.51 & 4.55 & $* * * *$ & 1.34 & 3.81 & $* * *$ \\
\hline 1 vehicle & & & & 0.33 & 1.40 & & 0.19 & 1.21 & \\
\hline \multicolumn{10}{|l|}{ Transit Pass (Yes) } \\
\hline 2 or more vehicles & & & & -2.21 & 0.11 & $* * * *$ & -2.23 & 0.11 & $* * * *$ \\
\hline 1 vehicle & & & & -1.63 & 0.20 & $* * * *$ & -1.74 & 0.18 & $* * * *$ \\
\hline \multicolumn{10}{|c|}{ Bikeshare Membership (Yes) } \\
\hline 2 or more vehicles & & & & 0.48 & 1.62 & & 0.74 & 2.09 & \\
\hline 1 vehicle & & & & -0.40 & 0.67 & & -0.35 & 0.71 & \\
\hline \multicolumn{10}{|c|}{ Freq. Carshare per month } \\
\hline 2 or more vehicles & & & & -0.24 & 0.79 & $* * *$ & 0.74 & 2.10 & ** \\
\hline 1 vehicle & & & & -0.20 & 0.82 & $* * *$ & -0.12 & 0.89 & \\
\hline \multicolumn{10}{|c|}{ Freq. Ridehail per month } \\
\hline 2 or more vehicles & & & & -0.21 & 0.81 & $* * *$ & -1.15 & 0.32 & $* * *$ \\
\hline
\end{tabular}




\begin{tabular}{|c|c|c|c|c|c|c|c|c|c|}
\hline & & $\begin{array}{l}\text { lodel } 1 \\
m .+ \text { BE }\end{array}$ & & Mode & $\begin{array}{l}\text { lodel } 2 \\
1+\mathrm{Tr}\end{array}$ & ans. & Mod & $\begin{array}{l}\text { odel } 3 \\
12+\text { In }\end{array}$ & \\
\hline & B & OR & & B & OR & & B & OR & \\
\hline 1 vehicle & & & & -0.12 & 0.89 & $* *$ & -0.39 & 0.68 & $* *$ \\
\hline Interactions & & & & & & & & & \\
\hline Interaction Income ${ }^{*} F r$ & Carsh & & & & & & & & \\
\hline Refused / Unknown & & & & & & & & & \\
\hline 2 or more vehicles & & & & & & & 0.37 & 1.44 & \\
\hline 1 vehicle & & & & & & & 0.14 & 1.15 & \\
\hline More than $\$ 75,000$ & & & & & & & & & \\
\hline 2 or more vehicles & & & & & & & -0.87 & 0.42 & $* *$ \\
\hline 1 vehicle & & & & & & & -0.58 & 0.56 & $* *$ \\
\hline$\$ 50,000$ to $\$ 74,999$ & & & & & & & & & \\
\hline 2 or more vehicles & & & & & & & -1.15 & 0.32 & ** \\
\hline 1 vehicle & & & & & & & -0.06 & 0.94 & \\
\hline Interaction BA and Hig & $r^{*}$ Fre & Carshar & & & & & & & \\
\hline 2 or more vehicles & & & & & & & -1.33 & 0.26 & $* * *$ \\
\hline 1 vehicle & & & & & & & -0.04 & 0.96 & \\
\hline Interaction $\mathrm{BA}$ and Hig & ${ }^{*}{ }^{*} F r \epsilon$ & Ridehai & & & & & & & \\
\hline 2 or more vehicles & & & & & & & 0.59 & 1.80 & $* *$ \\
\hline 1 vehicle & & & & & & & 0.12 & 1.13 & \\
\hline Interaction $\mathrm{HH}$ size ${ }^{*} \mathrm{Fr}$ & Rideh & & & & & & & & \\
\hline 3 or more & & & & & & & & & \\
\hline 2 or more vehicles & & & & & & & 0.70 & 2.02 & * \\
\hline 1 vehicle & & & & & & & -0.12 & 0.89 & \\
\hline 2 Persons & & & & & & & & & \\
\hline 2 or more vehicles & & & & & & & 0.62 & 1.86 & $* *$ \\
\hline 1 vehicle & & & & & & & 0.41 & 1.51 & $* * *$ \\
\hline Constant & & & & & & & & & \\
\hline 2 or more vehicles & 1.24 & & $*$ & -1.28 & & & -0.67 & & \\
\hline 1 vehicle & 0.31 & & & 1.08 & & $*$ & 1.51 & & $* *$ \\
\hline
\end{tabular}


Table 4-2 below provides for each predictor the significance level and the likelihood ratio test, to assess the variable relevance to the model.

Table 4-2 Likelihood Ratios of the variables used in the models

\begin{tabular}{|c|c|c|c|c|c|c|}
\hline & \multicolumn{2}{|c|}{$\begin{array}{l}\text { Model } 1 \\
\text { Dem. + BE }\end{array}$} & \multicolumn{2}{|c|}{$\begin{array}{c}\text { Model } 2 \\
\text { Model } 1+\text { Trans. }\end{array}$} & \multicolumn{2}{|c|}{$\begin{array}{c}\text { Model } 3 \\
\text { Model } 2+\text { Inter. }\end{array}$} \\
\hline & LR & Sig. & LR & Sig. & LR & Sig. \\
\hline \multicolumn{7}{|l|}{ Demographics } \\
\hline Income & 12.03 & 0.061 & 17.07 & 0.009 & 25.30 & 0.000 \\
\hline Household size & 67.50 & 0.000 & 72.34 & 0.000 & 37.61 & 0.000 \\
\hline Education & 19.12 & 0.000 & 14.47 & 0.001 & 11.90 & 0.003 \\
\hline Age & 7.48 & 0.024 & 9.51 & 0.009 & 11.96 & 0.003 \\
\hline \multicolumn{7}{|l|}{ Built Environment } \\
\hline Distance to Work & 14.82 & 0.022 & 19.46 & 0.003 & 20.11 & 0.003 \\
\hline Pop Density (Peop./Acre) & 3.03 & 0.220 & 3.68 & 0.159 & 3.83 & 0.147 \\
\hline Emp. Density (Jobs/Acre) & 6.67 & 0.036 & 2.82 & 0.244 & 8.69 & 0.013 \\
\hline Ped. Or. Inter. per acre ${ }^{*} 100$ & 11.83 & 0.003 & 9.36 & 0.009 & 7.05 & 0.029 \\
\hline \multicolumn{7}{|l|}{ Transportation Policy } \\
\hline Reported Parking & & & 14.19 & 0.001 & 11.18 & 0.004 \\
\hline Transit Pass & & & 41.07 & 0.000 & 38.78 & 0.000 \\
\hline Bikeshare Membership & & & 5.05 & 0.080 & 5.99 & 0.050 \\
\hline Freq. Carshare per month & & & 12.92 & 0.002 & 0.00 & 0.000 \\
\hline Freq. Ridehail per month & & & 8.53 & 0.014 & 0.00 & 0.000 \\
\hline \multicolumn{7}{|l|}{ Interactions } \\
\hline Income ${ }^{*}$ Carshare & & & & & 25.53 & 0.000 \\
\hline Education*Carshare & & & & & 13.84 & 0.001 \\
\hline Education*Ridehail & & & & & 6.96 & 0.031 \\
\hline Household size*Ridehail & & & & & 16.99 & 0.002 \\
\hline
\end{tabular}




\subsection{Goodness of Fit and Model Stability}

To evaluate the explanatory power of each of the three successive iterations, they were compared using three different measures of fit: the Akaike Information Criterion (AIC), Bayesian Information Criterion (BIC), Likelihood Ratio (LR Chi-square), and two different pseudo-R-squared measures, Nagelkerke and McFadden. The preferred model will have the smallest AIC and BIC values, a significant and higher LR Chi-square test, and the greatest pseudo-R-squared. AIC and BIC allow for better comparison across models than the LR Chi-square because they account for the goodness of fit and include a penalty for increasing the degrees of freedom. The BIC penalizes the inclusion of more parameters more than the AIC and thus is a better indicator of model parsimony. More information about the $\mathrm{AIC}$ and $\mathrm{BIC}$ criterion can be found in Potoglou and Susilo (2008) and on Pseudo R square in Allison (2014).

Table 4-3 below shows all the criteria for the three models calculated by SPSS 24. The Likelihood Ratio tests (LR Chi-square) indicates that the null hypothesis (all parameters in the models are zero) is not supported and therefore all of the models are statistically significant. All models perform well as indicated by the relatively high values of both pseudo-R-squared. Model three has a higher pseudo-R-squared. However, model two improved the explanatory power of model one more than model three improved model one. This trend is also seen if we compare the AIC values, where model three presents the lowest value, but 
the difference between model two and one is higher than between model three and two. For model three, the degrees of freedom is almost double of model 1. This choice is reflected in the BIC criteria, where model three is the worst performer, penalized by the introduction of several new predictors by the interactions.

Table 4-3 Comparison of Goodness of Fit Measures between the Models

\begin{tabular}{lrrr}
\hline & $\begin{array}{c}\text { Model 1 } \\
\text { Dem. + BE }\end{array}$ & $\begin{array}{c}\text { Model 2 } \\
\text { Model 1 + Trans }\end{array}$ & $\begin{array}{r}\text { Model 3 } \\
\text { Model 2 + Inter }\end{array}$ \\
\hline Overall model Statistics & & & \\
observations & 481 & 481 & 481 \\
df & 26 & 36 & 50 \\
-2LL intercept & 928.7 & 928.7 & 928.7 \\
-2LL model & 756.2 & 676.5 & 617.7 \\
LR Chi-square & 172.5 & 252.2 & 311.0 \\
Nagelkerke R Square & 0.35 & 0.48 & 0.56 \\
McFadden R Square & 0.18 & 0.27 & 0.33 \\
BIC & 929.1 & 911.2 & 938.9 \\
AIC & 812.2 & 752.5 & 721.7 \\
Overall Correct Pred. & $62 \%$ & $68 \%$ & $73 \%$ \\
Percentage & & & \\
\hline
\end{tabular}

The introduction of transportation policy measures variables to the models improved their predictive power and therefore should be considered in the analysis. Model two would be sufficient if we were using the model to predict vehicle ownership. For example, the output of model two would be used as input for a larger citywide travel behavior model. However, as we try to understand better the effects of the transportation policy measures on vehicle ownership, the 
interaction terms add valuable insights. The parameters estimates were stable across all the models, with no major changes in the direction of the parameters.

\subsection{Discussion of Results}

In the next subsections, we will discuss the implications of the parameter estimates for each of the independent variables on vehicle ownership. Based upon the previous section, Model three will be the focus of this discussion, which includes all the demographic, built environment, transportation policy, and the interaction variables. The base case for the MLR is the zero-vehicle household. In this section, the effects of the correlates of household vehicle ownership level will be discussed.

\subsubsection{Demographic Variables}

As is reiterated in the literature, income is highly significant, (LR ChiSquare $=25.30, p<0.000$ ), with almost all categories of the variable presenting significant influence on household vehicle ownership in comparison to the base case, which is households owning no vehicles and earning less than $\$ 50,000$. The coefficients for income were positive, which means when income values grow, so does the number of vehicles per household. We were expecting the Unknown / Refused category to be not significant, reflecting a non-biased nature of refusal and unknown group of respondents. However, the data suggest that this group is less likely to own two vehicles $(B=-1.80, O R=0.17, p<0.05)$ than 
zero vehicles. For both categories of income levels higher than $\$ 50,000$, the direction of the coefficient for a household with one or two or more vehicles is positive and very similar. This indicates that the higher the income, the higher the probability of owning one or more cars. For example, the odds of a person earning more than $\$ 75,000$ living in a one-vehicle household is $317 \%$ greater than living in a zero-vehicle household $(B=1.43, O R=4.17, p<0.000)$.

From Table 4-2 below provides for each predictor the significance level and the likelihood ratio test, to assess the variable relevance to the model.

Table 4-2, household size has the second largest value of log likelihood ratio, meaning it is a strong predictor of vehicle ownership $(\mathrm{LR}$ Chi-Square $=$ $37.61, p<0.000)$. This suggests that as the number of persons in the household increase, the odds of owning more vehicles also increases. A household with 3 or more persons more is likely to own 2 or more vehicles than a one-person household $(B=1.79, O R=5.97, p=0.052)$. The strongest influence, however, is of a two persons' household with two or more vehicles. The odds are greater than $1200 \%$ of a two persons' household owning two or more vehicles than the base case, a one-person household with no vehicles, $(B=2.6, O R=13.44, p$ $<0.000)$. This result is intuitive and consistent with the literature, as seen in section 2.1.

The educational level presents a significant influence on vehicle ownership (LR Chi-Square $=11.9, p=0.003)$, suggesting respondents with 
higher education will likely own more vehicles. However, respondents with college or higher education are less likely to own two or more vehicle $(B=0.91$, $\mathrm{OR}=2.48$, n.s. $)$ than one vehicle $(B=1.39, \mathrm{OR}=4.02, \mathrm{p}<0.000)$. This finding suggests that educated respondents have more ability or desire to live with fewer vehicles.

The age of the respondent $(\mathrm{LR}$ Chi-Square $=11.96, \mathrm{p}=0.003)$ is significant in predicting the number of household vehicles. Comparing to the base case of owning zero vehicles and age under 35 years, either vehicle ownership categories (one or two or more) present negative coefficients. If the respondents are 35 years or older, it is likely they will own fewer cars. However, this is significant only for two or more vehicles $(B=-1.43, O R=0.24, p<0.000)$. The literature suggests millennials (roughly with age lower than 35 years today) are postponing the purchase of vehicles (Oakil, Manting, \& Nijland, 2016), either for economic or lifestyle reasons. However, our sample suggests the opposite.

\subsubsection{Built Environment Variables}

Distance to work is significantly and positively associated with the number of household vehicles (LR Chi-Square $=20.11, p=0.003$ ). The farther the workplace is located from home, the more vehicles a household is expected to own. This is especially true for respondents commuting more than 10 miles, which are 14.59 times more likely to own 2 or more vehicles than those living 
less than 2 miles from work $(B=2.68, O R=14.59, p<0.000)$. For those respondents not working, there was no significant difference between the levels of car ownership, confirming that commuting is a high driver of vehicle ownership.

Population density was not significant in explaining vehicle ownership (LR Chi-Square $=3.83, p=0.147$ ), in contradiction with what the literature suggests. One reason might be the sample density variability of the sample is not high (all the sites were in urban areas with an average of 17.3 people per acre and std. deviation of 15.0). However, as the coefficients are positive, the effect of a higher density is theoretically correct, as an increase in population density decreases the chance of owning more vehicles, despite not being significant.

Employment density, on the other hand, was a significant predictor of vehicle ownership (LR Chi-Square $=8.69, p=0.013$ ). Employment density is used as a proxy for local access to destination and may also permit a lifestyle that is less reliant on the automobile. The coefficients for employment density are negative, reducing the odds of owning more vehicles as the density increases, compared to the base case (for 2 or more vehicle households, $\mathrm{B}=-0.030, \mathrm{OR}=$ $0.97, p=0.005 ;$ for 1 vehicle, $B=-0.012, O R=0.062, p=0.062$ ). Intersection density is an indicator of pedestrian connectivity and has a smaller effect on vehicle ownership than employment density, but is still significant $(\mathrm{LR}$ Chi-Square $=7.05, \mathrm{p}=0.029)$. The coefficients found in the model 
for any level of vehicle ownership, in comparison with the base case of zero vehicles, are negative. Despite their small effect, the higher number of intersections, the smaller the odds of owning vehicles (for 2 or more vehicle households, $\mathrm{B}=-0.009, \mathrm{OR}=0.99, \mathrm{p}=0.012$; for 1 vehicle, $\mathrm{B}=-0.005, \mathrm{OR}=$ $0.99, p=0.029)$.

\subsubsection{Transportation Policy Variables}

Parking supply is positively associated with vehicle ownership (LR ChiSquare $=11.18, p=0.004)$, as has been explained in section 2.3. The association of parking is significant for households with two or more vehicles. The existence of parking increases the odds of a household owning two or more vehicles by 3.81 comparing to the base case of no parking and zero vehicle household. For households with one vehicle, parking does not have a significant association (for 2 or more vehicle households, $B=1.34$, $O R=3.81, p=0.006$; for 1 vehicle, $B=0.19, O R=1.21, p=0.583)$.

Transit pass ownership had the most significant value of log likelihood ratio, meaning it has a strong relationship with vehicle ownership (LR Chi-Square $=38.78, p=0.000)$. The existence of a transit pass owner in the household decreases the odds of owning one or more cars substantially, 0.18 times for onevehicle households and 0.11 times for two vehicle households. It is difficult to assess the direction of this relationship if the ownership of transit passes induces 
the reduction of vehicle ownership or a reduced number of vehicles leads to the ownership of a transit pass.

Bikeshare membership was barely significant (LR Chi-Square $=5.99, p=$ 0.050), but the effects of having or not a bikeshare membership were different for one and two vehicle households. Respondents that had a bikeshare membership were less likely to live in a one-vehicle household than a zero-vehicle household. On the other hand, respondents having bikeshare were more likely to live in a two-vehicle household than a zero-vehicle household. However, the coefficients for both cases were not significant (for two or more vehicle households, $B=0.74$, $\mathrm{OR}=2.09, \mathrm{p}=0.210 ;$ for one vehicle, $\mathrm{B}=-0.35, \mathrm{OR}=0.71, \mathrm{p}=0.434$ ).

The influence of frequency of carshare use per month changed significantly from model two to model three, with the addition of the interactions. The sign of the coefficient changed for households with two or more vehicles (in model two, $B=-0.24, \mathrm{OR}=0.79, \mathrm{p}=0.004$; in model three, $\mathrm{B}=0.74, \mathrm{OR}=2.10$, $p=0.032$ ). For model three, the use of carshare increases the odds of owning two or more vehicles in comparison with the base case of zero vehicles. One possible explanation is the need to be an able driver to use carshare. There are 31 respondents not able to drive living in zero vehicle households, but there is only 1 respondent not able to drive in two or more vehicle household. For one vehicle household, the coefficient in model three was not significant. 
The coefficients for the frequency of ridehail use were both negative and significant (for one vehicle, $B=-0.39, \mathrm{OR}=0.68, \mathrm{p}=0.012$; for two or more vehicles, $B=-1.15, O R=0.32, p=0.002$ ). The increased use of ridehail reduces the odds of owning more than one vehicle in comparison with owning zero vehicles. Once the interactions were added to model three, the magnitude of these effects increased. As we will see in the next subsection, the interactions identified some groups that the use of ridehail were instead associated with greater odds of not owning zero vehicles.

\subsubsection{Interactions}

The interaction of income and carshare use was the most significant interaction (LR Chi-Square $=25.53, p<=0.000)$. All the coefficients are negative, meaning that the higher the income, the higher the use of car share and therefore the smaller the odds of owning more than zero vehicles. For example, respondents earning more than $\$ 75,000$ and using carshare are 0.42 times less likely to own 2 or more vehicles $(B=-0.87, O R=0.42, p=0.032)$ and 0.56 times less likely to own 1 vehicle $(B=-0.58, O R=0.56, p=0.030)$.

The interaction education and carshare use was also significant (LR ChiSquare $=13.85, p=0.001)$. The coefficients were negative, confirming that the higher the education level, the higher the use of carshare and therefore the smaller the odds of owing cars. However, this was significant only for households 
owning two or more vehicles, as they are 0.26 times more likely to own two vehicles than households with less education $(B=-1.33, O R=0.26, p=0.002)$. Carsharing seems an option for educated households that decided to get rid of one vehicle but are not willing to become car-free. For households with one vehicle, the coefficient was not significant and almost zero $(B=-0.04, O R=0.96$, $\mathrm{p}=0.834)$.

The interaction education and ridehail use were significant (LR Chi-Square $=6.97, p=0.031)$ and all the coefficients were positive. The odds of owning two or more vehicles were $80 \%$ greater for households who were educated and used ridehail $(B=0.59, O R=1.80, p=0.039$ ), compared to the base case. This effect is the opposite of the interaction between carshare and education.

The interaction household size and ridehail use showed a positive relationship with vehicle ownership (LR Chi-Square $=17.00, p=0.002)$. It suggests more use of ridehail increases the odds of owning one or more vehicles as the households have more persons, comparing to the base case of owning no vehicles, for a household of one person.

\subsection{Summary}

This chapter describes the results of models of vehicle ownership levels as a function of demographics, built environment, transportation policy, and interactions between shared mobility use and demographics. We compared the 
influence of adding each of these sets of variables on the model explanatory power and found that the transportation policy and interaction variables significantly improved model fit. We found that transportation policy variables, as parking availability, transit pass ownership, and shared mobility are significantly associated with vehicle ownership levels.

Table 4-4 summarizes the significant associations as well as the direction of influence on vehicle ownership for demographics, built environment, and transportation policy and for the interactions of shared mobility. Consistent with other studies, the most significant variables to influence vehicle ownership are income, household size, education, and distance to work.

Transportation demand management policy measures (transit passes and parking availability) were also significant with transit having a negative impact on vehicle ownership and parking having a positive one.

The study is focused on how shared mobility may support or detract from vehicle ownership. Bikesharing was not significantly associated with vehicle ownership levels. This may be due to the fact that the system was relatively new at the time of the study and had not been in operation long enough to be associated with vehicle ownership decisions (Biketown started in July 2016 and this survey was completed in September 2017). 
Table 4-4 Summary of model three results without interactions

\begin{tabular}{|c|c|c|}
\hline Variables & 1 vehicle & $\begin{array}{c}2 \text { or more } \\
\text { vehicles }\end{array}$ \\
\hline \multicolumn{3}{|l|}{ Demographics } \\
\hline Income & + & + \\
\hline Household size & & ++ \\
\hline Education (BA and higher) & + & \\
\hline \multicolumn{3}{|l|}{ Age (More than 35) } \\
\hline \multicolumn{3}{|l|}{ Built Environment } \\
\hline Distance to Work & + & ++ \\
\hline Pop. Density & - & \\
\hline Emp. Density & - & - \\
\hline Ped. Oriented Inter. per acre*100 & - & - \\
\hline \multicolumn{3}{|l|}{ Transportation Policy } \\
\hline Reported Parking (Yes) & & + \\
\hline Transit Pass (Yes) & -- & -- \\
\hline \multicolumn{3}{|l|}{ Bikeshare Membership (Yes) } \\
\hline Freq. of carshare use & & + \\
\hline Freq. of ridehail use & - & - \\
\hline \multicolumn{3}{|l|}{ Interactions } \\
\hline \multicolumn{3}{|l|}{ Interaction Income ${ }^{*}$ Freq.Carshare } \\
\hline \multicolumn{3}{|l|}{ Refused / Unknown } \\
\hline More than $\$ 75,000$ & - & - \\
\hline$\$ 50,000$ to $\$ 74,999$ & & -- \\
\hline Interaction BA and Higher*Freq.Carshare & & -- \\
\hline Interaction BA and Higher*Freq.Ridehail & & + \\
\hline \multicolumn{3}{|l|}{ Interaction $\mathrm{HH}$ size*Freq. Ridehail } \\
\hline \multicolumn{3}{|l|}{3 or more } \\
\hline 2 Persons & + & + \\
\hline
\end{tabular}

Note: only significant variables at 0.05 level shown

The use of interactions between shared mobility use and some demographic traits allowed us to understand better how vehicle ownership is related to these emerging mobility options. Carsharing was significantly 
associated with vehicle ownership levels. Users of carshare in general present higher odds of owning fewer cars (Namazu \& Dowlatabadi, 2018 ). The use of carshare is effective in reducing the odds of owning two vehicles, for households where the residents have higher education and middle income to high income. For other types of household, especially those where the respondent is not an able driver, this is not true.

However, the same trend is not found in ridehailing, where the interactions showed a propensity to own more vehicles for residents using ridehail with a higher level of education or more than one person in the household. For all other cases, the use of ridehail decrease the odds of owning more vehicles.

But how much use of shared mobility is needed to sustain lower levels or even reduce vehicle ownership? In the next chapter, we will use the model three to test different scenarios and evaluate possible thresholds of shared mobility use. 


\section{Chapter 5. Scenario and Impact Analysis}

One of the drawbacks of the modeling methodology chosen, the MLR, is that the interpretation is not always straightforward. In the next two sections, we will use the model three developed in the last chapter to understand the impacts of shared mobility and transportation policy in vehicle ownership. In the first section, the scenario analysis, we will compare different individual households characteristics varying the frequency of shared mobility use and analyze how the probabilities of each level of household vehicle ownership changes. In the final section, we will simulate vehicle ownership in four different scenarios in a disaggregate level for all the sample.

\subsection{Scenario Analysis}

In this section, we will compare the effects of shared mobility use using scenario analysis. Specifically, we take a "representative agent", i.e., someone who is "average" on all variables except for a target variable, and plot how the probability of each vehicle ownership outcome changes as shared mobility use increases.

By varying the combined frequency of carshare and ridehail use, we estimated the probabilities of owning zero, one, and two or more vehicles for each different type of household. We will then assess the influence of shared 
mobility in different kinds of households. The households that we will test are hypothetical. Note that we will describe the household regarding employment, student or not, divorced or not, but these characteristics were examined and were not found significant to the model. We will use these terms as a label to better describe the possible life stage of that household (the "representative agent”). For all the scenarios, we will use values typically observed in the Hawthorne area for population, employment, and intersection density, where new developments with no parking and abundant access to shared mobility and transit are found.

The first household we tested (Figure 5-1) was a one-person household, earning less than $\$ 50,000$ per year, with no Bachelor or equivalent degree, with age less than 35 years, the commute distance is between 2 to 10 miles, owning a transit pass and living in a building with no parking. Note that the values in the $\mathrm{X}$ axis comprises of the sum of carshare and ridehail use per month, both assuming the same amount. For example, the number 12 refers to 6 uses per month of ridehail and carshare services. We call the first household "the student," as it resembles the profile of a student working in a low earning job finishing his or her undergraduate. For this profile, the use of shared mobility only increases the already high chance of not owning a car. 
Vehicle ownership levels probabilities varying shared mobility use for income less than $\$ 50 \mathrm{k}, 1$ person household, no BA, less than 35 years old, transit pass available and no parking

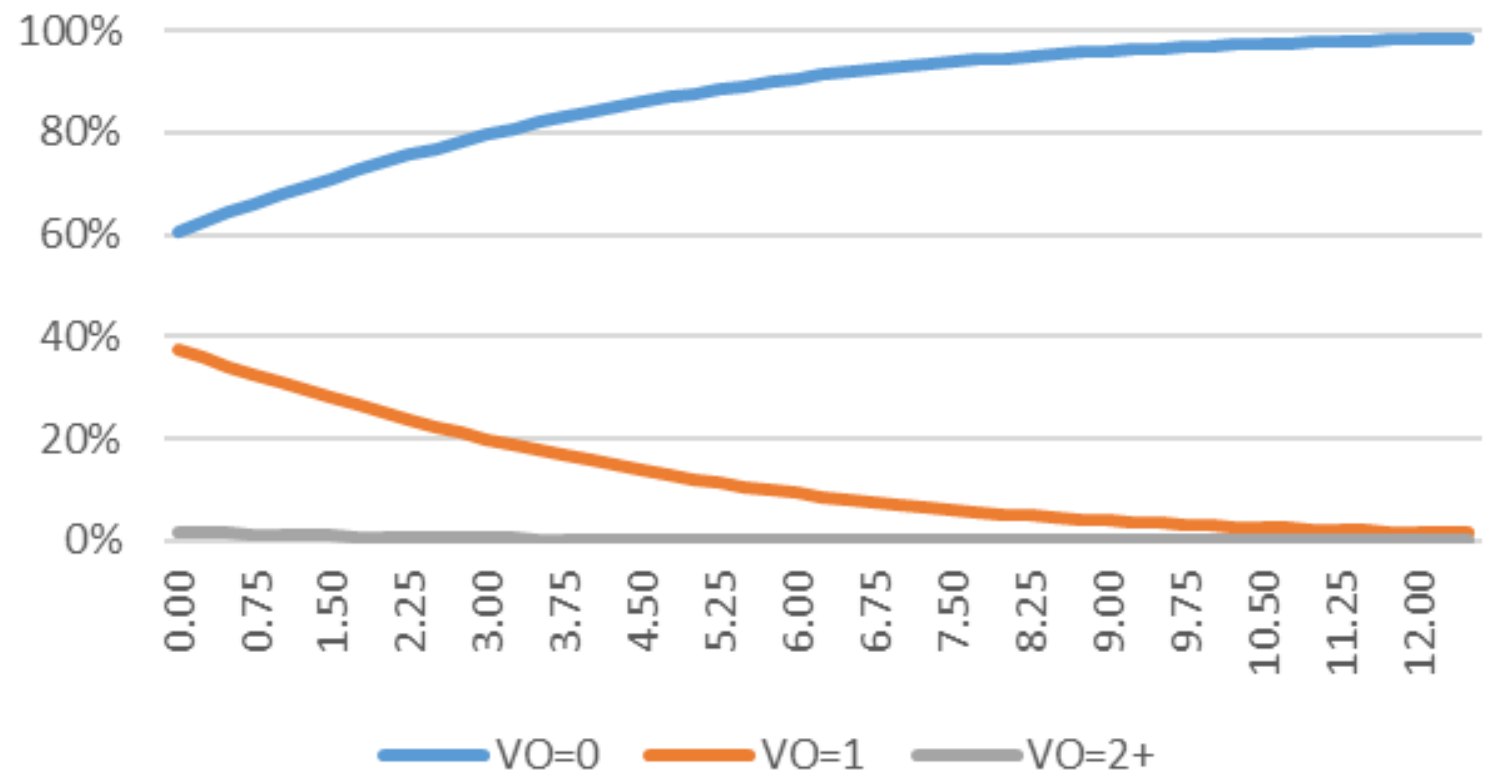

Figure 5-1 Vehicle ownership probabilities varying shared mobility use for "The Student" household profile

The next household tested had the same characteristics of the first, but now we added a Bachelors degree (Figure 5-2). We label this household "the graduate." It is clear how, without any use of shared mobility, the probability of owning one car is higher than not owning a car. 

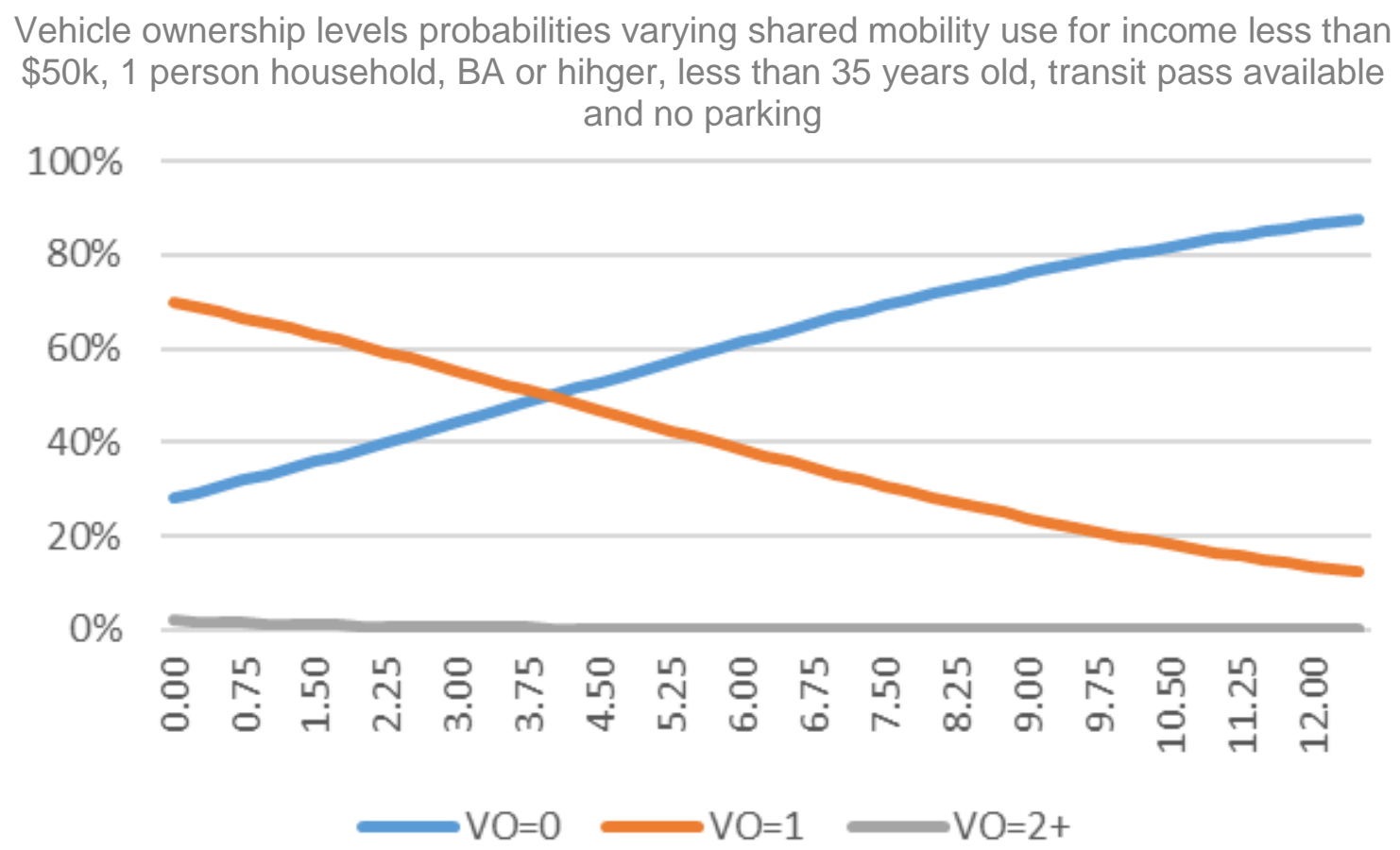

Figure 5-2 Vehicle ownership probabilities varying shared mobility use for "The Graduate" household profile

The influence of educational levels is significant for all income levels.

Figure 5-3 shows the probability of owning zero vehicles varying income and education and keeping the same characteristics above (a one-person household, with less than 35 years, the commute distance is between 2 to 10 miles, owning a transit pass and living in a building with no parking). The probability of holding zero vehicles varies significantly, from $7 \%$ ( $>75 \mathrm{k}$, BA or Higher) to $54 \%(<50 \mathrm{k}$, no BA) when no shared mobility is used. But relatively low monthly use (between 1 and 2.5 times each, 2 to 5 in total)) can equal the probability of owning one or 
zero cars for all income and educational levels, except for those earning between \$50k and \$75k with BA.

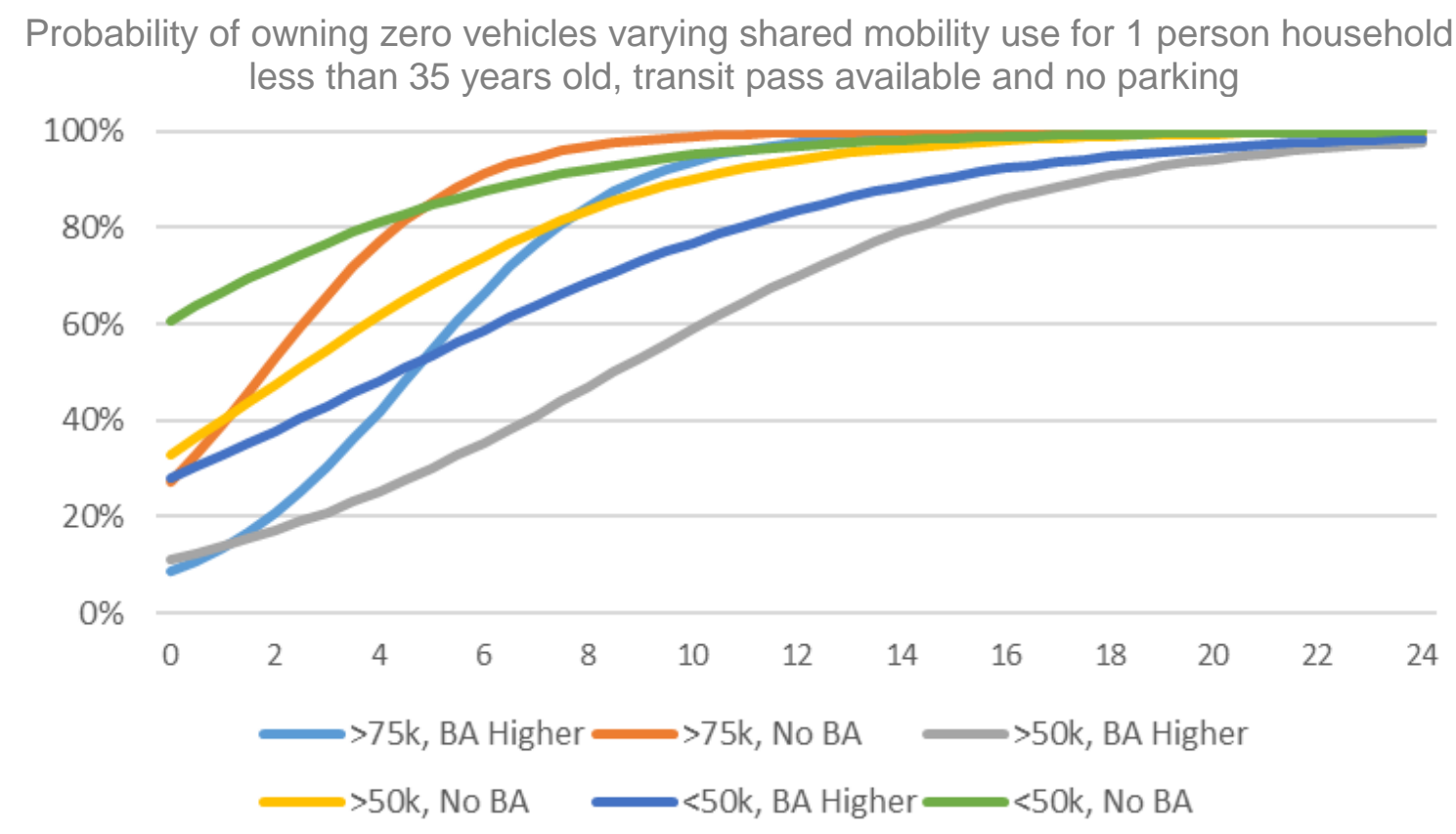

Figure 5-3 Probability of owning zero vehicle for different levels of education and income, varying shared mobility

The next household tested (Figure 5-4) had the same characteristics of the last, but with a higher income (between $\$ 50,000$ and $\$ 75,000$ ). We call this scenario "new job." Comparing the probability of zero-vehicle in Figure 5-4 with Figure 5-3, changing one income category reduced the likelihood of owning zero cars from $28 \%$ to $11 \%$. Also, to increase the odds of holding zero vehicles for this household, a significant amount of ridehail and carshare should be used (to reach $50 \%$ chance, 8.5 times per month of ridehail (4.25) and carshare (4.25)). 
Vehicle ownership levels probabilities varying shared mobility use for income between

$\$ 50 \mathrm{k}$ and $\$ 75 \mathrm{k}, 1$ person household, BA or higher, less than 35 years old, transit pass available and no parking

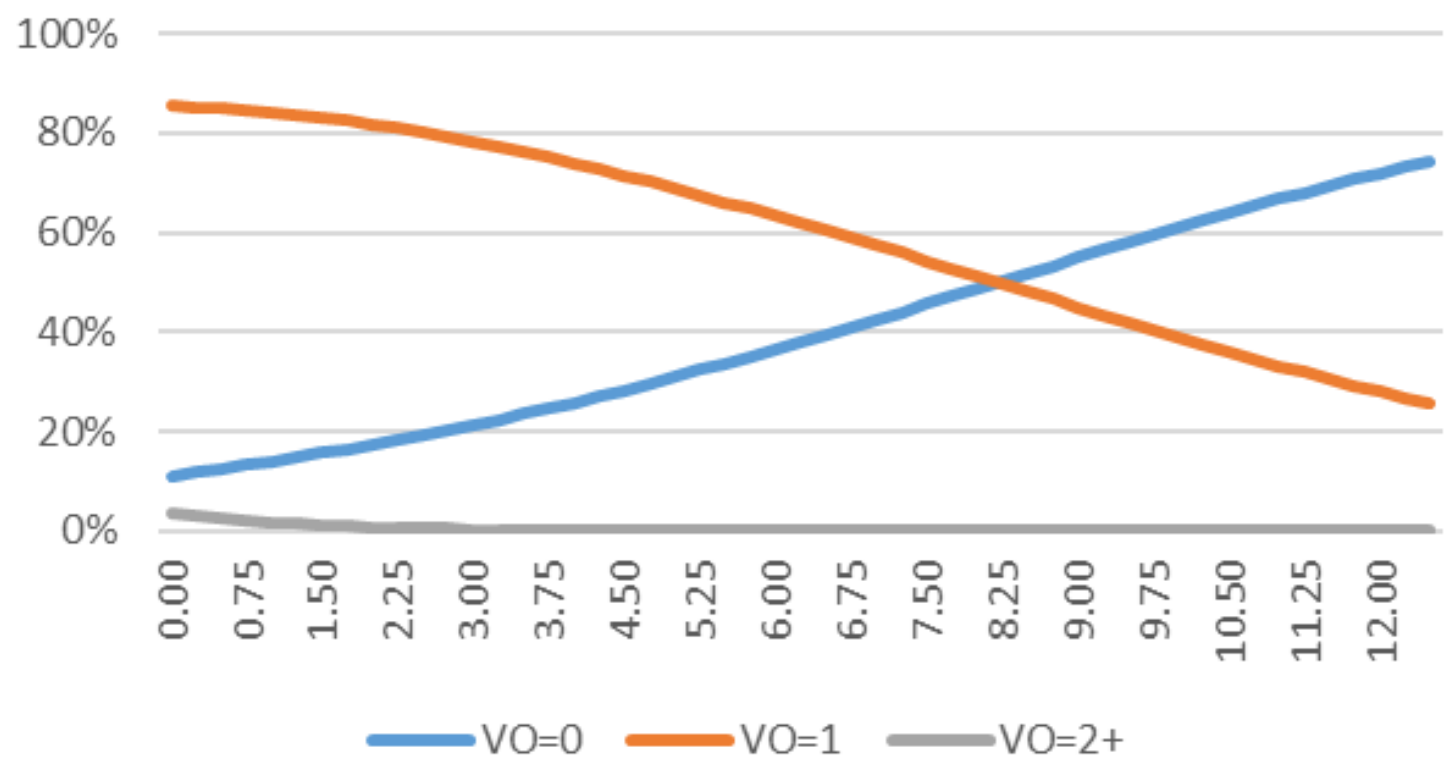

Figure 5-4 Vehicle ownership probabilities varying shared mobility use for "New Job" household profile

For the next household, there are some significant changes. We kept the earnings between $\$ 50,000$ and $\$ 75,000$ per year, with Bachelor or equivalent degree, still less than 35 years, the commute distance is between 2 to 10 miles, and owning a transit pass. However, now we tested a two-person household now living in a building with parking. We call this scenario "recently married" and can be seen in Figure 5-5. Now the probability of owning two or more vehicles is the greatest, if there is no use of shared mobility, with $54 \%$. But it rapidly declines 
with the use of shared mobility, as with 0.25 uses per month of ridehail and carshare the chances of owning one vehicle are higher than two vehicles.

Vehicle ownership levels probabilities varying shared mobility use for income between $\$ 50 \mathrm{k}$ and $\$ 75 \mathrm{k}, 2$ person household, BA or higher, less than 35 years old, transit pass available and parking available

\section{$100 \%$}

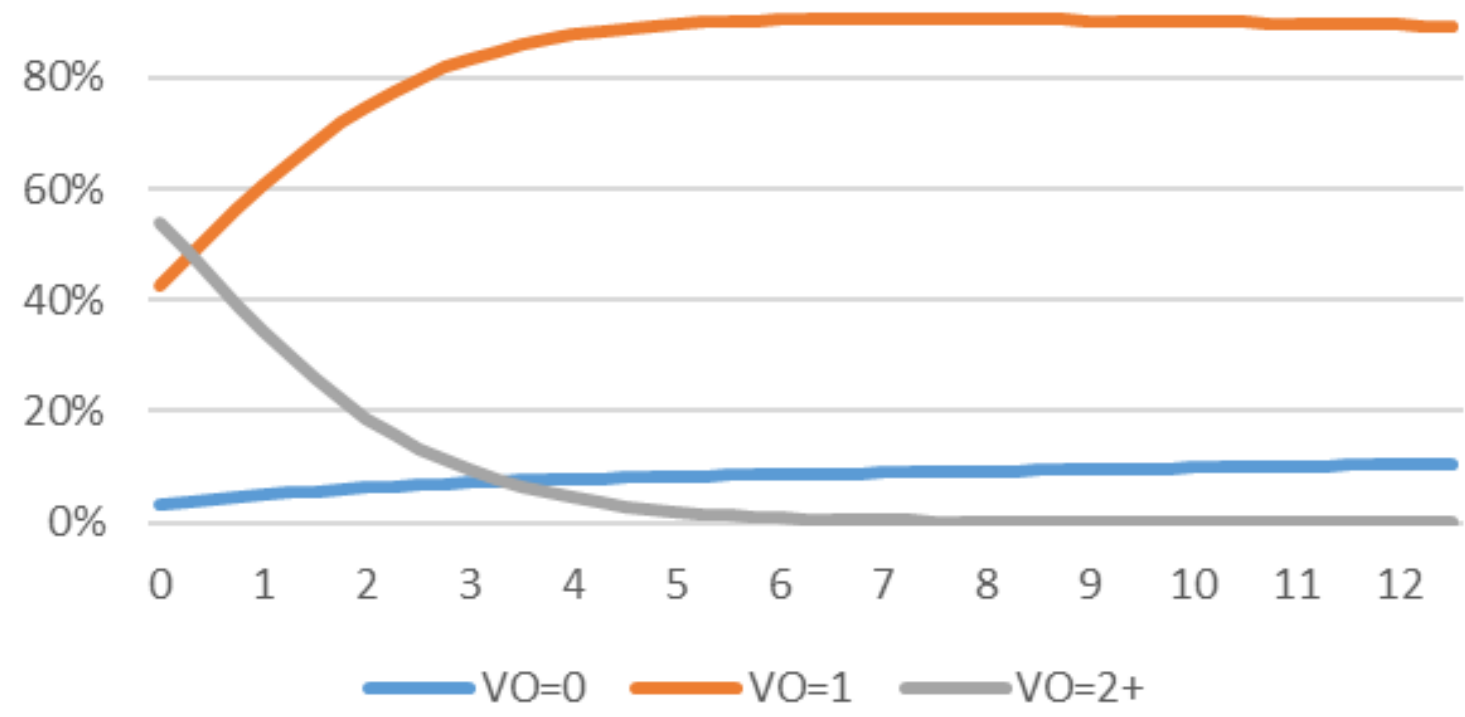

Figure 5-5 Vehicle ownership probabilities varying shared mobility use for "Recently Married" household profile

The influence of parking is similar across income levels, but it tends to be overshadowed by shared mobility after a threshold. Figure 5-6 shows the probability of owning one vehicle varying income and parking availability and maintaining the same characteristics from the last scenario (two-person household, with less than 35 years, the commute distance is between 2 to 10 miles, owning a transit pass with a BA or higher education). For example, for a household earning between $\$ 50,000$ and $\$ 75,000$, the probability of owning one 
vehicle is $43 \%$ and $67 \%$, with and without parking, respectively, with no use of shared mobility. But after approximately two uses per month of carshare and ridehail, the probabilities of owning one vehicle for properties with or without parking are the same.

Another trend from Figure 5-6 is the influence of the use of shared mobility in reducing vehicle ownership in the higher income households. There is a significant decrease in the probability of owning one vehicle in detriment of holding zero vehicles after approximately 2.5 uses per month of carshare and ridehail, what is not observed in other income levels.

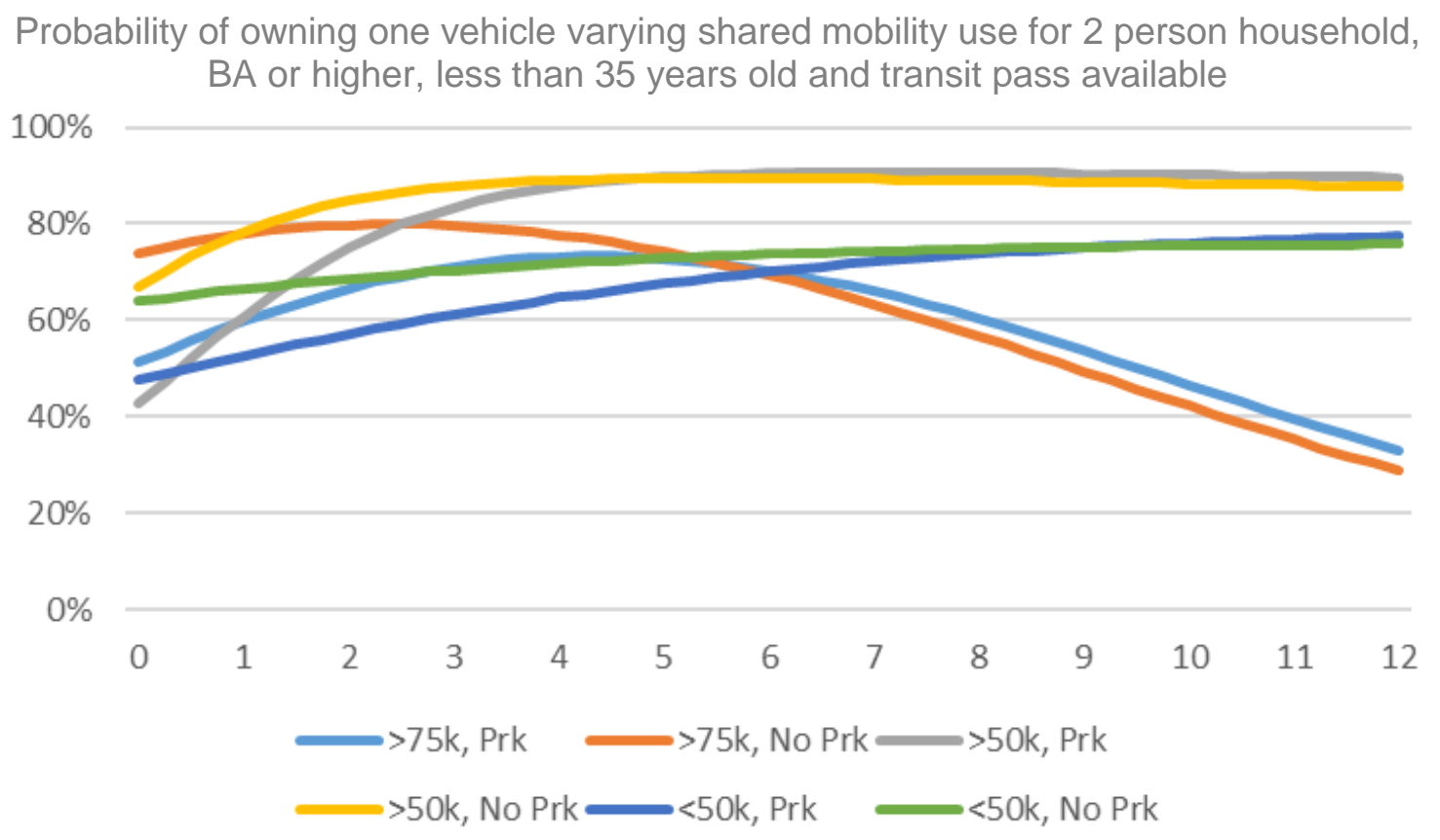

Figure 5-6 Probability of owning one vehicle for different levels of parking and income, varying shared mobility 
However, the influence on car ownership is not equal for carshare and ridehail. Figure 5-7 below uses the same household characteristics to show the impact of only ridehail in vehicle ownership, varying income and parking. As can be seen, the importance of ridehail is minimal. Even if the use increases more than six times per month, the linear trend continues and for all initial values to double, the use per month should be 24 times. Therefore, the primary influence on high-income households with two persons comes mainly from carshare. However, for all scenarios involving two or more persons in the households, the pattern is similar, for all levels of income.

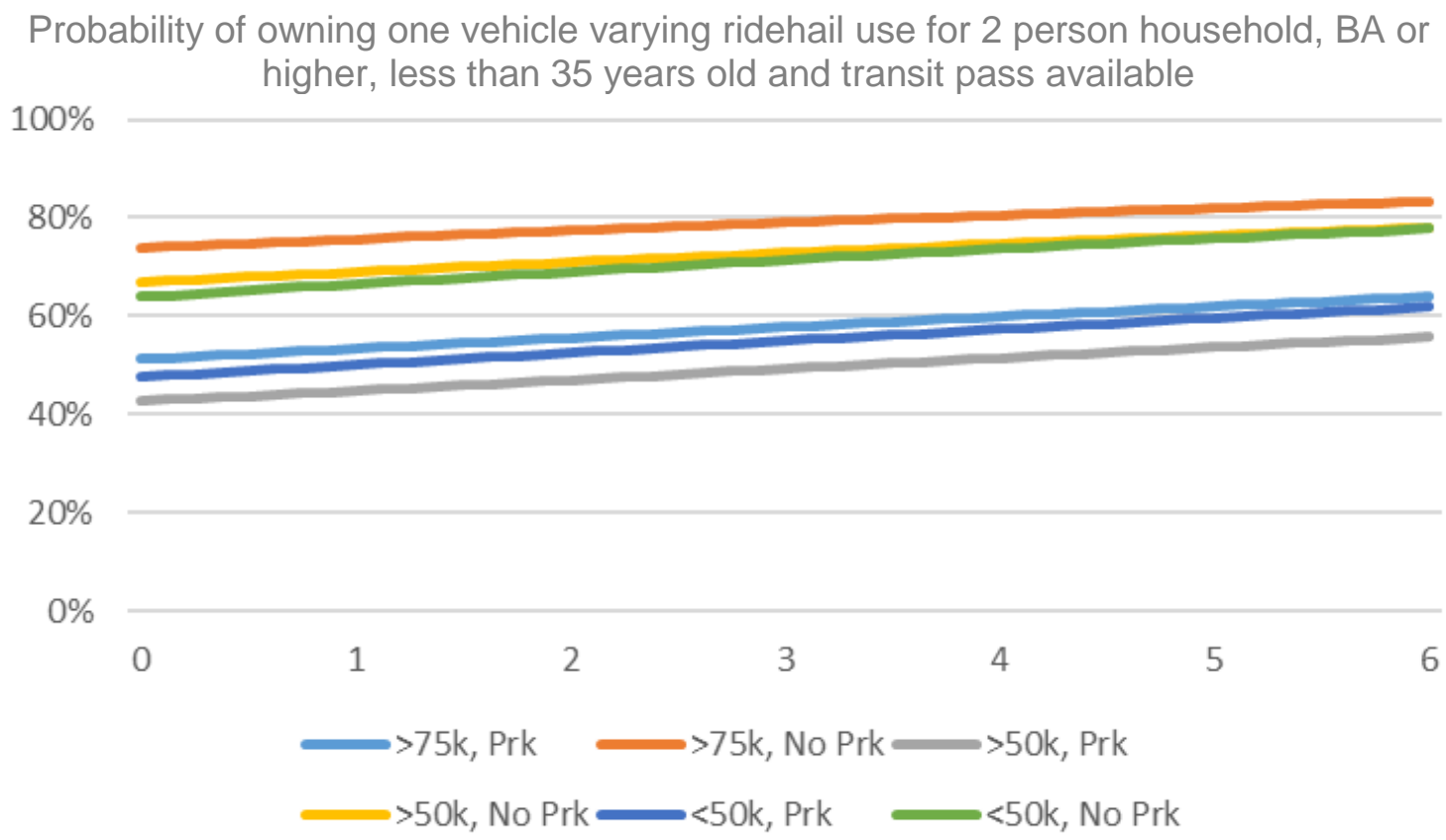

Figure 5-7 Probability of owning one car for different levels of education and income, varying ridehail use 
For the next scenario, we changed the age to more than 35 years. We kept the transit pass, income level, distance to work, Bachelor or equivalent degree and parking available, for a two-person household. We call this scenario "Ex-Millenial" (Figure 5-8). Comparing the initial probability of owning one vehicle from this scenario (which is $64 \%$ ) to the "Recently Married" scenario in Figure 5-5 (which is $43 \%$ ), shows the effect of age on vehicle ownership. There is a proportional increase in the probability of owning two cars, for individuals with less than 35 years. As discussed in section 3.2, this finding is different from the literature, where younger people usually has fewer cars.

Vehicle ownership levels probabilities varying shared mobility use for income between $\$ 50 \mathrm{k}$ and $\$ 75 \mathrm{k}, 2$ person household, BA or higher, more than 35 years old, transit pass available and parking available

$100 \%$

$80 \%$

$60 \%$

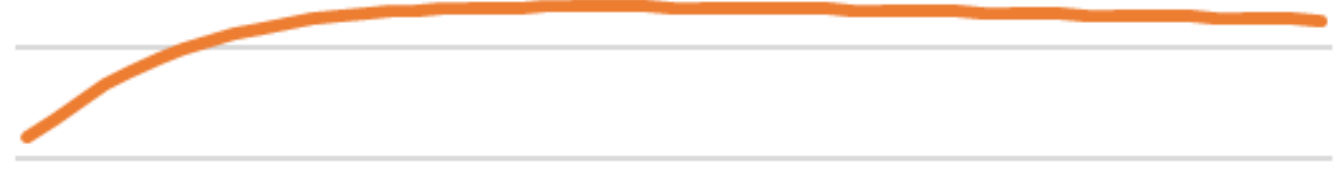

$40 \%$

$20 \%$

$0 \%$

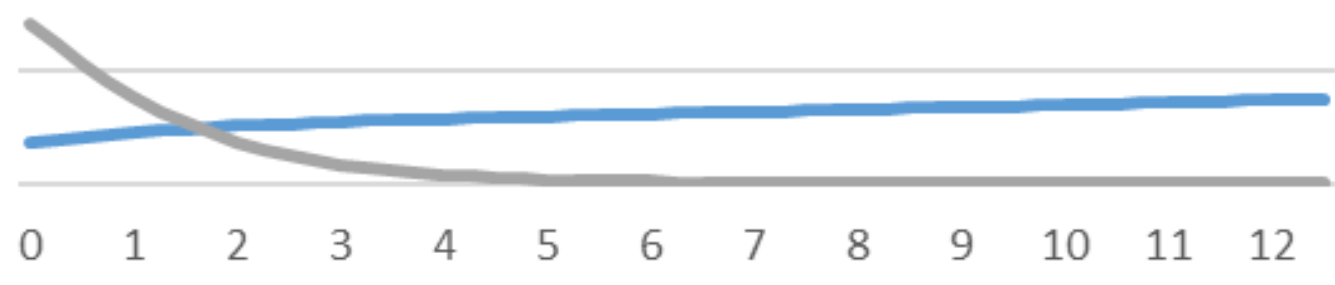

$\mathrm{VO}=0 \longrightarrow \mathrm{VO}=1 \longrightarrow \mathrm{VO}=2+$

Figure 5-8 Vehicle ownership probabilities varying shared mobility use for "ExMillennial" household profile 
For the next scenario (Figure 5-9), we changed income, and the availability of transit passes. We called this scenario "Promotion." We can see the influence of shared mobility in increasing the probabilities of owning zero vehicles.

Vehicle ownership levels probabilities varying shared mobility use for income more than $\$ 75 \mathrm{k}, 2$ person household, BA or higher, more than 35 years old, no transit pass and parking available

$100 \%$
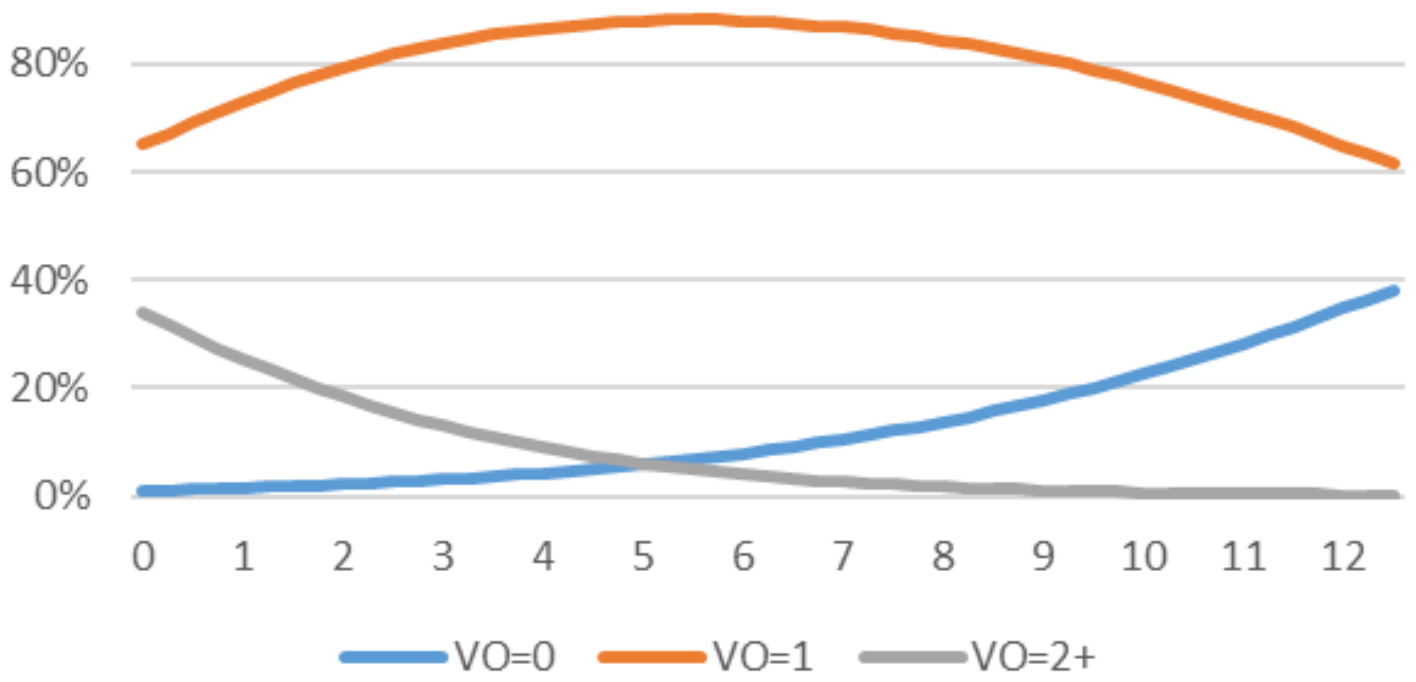

Figure 5-9 Vehicle ownership probabilities varying shared mobility use for "Promotion" household profile

However, the impact of the availability of transit passes is significant when combined with the use of shared mobility. It is not a clear indicator of transit use, but its ownership has a more substantial effect on vehicle ownership (mainly in reducing the probability of owning two or more vehicle) when the use of shared 
mobility increases, as shown in Figure 5-10 below. For example, for those households earning less than $\$ 50,000$, with no use of shared mobility, the probability of owning one vehicle is $60 \%$ (the chance of two or more vehicles is $18 \%$ ) with transit passes and $64 \%$ (the chance of two or more vehicles is $32 \%$ ) without transit passes. However, using carshare and ridehail six times per month, the probability changes to $72 \%$ (the probability of two or more vehicles is $1 \%$ ) and $92 \%$ (the chance of two or more vehicles is $2 \%$ ). It is worth remembering that ridehailing plays a minor role in the shared mobility influence also in this scenario, in a pattern similar as was stated in Figure 5-7.

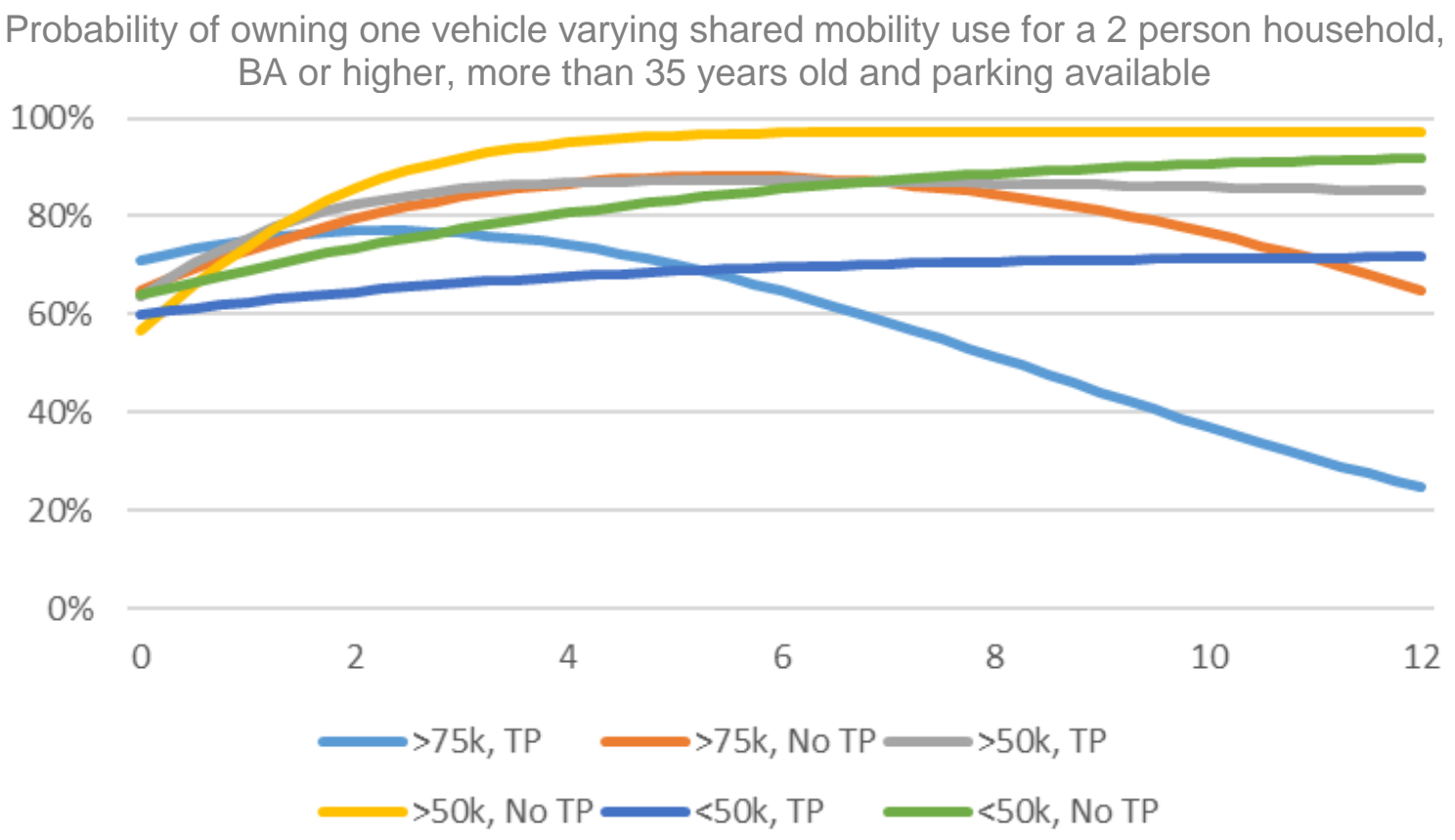

Figure 5-10 Probability of owning one vehicle for different levels of transit pass availability and income, varying shared mobility use 
For the next scenario, we increase the number of persons in the household to three, keeping all the other characteristics the same. We called this scenario "New family" and can be seen in Figure 5-11 below. However, the results should be taken with cautions, as the number of families in our sample with three or more persons, despite statistically valid, is much smaller than two or one family households.

Vehicle ownership levels probabilities varying shared mobility use for income more than $\$ 75 \mathrm{k}, 3$ person household, BA or higher, more than 35 years old, no transit pass and parking available

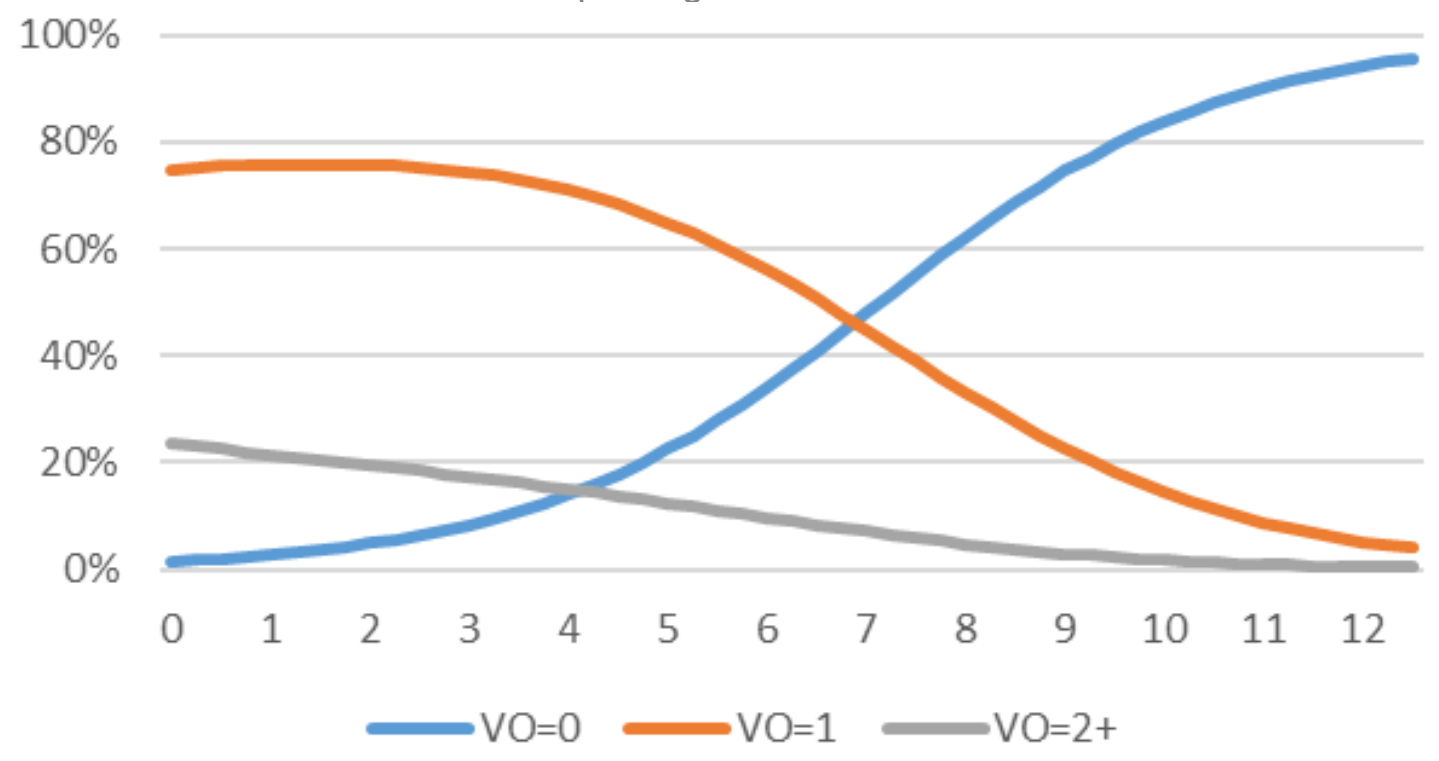

Figure 5-11 Vehicle ownership probabilities varying shared mobility use for "New Family" household profile

Comparing the probabilities of owning one car in different income levels for households of two and three or more persons, shows the influence of shared mobility in vehicle ownership, as can be seen in Figure 5-12. Without the use of 
shared mobility, the probability of owning one vehicle is similar for all households. However, the use of shared mobility has different effects. For example, for households earning less than $\$ 50,000$, the initial probability of owning one vehicle is $72 \%$ ( $6 \%$ for zero cars) and $64 \%$ ( $4 \%$ for zero cars), for 3 and twoperson household, respectively. Nevertheless, when there is a use of six times per month of ridehail and carshare, the probability of owning one vehicle is $27 \%$ (60\% for zero vehicles) and $92 \%$ (6\% for zero vehicles), for three and two-person household, respectively. From the figure below, an inflection point for all the income and household levels of shared service use influence on vehicle ownership seems to be between two and four.

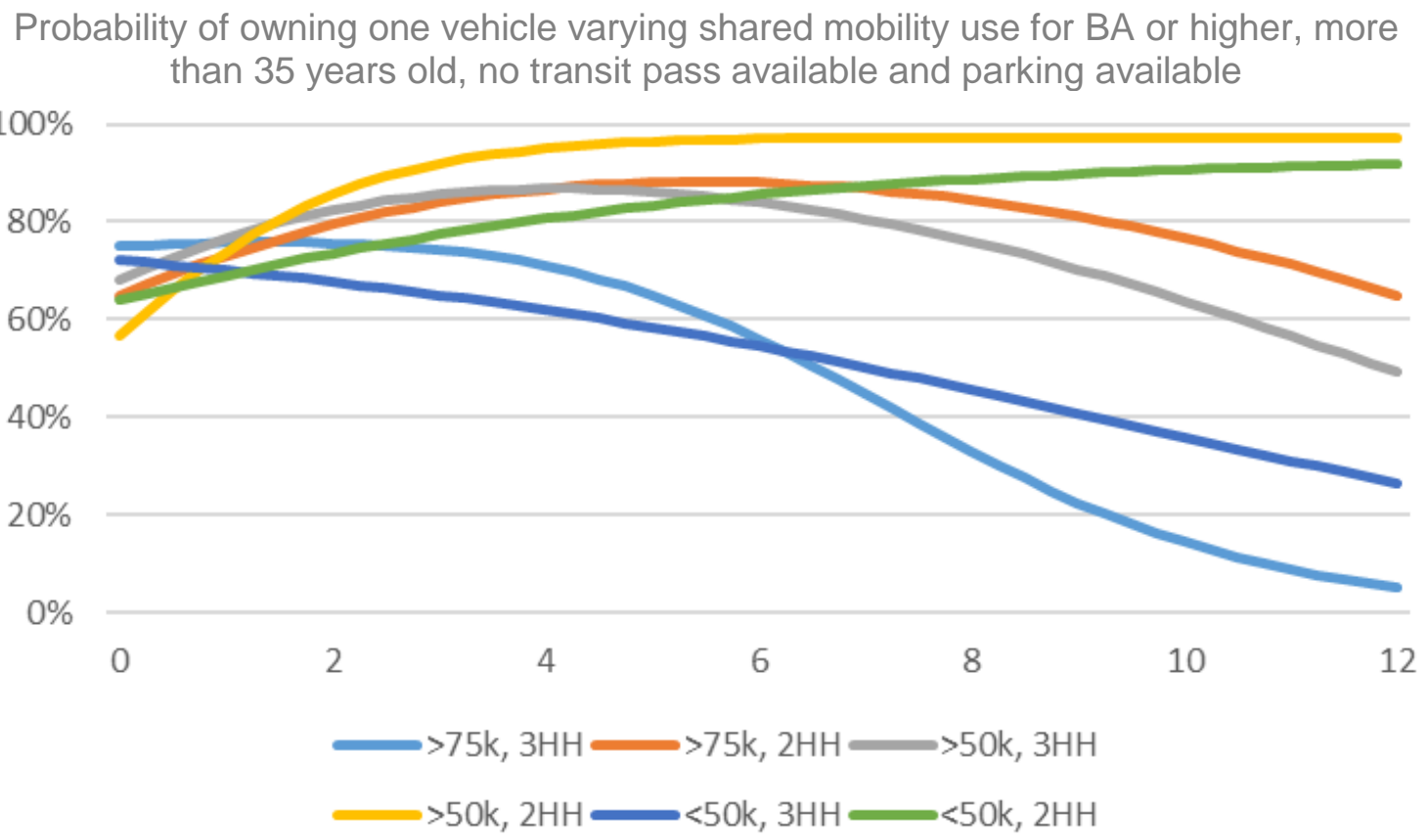

Figure 5-12 Probability of owning one car for different levels of household size and income, varying shared mobility use 
The influence of ridehail and carshare are very different for this scenario, as can be seen in Figure 5-13. For two-person households, independent of income, there is a very slight increase in the probability of owning one car as ridehail use increases. However, for a three or more-person household, the use of ridehail decreases the chances of owning one car, does not influence the probability of owning zero cars and increase the probability of owning two or more cars.

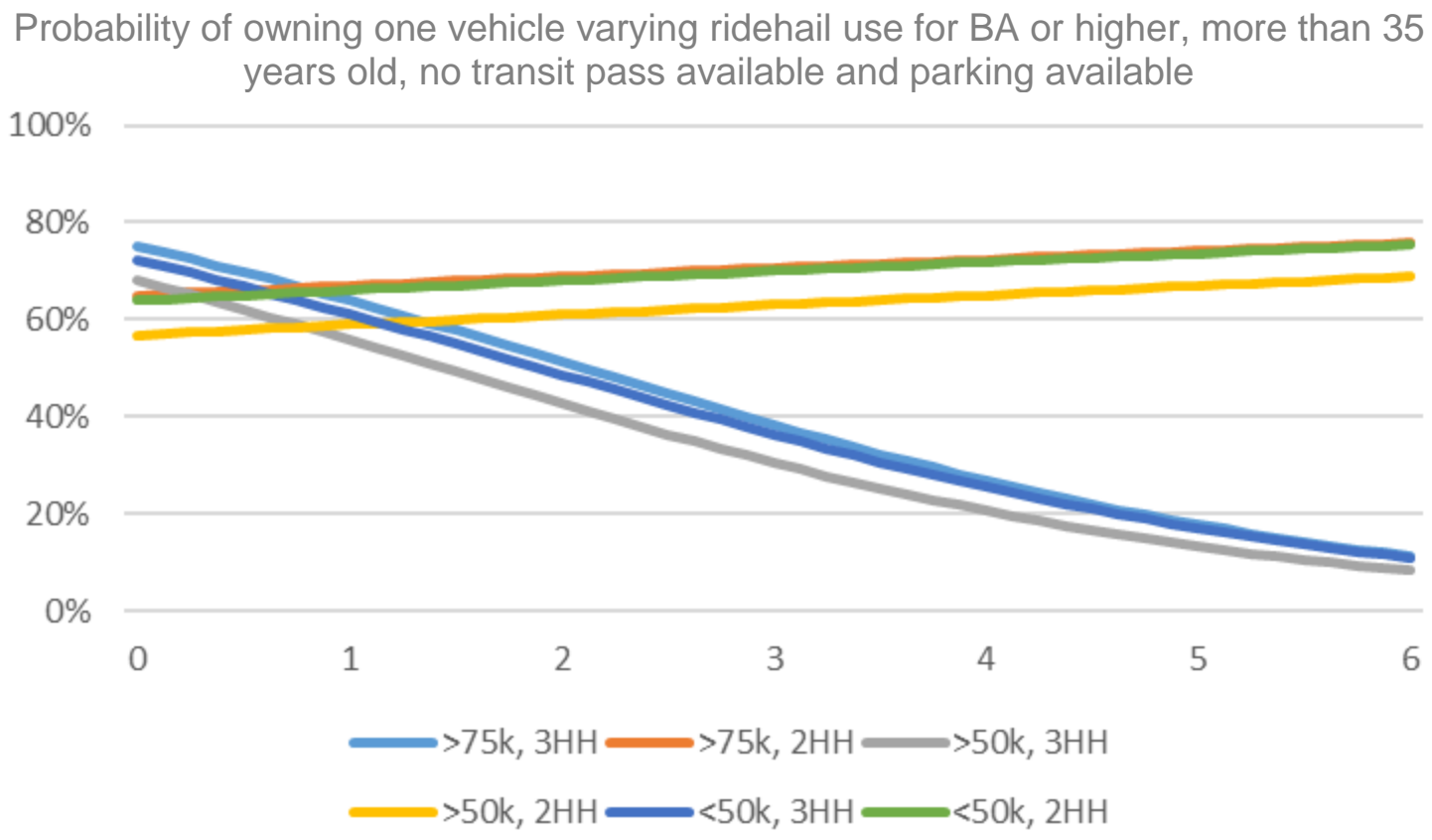

Figure 5-13 Probability of owning one vehicle for different levels of houehold size and income, varying ridehail use 


\subsection{Impact Analysis}

In this section, we will test some policies and their respective effects on household vehicle ownership. Four scenarios were simulated, and for each scenario the household vehicle ownership compared with the observed data predicted by the model. Each scenario was applied at a disaggregate level, for each of the 481 respondents. Then the model estimated the new probabilities for each vehicle ownership level (zero vehicle, one vehicle or two or more vehicles) and then the results were aggregated. For the current scenario, the model slightly overestimates the overall number of cars in the household by $1.4 \%$, which is acceptable (1.08 vs. 1.06). The four scenarios chosen are:

1. Change in activity density: $100 \%$ increase in the average employment and population density observed.

2. Change in parking supply: exclusion of all parking supply from the developments where the respondent answered "parking is available".

3. Change in shared mobility use: increase in the overall average frequency of carshare and ridehail use per month from 0.6 to 2.8 and 1.6 to 2.5 , respectively. The new frequencies represent the average use of shared mobility only by those respondents that are members of each service. It is an increase of $340 \%$ in the carshare frequency and $54 \%$ in the ridehail use against the overall average of each mode. 
4. All the three previous scenarios combined.

All the four scenarios decrease the average number of cars per household, as can be seen in Table 5-1. The first scenario, doubling the employment and population density observed figures resulted in a decrease of $4.2 \%$ in vehicle ownership. We chose to combine both density variables and duplicate them as their marginal increase produces parallel effects with little influence on the outcome. This finding is in line with those in the literature (Cirillo \& Liu, 2013; Fang, 2008; Guo Z. , 2013). However, these authors found that households with more vehicles are more affected by density increases. In this study, households with one vehicle were the most affected by the density increase. Those who had two or more vehicles were not much influenced by the increase in density, suggesting this strategy is aimed to increase the number of car-free households, not just to reduce the ownership of vehicles, for this population.

On the other hand, when parking is excluded from all developments, the influence on households with two or more vehicles is substantial. There is a reduction of 12 p.p. or $70 \%$ in the number of households with 2 or more vehicles, migrating to one-vehicle households. This reduction suggests that today finding at least one parking spot off-site is not a barrier to owning a car, as has been suggested by Guo (2013) for single-family residents. The decline in vehicle ownership for all households was of $8.4 \%$. If we compare to the first scenario of 
activity increase, the exclusion of parking duplicates the reduction in car ownership, as it affects households with more vehicles.

The third scenario provides a $15 \%$ reduction in overall vehicle ownership, but with significant increases in the use of ridehail and specially carshare. Households with zero and with two or more vehicles were most affected, suggesting a relatively linear reduction in one car for all the households that own vehicles. Effectively, the shared mobility is reducing vehicle ownership. However, it remains to be seen if the significant increase in its use (carshare and ridehail use per month from 0.6 to 2.8 and 1.6 to 2.5 , respectively) might be achievable in the short term.

The fourth scenario combines all the strategies to reach a reduction in car ownership of $38 \%$, decreasing from 1.08 to 0.61 cars per household. The decrease in car ownership is mainly due to the substantial increase in zerovehicle households in comparison with households that own a vehicle. The combination of the three strategies (activity density increase to stimulate car-free households; no parking to induce fewer two or more vehicle families; and shared mobility to substitute the general need to move by car) provides a reduction in car ownership greater than the sum of each one. 
Table 5-1 Comparison of Four Scenarios of Vehicle Ownership

\begin{tabular}{lrrrrr}
\hline \multicolumn{1}{c}{ Vehicle Ownership } & Current & $\begin{array}{c}\text { Activity } \\
\mathbf{+ 1 0 0 \%}\end{array}$ & $\begin{array}{c}\text { No } \\
\text { parking }\end{array}$ & $\begin{array}{c}\text { Shared } \\
\text { Mobility } \\
\text { Use Increase }\end{array}$ & $\begin{array}{c}\text { All } \\
\text { combined }\end{array}$ \\
\hline & & & & & \\
0 vehicles & $15 \%$ & $24 \%$ & $16 \%$ & $27 \%$ & $43 \%$ \\
1 vehicle & $68 \%$ & $61 \%$ & $79 \%$ & $65 \%$ & $54 \%$ \\
2 or more vehicles & $17 \%$ & $15 \%$ & $5 \%$ & $8 \%$ & $3 \%$ \\
Total & $100 \%$ & $100 \%$ & $100 \%$ & $100 \%$ & $100 \%$ \\
Average cars per household & 1.08 & 0.95 & 0.90 & 0.83 & 0.61 \\
\% change to current scenario & - & $-4.2 \%$ & $-8.4 \%$ & $-15.5 \%$ & $-37.7 \%$ \\
\hline
\end{tabular}

\subsection{Summary}

This chapter provided two types of analysis using model three developed in the previous chapter, to demonstrate the effects of shared mobility and transportation policy on vehicle ownership.

The first analysis, done at the household level, estimated the probabilities of vehicle ownership for different profiles of households. We found that the use of shared mobility (mainly carsharing) between two to 3 times per month can reduce the probability of owning an additional car and offset the effects of parking availability.

The second analysis, with aggregate results from all the households, estimated the effects of transportation policy and shared mobility use on the whole sample. Here we found that a combination of several strategies is more effective than the sum of the parts and reinforced the effectiveness of shared mobility in reducing car ownership. 


\section{Chapter 6. Conclusions}

There is a strong association between share mobility use and car ownership. However, it is not as significant as the effects of income, household size, distance to work, and transit pass ownership. As mentioned in the literature review and shown in section 5.1, the effects of carshare on reducing vehicle ownership are stronger than the impact of ridehail, especially for higher income and more educated households, with two or more persons. It is important to remember that the survey sample consisted of only multifamily apartments living in areas with a higher than average offer of public transport and shared mobility options. This characteristics already induce households to own fewer vehicles. In our sample, as shown in section 3.2, households owning fewer cars present some characteristics in common. Households with zero vehicles tend to be a single person, male with lower income. This single person household also has more chances of not having a bachelor's degree, of not working or working closer than 2 miles and own a transit pass than a one-vehicle household. The residential, employment and pedestrian intersection density of the census block group where zero vehicles households live are also higher than one-vehicle households. Zero-vehicle households are using shared mobility more than the other two types of households. 
There are several effects of shared mobility and transportation policy on the number of household's vehicles. One of the advantages of the Multinomial Logistic Regression model chosen for this analysis is its nonlinear structure, allowing analysis of specific niches. That proved valuable in this study, as the effects of both shared mobility and transportation policies are not equal for the different levels of household vehicle ownership. For example, the use of carshare for mid-income families is more effective in reducing the odds of owning two cars than lowering the odds of owning one car.

Carshare use was negatively associated with household vehicles, meaning that it is a useful tool in reducing car ownership. For respondents with higher education and median or higher income levels, increased carshare use produces the most promising results. Ridehail use, however, was not as clearly associated with reducing vehicle ownership and the effect was much smaller than those of carshare, as can be seen in Figure 5-7 and Figure 5-13.

Parking availability in the building also has significant effects on vehicle ownership. In sites with no parking available, there is an increased chance of the household owning fewer than two cars. The same effect can be obtained with the increased use of shared mobility, as shown in Figure 5-6. For all income levels, monthly use of ridehail and carshare between two and three times seem enough to reduce the chances of owning two or more vehicles. 
The shared mobility services are not evenly widespread and used among the respondents. Results from section 3.2 show there are substantially more members of ridehail services (58\%) than carshare services (23\%) and owners of transit passes (36\%). Only for zero-vehicle households, the number of transit passes is greater than ridehail membership. A smaller number of households owns bikeshare membership (14\%).

Of $300(62 \%)$ of households who are members of any shared mobility services (ridehailing, carsharing and bikesharing), 28 (9\%) have affiliation to all services, 91 (30\%) are members of carshare and ridehail, $278(93 \%)$ are members of ridehail and $109(37 \%)$ are members of carshare. Carsharing tends to be more used by its members than ridehailing. Carshare members use on average 2.8 times per month and zero vehicles households with carshare membership are using the most, with 3.7 times per month. Ridehail members use on average 2.5 times per month, with zero vehicles households using the most, with 3.2 times per month. Several reasons may contribute to carshare being more used than ridehail by its members: the lower cost of carshare use for some trips, privacy concerns, and the no-cost entrance fee for ridehail membership, broadening its base of customers but not its use.

The main differences between the users of shared mobility services can be seen in Table 6-1 and 
Table 6-2 below. We compared the demographics, built environment and transportation policy options from section 3.2 of respondents using at least one time per month ridehail or carshare, with those respondents not using any shared mobility service. As shown in the literature review, users of shared mobility are younger, more affluent and live in more mixed land use zones, all confirmed in this study by Table 6-1. They are also multi-modal, owning fewer cars and more transit passes. It is more likely that users of shared mobility are working and live closer to their jobs. Males tend to use more shared mobility services.

Table 6-1 Significant differences between ridehail and carshare users and not users continuous variables

\begin{tabular}{clrrrrr}
\hline & $\begin{array}{c}\text { Ride and Car- } \\
\text { share use per } \\
\text { month }\end{array}$ & N & Mean & S.D. & Min & Max \\
\hline \multirow{2}{*}{$\begin{array}{c}\text { Personal car } \\
\text { ownership }\end{array}$} & No use & 226 & 0.8 & 0.5 & - & 2.0 \\
& More than once & 253 & 0.7 & 0.6 & - & 4.0 \\
& TOTAL & $\mathbf{4 7 9}$ & $\mathbf{0 . 8}$ & $\mathbf{0 . 6}$ & - & $\mathbf{4 . 0}$ \\
& No use & 228 & 42.8 & 15.9 & 18.0 & 88.0 \\
Age & More than once & 253 & 33.7 & 10.5 & 18.0 & 74.0 \\
& TOTAL & $\mathbf{4 8 1}$ & $\mathbf{3 8 . 0}$ & $\mathbf{1 4 . 1}$ & $\mathbf{1 8 . 0}$ & $\mathbf{8 8 . 0}$ \\
Emp. & No use & 228 & 17.0 & 20.5 & 0.5 & 105.5 \\
$\begin{array}{c}\text { Density } \\
\text { (Jobs/Acre) }\end{array}$ & More than once & 253 & 23.0 & 23.7 & 0.5 & 105.5 \\
& TOTAL & $\mathbf{4 8 1}$ & $\mathbf{2 0 . 2}$ & $\mathbf{2 2 . 4}$ & $\mathbf{0 . 5}$ & $\mathbf{1 0 5 . 5}$ \\
$\begin{array}{c}\text { Personal } \\
\text { income } \\
\text { (USD) }\end{array}$ & No use & 207 & 53,249 & 35,137 & 5,000 & 137,500 \\
\hline
\end{tabular}


Table 6-2 Significant differences between ridehail and carshare users and not users discrete variables

\begin{tabular}{clrrr}
\hline \multirow{2}{*}{ Variable } & \multicolumn{1}{c}{ Factor } & \multicolumn{2}{c}{$\begin{array}{c}\text { Ride and Car-share } \\
\text { use per month }\end{array}$} \\
\cline { 3 - 4 } & & No use & $\begin{array}{c}\text { More } \\
\text { than once }\end{array}$ & \\
\cline { 3 - 4 } Gender & Sample Size & 228 & 253 & 481 \\
& Female & $59 \%$ & $52 \%$ & $55 \%$ \\
& Male & $41 \%$ & $46 \%$ & $44 \%$ \\
\multirow{3}{*}{ Transit Pass } & Other & $0 \%$ & $2 \%$ & $1 \%$ \\
& Available & $29 \%$ & $41 \%$ & $36 \%$ \\
& Homework & $4 \%$ & $5 \%$ & $5 \%$ \\
& Less than 2 miles & $15 \%$ & $32 \%$ & $24 \%$ \\
& Between 2 and 10 miles & $30 \%$ & $32 \%$ & $31 \%$ \\
\cline { 2 - 4 } Distance to Work & More than 10 miles & $11 \%$ & $11 \%$ & $11 \%$ \\
& Not working & $36 \%$ & $16 \%$ & $25 \%$ \\
& Unknown & $3 \%$ & $4 \%$ & $4 \%$ \\
\hline
\end{tabular}

\subsection{Implications for Policy}

The results found on this research supports the current literature that shared mobility has an essential role in reducing vehicle ownership. The effects of car ownership reduction are higher for younger, educated and affluent people. It is hard to say if these people will keep their travel habits as they age, but indeed is an opportunity for city planners to maintain and expand the offer of shared mobility for this group, both because they can be influencers and because they will still be on the travel market for a long time. 
There is also a stronger reduction in vehicle ownership for the users of carshare than those using ridehail and an excellent opportunity for public officials to work together with developers, community leaders and carshare companies. An increase in carshare use is sufficient to reduce vehicle ownership in general, with several benefits, as reducing parking requirements, thus reducing the cost of building housing; increasing the use of transit, as households with fewer vehicles tend to own more transit passes. Some ways to achieve these targets could be the distribution of free membership to potential users (as car2go offers free membership to university students), reduction in parking requirements for developments with dedicated parking spots to carshare services and marketing campaigns explicitly targeting vehicle ownership reduction. A more politically sensitive option would be raising the cost of on-street parking, as one-way carshare does not pay for parking.

Parking availability also reduces car ownership but is more effective for households owning more than two vehicles. Nevertheless, the increased use of shared mobility can achieve the same results as not offering parking in the building for all household types, as shown in Figure 5-6. The use of both options, relaxing parking requirements and shared mobility availability, seems the best strategy to reduce vehicle ownership now and in the long term, for two reasons. First, for the short term, it is an alternative to those residents that decide to get rid of one of all cars but still are not ready to give up the usage of cars. The second 
reason, for the long term, a new relationship with vehicle ownership can be built now for the younger generation. This new type of relationship with the car does not consider the automobile as a symbol or an intrinsic part of the American dream, but as another option for mobility, available to be used (and not possessed) as needed.

There is also an important relationship between land use, shared mobility and parking supply that urban planners should take into consideration. Denser areas provide better opportunities for shared mobility providers, offering more potential consumers and higher levels of service (e.g., more available cars and less wait time). On the other hand, the cost of parking in developed areas are also higher. Taking these two characteristics into account, urban planners can smartly induce new developments and zoning codes that require less parking in denser areas, taking advantage of the attractiveness for shared mobility services of serving highly dense areas to foster their supply and use, as an alternative to private vehicle ownership.

However, we cannot say that shared mobility reduces vehicle usage. Nevertheless, it is a first step in the direction of a more sustainable fleet of vehicles: it is easier to change the entire fleet of one company to electric than several owners. 


\subsection{Limitations}

There are several limitations to this work. The cross-sectional nature of this dataset limits the ability to assess causality behind the observed behaviors. The characteristics of shared mobility services and their users are continuously evolving, increasing the uncertainty about the observed relationships. The quality of the responses in some variables prevented us from expanding the analysis, as for example vehicle usage or VMT. It is a study designed for multifamily housing located in urban areas, thus not appropriate to use in suburban areas or singlefamily residence. Some respondents may have recently moved, meaning we captured a transition phase of their lives, which do not portray their actual travel behavior.

\subsection{Recommendations and Future Research}

This research confirms previous shared mobility findings and brings insights into the role emerging transportation services have on vehicle ownership. We have shown that ridehail and especially carshare use are associated with lower levels of vehicle ownership and combined with other transportation policy measures, such as reduced parking, could reduce even more the levels of vehicle ownership. As this research is cross-sectional, a longitudinal study in the future could provide more light on the causational 
relationships between shared mobility, transportation policy measures and vehicle ownership.

This work could also be expanded and compared to more suburban areas or single family housing. Historically, these types of households depend almost exclusively on private vehicles to travel. How new shared mobility services are penetrating (or not) in this significant part of the American landscape is a topic to be understood. Finally, this research could be expanded to not only vehicle ownership, but also vehicle usage. How mobility sharing services contribute to overall vehicle miles traveled and the subsequent result on household well-being, congestion, and the environment is important to consider. 


\section{Chapter 7. References}

Agostino, A. B. (1996). A random effects multinomial probit model of car ownership choice. Proceedings of the Third Workshop on Bayesian Statistics in Science and Technology: Case Studies.

Agresti, A. (2013). Categorical data analysis. New York: John Wiley \& Sons.

Alemi, F. (2018). What Makes Travelers Use Ridehailing? Exploring the Latent Constructs behind the Adoption and Frequency of Use of Ridehailing Services, and Their Impacts on the Use of Other Travel Modes. University of California Davis: PhD Dissertation.

Alemi, F., Circella, G., Handy, S., \& Mokhtarian, P. (2018). What influences travelers to use Uber? Exploring the factors affecting the adoption of ondemand ride services in California. Travel Behaviour and Society, 13, 88104.

Alemi, F., Circella, G., Handy, S., \& Mokhtarian, P. L. (2017). What Influences Travelers to Use Uber? Exploring the Factors Affecting the Adoption of On-Demand Ride Services. TRB 96th Annual meeting Compendium of Papers, No: 17-05630.

Alemi, F., Circella, G., Mokhtarian, P., \& Handy, S. (2018). Exploring the latent constructs behind the use of ridehailing in California. Journal of Choice Modelling 29, 47-62. 
Allison, P. D. (2014). Measures of fit for logistic regression. SAS Global Forum. Washington DC.

Anowar, S., Eluru, N., \& Miranda-Moreno, L. F. (2014). Alternative Modeling Approaches Used for Examining Automobile Ownership: A Comprehensive Review. Transport Reviews, 34:4, 441-473.

Bento, A. M., Cropper, M. L., Mobarak, A. M., \& Vinha, K. (2005). The effects of urban spatial structure on travel demand in the United States. Review of Economics and Statistics, 87(3), 466-478.

Bhat, C. R. (1993). An endogenous switching simultaneous equation system of employment, income, and car ownership. Transportation Research A 27, 447-459.

Bhat, C., \& Guo, J. (2007). A comprehensive analysis of built environment characteristics on household residential choice and auto ownership levels. Transportation Research Part B 41, 506-526.

Bhat, C., \& Pulugurta, V. (1998). A Comparison of two alternative behavioral choice mechanisms for household auto ownership decisions. Transportation Research Part B.

Bhat, C., Sen, S., \& Eluru, N. (2009). The impact of demographics, built environment attributes, vehicle characteristics, and gasoline prices on household vehicle holdings and use. Transportation Research Part B 43, $1-18$. 
Botsman, R. (2010). What's mine is yours : The rise of collaborative consumption. New York: Harper Business.

Brant, R. (1990). Assessing proportionality in the proportional odds model for ordinal logistic regression. Biometrics 46, 1171-1178.

BroadbandNow. (2017, 11 30). BroadbandNow. Retrieved 10 02, 2018, from https://broadbandnow.com/Oregon

Cao, X., Mokhtarian, P., \& Handy, S. (2007). Cross-Sectional and Quasi-Panel Explorations of the Connection between the Built Environment and Auto Ownership. Environment and Planning A: Economy and Space, 830-847.

Cervero, R., \& Kockelman, K. (1997). Travel demand and the 3Ds: density, diversity, and design. . Transport. Res. D 2 (3), , 199-219.

Cervero, R., Golub, A., \& Nee, B. (2007). City CarShare: longer-term travel demand and car ownership impacts. Transportation Research Record 1992, 70-80.

Chu, Y.-L. (2002). Automobile ownership analysis using ordered probit models. . Transportation Research Record: Journal of the Transportation Research Board, 1805, 60-67.

Circella, G., Alemi, F., Tiedeman, K., Berliner, R. M., Lee, Y., Fulton, L., . . . Handy, S. (2017). What Affects Millennials' Mobility? PART II: The Impact of Residential Location, Individual Preferences and Lifestyles on Young 
Adults' Travel Behavior in California. . University of California, Davis: National Center for Sustainable Transportation.

Circella, G., Alemi, F., Tiedeman, K., Handy, S., \& Mokhtarian, P. (2018). The Adoption of Shared Mobility in California and Its Relationship with Other Components of Travel Behavior. Davis, CA: National Center for Sustainable Transportation.

Circella, G., Fulton, L., Alemi, F., Berliner, R. M., Tiedeman, K., Mokhtarian, P. L., \& Handy, S. (2016). What Affects Millennials' Mobility? PART I: Investigating the Environmental Concerns, Lifestyles, Mobility-Related Attitudes and Adoption of Technology of Young Adults in California. University of California, Davis: National Center for Sustainable Transportation.

Cirillo, C., \& Liu, Y. (2013). Vehicle Ownership Modeling Framework for the State of Maryland: Analysis and Trends from 2001 and 2009 NHTS Data. Journal of Urban Planning and Development, Vol. 139, 1-11.

Cirillo, C., Liu, Y., \& Tremblay, J.-M. (2017). Simulation, numerical approximation and closed forms for joint discrete continuous models with an application to household vehicle ownership and use. Transportation, 1105-1125.

City of Portland. (2018, May 24). Zoning Code. Retrieved from Bureau of Public Services: https://www.portlandoregon.gov/bps/title33_complete_print.pdf 
Clark, B. (2012). Understanding how household car ownership changes over time, PhD thesis. University of the West of England.

Clifton, K. J., Gehrke, S. R., \& Currans, K. M. (2015). Understanding Residential Location Choices for Climate Change and Transformation Decision Making. Portland, Oregon: ODOT/NITC.

Davidson, T., \& Webber, M. E. (2017, October 21). Using Only Uber or Lyft Is Cheaper than Owning a a Car for $25 \%$ of Americans- Here's How to Know If You Apply. Retrieved October 22, 2018, from Business Insider: http://www.businessinsider.com/uber-or-lyft-could-be-cheaper-thanowning-a-car-2017-10

de Jong, G., Fox, J., Daly, A., Pieters, M., \& Smit, R. (2004). Comparison of car ownership models. Transport Reviews, 24:4, 379-408.

Durning, A. (2013, October 16). Parking Break: Cities are Already Ditching Parking Quotas. Retrieved from Sightline Daily: http://daily.sightline.org/2013/10/16/parking-break/ Engel-Yan, J., \& Passmore, D. (2013). Carsharing and Car Ownership at the Building Scale: Examining the Potential for Flexible Parking Requirements. Journal of the American Planning Association, 82-91.

Ewing, R., \& Cervero, R. (2010). Travel and the built environment. J. Am. Plann. Assoc. 76 (3),, 265-294. 
Fang, H. (2008). A discrete-continuous model of households' vehicle choice and usage, with an application to the effects of residential density. Transp. Res. B, 736-758.

Feigon, S., \& Murphy, C. (2016). Shared Mobility and the Transformation of Public Transit. Transportation Research Board, Washington, D.C.: TCRP Report 188.

Feigon, S., \& Murphy, C. (2018). Broadening Understanding of the Interplay Between Public Transit, Shared Mobility, and Personal Automobiles. Transportation Research Board, Washington, D.C: TCRP Research Report 195.

Frank, L. D., Sallis, J. F., Conway, T. L., \& Chapman, J. E. (2006). Many Pathways from Land Use to Health: Associations between Neighborhood Walkability and Active Transportation, Body Mass Index, and Air Quality. Journal of the American Planning Association, 75-87.

Gabbe, C. J., \& Pierce, G. (2016). Hidden Costs and Deadweight Losses: Bundled Parking and Residential Rents in the Metropolitan United States. Housing Policy Debate, 217-219.

Gehrke, S., Felix, A., \& Reardon, T. (2018). Fare choices: A survey of ride-hailing passengers in metro Boston. Boston, MA: Metropolitan Area Planning Council. 
Guevara, C. A. (2015). Critical assessment of five methods to correct for endogeneity in discrete-choice models. Transportation Research Part A: Policy and Practice, 240-254.

Guo, Z. (2013). Residential Street Parking and Car Ownership. Journal of the American Planning Association, 79:1, 32-48.

Guo, Z., \& Ren, S. (2012). From Minimum to Maximum: Impact of the London Parking Reform on Residential Parking Supply from 2004 to 2010? Urban Studies, vol. 50, 1183-1200.

Hampshire, R., Simek, C., Fabusuyi, T., Di, X., \& Chen, X. (2017). Measuring the Impact of an Unanticipated Disruption of Uber/Lyft in Austin, TX. Available at SSRN: https://ssrn.com/abstract=2977969 or http://dx.doi.org/10.2 .

Henderson, P. (2017, May 25). Some Uber and Lyft riders are giving up their own cars: Reuters/lpsos poll. Retrieved october 22, 2018, from Reuters: https://mobile-reuterscom.cdn.ampproject.org/c/mobile.reuters.com/article/amp/idUSKBN18L1D A

Hess, D. B. (2017). Repealing minimum parking requirements in Buffalo: new directions for land use and development. Journal of Urbanism: International Research on Placemaking and Urban Sustainability, 442467. 
Hess, D. B., \& Ong, P. M. (2002). Traditional neighborhoods and automobile ownership. Transportation Research Record: Journal of the Transportation Research Board, 1805, 35-44.

Holtzclaw, J., Clear, R., Dittmar, H., Goldstein, D., \& Haas, P. (2002). Location efficiency: Neighborhood and socio-economic characteristics determine auto ownership and use — studies in Chicago, Los Angeles and San Francisco. Planning and Technology, 25(1),, 1-27.

Jia, W., \& Wachs, M. (1999). Parking requirements and housing affordability: a case study of San Francisco. Transportation Research Record, 156-160.

Kain, J. (1967). Postwar metropolitan development: housing preferences and auto ownership. The American Economic Review, 57(2), 223-234.

Kromrey, J. D., \& Rendina-Gobioff, G. (2002). An empirical comparison of regression analysis strategies with discrete ordinal variables. Multiple linear regression viewpoints, 30-43.

Litman, T. (2010). Parking requirement impacts on housing affordability. Retrieved from Victoria Transport Policy Institute: http://www.vtpi.org/parkhou.pdf

Long, J. (1997). Regression models for categorical and limited dependent variables. . Thousand Oaks, CA: Sage. 
Manville, M. (2013). Parking requirements and housing development: Regulation and Reform in Los Angeles. Journal of the American Planning Association, 49-66.

Martin, E., \& Shaheen, S. (2011). The impact of carsharing on public transit and non-motorized travel: an exploration of North American carsharing survey data. Energies, 4, 2094-2114.

Martin, E., Shaheen, S. A., \& Lidicker, J. (2010). Impact of Carsharing on Household Vehicle Holdings. Transportation Research Record: 2143, 150158.

McDonnell, S., Madar, J., \& Been, V. (2011). Minimum parking requirements and housing affordability in New York City. Housing Policy Debate, 45-68.

Mishra, G. S., Clewlow, R. R., \& Mokhtarian, P. L. (2015). The effect of carsharing on vehicle holdings and travel behavior: A propensity score and causal mediation analysis of the San Francisco Bay Area. Research in Transportation Economics 52, 46-55.

Nair, R., Miller-Hooks, E., Hampshire, R. C., \& Busic, A. (2013). Large-scale vehicle sharing systems: Analysis of velib. International Journal of Sustainable Transportation, 7(1), 85-106.

Namazu, M., \& Dowlatabadi, H. (2018). Vehicle ownership reduction: A comparison of one-way and two-way carsharing systems. Transport Policy $64,38-50$. 
Njus, E. (2017, November 01). Car-sharing in Portland: Driver's guide to options in a growing market. Retrieved from The Oregonian: https://www.oregonlive.com/commuting/index.ssf/2016/09/carsharing_in_portland_driver.html

Oakil, A. T., Manting, D., \& Nijland, H. (2016). Determinants of car ownership among young households in the Netherlands: The role of urbanisation and demographic and economic characteristics. Journal of Transport Geography, 229-235.

Pew Research Center. (2016). Shared, Collaborative and On Demand: The New Digital Economy. Pew Research Center.

Pew Research Center. (2018, 03 01). Defining generations: Where Millennials end and post-Millennials begin. Retrieved october 22, 2018, from Pew Research Center: http://www.pewresearch.org/facttank/2018/03/01/defining-generations-where-millennials-end-and-postmillennials-begin/

Potoglou, D., \& Susilo, Y. (2008). Comparison of Vehicle-Ownership Models . Transportation Research Record - Vol 2076, Issue 1, 97-105.

Purvis, L. C. (1994). Using census public use micro data sample to estimate demographic and automobile ownership models. Transportation Research Record 1443, 21-30. 
Ramsey, K., \& Bell, A. (2014). Smart Location Database: Version 2.0 User Guide. Washington, DC: Environmental Protection Agency. Rayle, L., Shaheen, S., Chan, N., Dai, D., \& Cervero, R. (2014). App-Based, OnDemand Ride Services: Comparing Taxi and Ridesourcing Trips and User Characteristics in San Francisco. Berkeley, CA: University of California Transportation Center.

Rivasplata, C., Guo, Z., Lee, R. W., \& Keyon, D. (2013). Residential On-Site Carsharing and Off-Street Parking in the San Francisco Bay Area, California. Transportation Research Record, 2359(1), 68-75.

Schimek, P. (1996). Household motor vehicle ownership and use: How much does residential density matter? . Transportation Research Record: Journal of the Transportation Research Board, 1552, 120-125.

Schure, J. t., Napolitan, F., \& Hutchinson, R. (2012). Cumulative Impacts of Carsharing and Unbundled Parking on Vehicle Ownership and Mode Choice. Transportation Research Record, 2319(1), 96-104.

SFCTA, S. F. (2017). TNCs Today: A Profile of San Francisco Transportation Network Company Activity. San Francisco, California: SFCTA.

Shaheen, S., \& Cohen, A. (2018). Shared ride services in North America: definitions, impacts, and the future of pooling. Transport Reviews. 
Shaheen, S., Chan, N., Bansal, A., \& Cohen, A. (2015). Shared Mobility: Definitions, Industry Developments, and Early Understanding. UC Berkeley: Transportation Sustainability Research Center.

Shaheen, S., Cohen, A., \& Zohdy, I. (2016). Shared Mobility: Current Practices and Guiding Principles. Washington DC: FHWA. Retrieved october 19, 2018, from https://ops.fhwa.dot.gov/publications/fhwahop16022/fhwahop16022.pdf

Shaheen, S., Cohen, A., Zohdy, I., \& Kock, B. (2016). Smartphone Applications to Influence Travel Choices: Practices and Policies. Washington DC: FHWA. Retrieved october 19, 2018, from https://ops.fhwa.dot.gov/publications/fhwahop16023/fhwahop16023.pdf

Shaheen, S., Martin, E., \& Bansal, A. (2018). Peer-To-Peer (P2P) Carsharing: Understanding Early Markets, Social Dynamics, and Behavioral Impacts. Berkeley, CA: UC Berkeley.

Shaheen, S., Martin, E., Chan, N., Cohen, A., \& Pogodziniski, M. (2014). Public Bikesharing in North America During a Period of Rapid Expansion: Understanding Business Models, Industry Trends and User Impacts. Mineta Transportation Institute.

Shaheen, S., Totte, H., \& Stocker, A. (2018). Future of Mobility White Paper. UC Berkeley, California: Institute of Transportation Studies. 
Shoup, D. C. (2005). The high cost of free parking (Vol. 206). Chicago: Planners Press.

Tanner, J. (1983). International comparison of cars and car usage. Crowthorne, Berkshire, UK: TRRL Report 1070, Access and Mobility Division, Transport Operations Department, Transport Road Research Laboratory, .

Taylor, B. D., Chin, R., Crotty, M., Dill, J., Hoel, L. A., Manville, M., . . al., e. (2015). Between Public and Private Mobility: Examining the Rise of Technology-Enabled Transportation Services. Washington, DC:

Transportation Research Board: Committee for Review of Innovative Urban Mobility Services.

Train, K. (1986). Qualitative choice analysis: Theory, econometrics and an application to automobile demand. Cambridge, MA: MIT Press.

Weinberger, R. (2012). Death by a thousand curb-cuts: Evidence on the effect of minimum parking requirements on the choice to drive. Transport Policy, 20, 93-102.

Weinberger, R., Seaman, M., Johnson, C., \& Kaehny, J. (2008). Guaranteed parking - guaranteed driving: comparing Jackson Heights, Queens and Park Slope, Brooklyn shows that a guaranteed parking spot at home leads to more driving to work. New York: Report prepared for Transportation Alternatives. 
Whelan, G. (2007). Modelling car ownership in Great Britain. Transportation Research Part A 41, 205-219.

Wong, Y., Hensher, D., \& Mulley, C. (2017). Emerging transport technologies and the modal efficiency framework: A case for mobility as a service (MaaS). 15th International Conference on Competition and Ownership of Land Passenger Transport (Thredbo 15), (pp. 1-24). Stockholm.

Yagi, M., \& Managi, S. (2016). Demographic determinants of car ownership in Japan. Transport Policy 50, 37-53. 


\section{Appendix A. Postcard}

Kelly J. Clifton, Ph.D.

Maseeh College of Engineering

\& Computer Science

Portland State University

Post Office Box 751 CEE

Portland, Oregon 97207-0751

NON PROFIT ORG.

US POSTAGE

PAID

PERMIT NO. 770

PORTLAND, OR

RETURN SERVICE REQUESTED

CURRENT RESIDENT

«fulladd"

«city», «state» «zip» 
Dear Current Resident,

\section{\& Portland $\underset{\text { UnIVERSITY }}{\text { State }}$}

As part of the "Neighborhood Transportation Study", our research team would like to learn more about the housing, neighborhood, and transportation features that are most important to you.

To do so, we invite you to participate in our 15-minute online survey.

To find out more information, complete our survey, and also enter for a chance to win one of 5 gift cards of $\$ 50$ value, please visit our survey website at:

\section{http://bit.ly/tstudy \\ Household ID Number: «hhid»}

Your input is valuable to us and will ensure this study is a success!

Kelly J. Clifton, Ph.D.

Professor, Civil \& Environmental Engineering tstudy@pdx.edu; (503) 489-8638

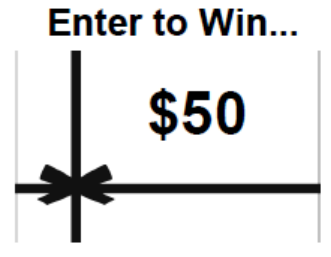




\section{Appendix B. Survey Instrument}

\section{Introduction}

\section{Dear Portland Resident:}

You are invited to participate in a research study conducted by Portland State University about housing and transportation in the Portland area. As Portland grows, residents are faced with a number of new housing and transportation options. We would like to understand more about your choices and preferences to better inform land development and transportation policies that impact our neighborhoods. This online survey should take you about 20 minutes to complete.

If you have any questions about the Neighborhood Transportation Study, please feel free to call us at (503) 489-8638 or email us at tstudy@pdx.edu.

Thank you,

Dr. Kelly J. Clifton

Department of Civil and Environmental Engineering

Portland State University 
By completing this online survey, you acknowledge that you are at least 18 years of age and consent to participate in the study. Your involvement in this study is completely voluntary, and you may choose not to participate or terminate your participation at any point. The responses you provide here and your personal information will remain confidential. Upon your request, we can provide you with a copy of this informed consent statement.

After the survey, you will be invited to enter your name into a drawing for a chance to win a $\$ 50$ gift card as a thank you for participation. The contact information you provide will not be linked to your survey responses.

If you have any concerns or problems about your participation or your rights as a research subject, please contact the Human Subjects Research Review Committee, Office of Research and Strategic Partnerships, Post Office Box 751, Portland State University, (877) 480-4400.

Please begin this survey by entering the 6-digit Household ID provided on the postcard we sent you:

\section{6-digit Household ID number}

\section{Household and Current Residence}

In your household, how many people, INCLUDING YOURSELF are in each of these categories?

Number of people aged 16 years and older

Number of people under the age of 16

Total

US zip code:

Country (if outside the US): 
Which of the following describes your household?

Family: Couple or partner

Family: Couple or partner with children

Family: Single parent

Nonfamily: Single person

Nonfamily: Roommates or friends

Blended family: Combination of family and nonfamily

Other, specify

Are you a licensed driver?

Yes, and I am currently able to drive

Yes, but I am not currently able to drive

No, I am not a licensed driver

How long have you lived at your CURRENT residence?

Less than 1 year

1 to 3 years

3 to 10 years

$10+$ years

How many bedrooms are in your current residence?

Studio with no separate bedroom

1 bedroom

2 bedrooms

3 or more bedrooms 
What is the zip code of your PREVIOUS address?

\begin{tabular}{|l|}
\hline \\
\hline \\
\hline
\end{tabular}

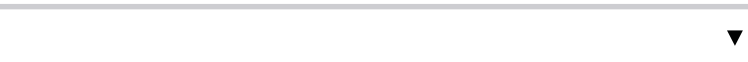

Speaking of your CURRENT residence, do you:

Own

Rent

Live there without payment of rent

Other, specify

Don't know

How much do you PERSONALLY pay in rent or mortgage each month?

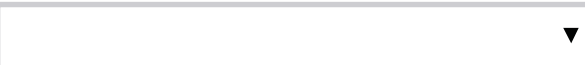

\section{Previous Residence}

How long did you live there?

Less than 1 year

1 to 3 years

3 to 10 years

$10+$ years 
Indicate how the following items have changed for YOU since you moved from your PREVIOUS residence. Please drag and drop each item into the appropriate box.

\section{Items}

The number of personal vehicles owned or leased (cars, motorcycles, etc.)

Travel by personal vehicle

The number of bicycles owned

Ownership of transit passes (monthly/yearly)

Carsharing memberships (Car2Go, Zip Car, Reach Now, Get Around)

Bikesharing memberships

Rideshare membership (Uber, Lyft, taxi, etc.)

Commuting distance
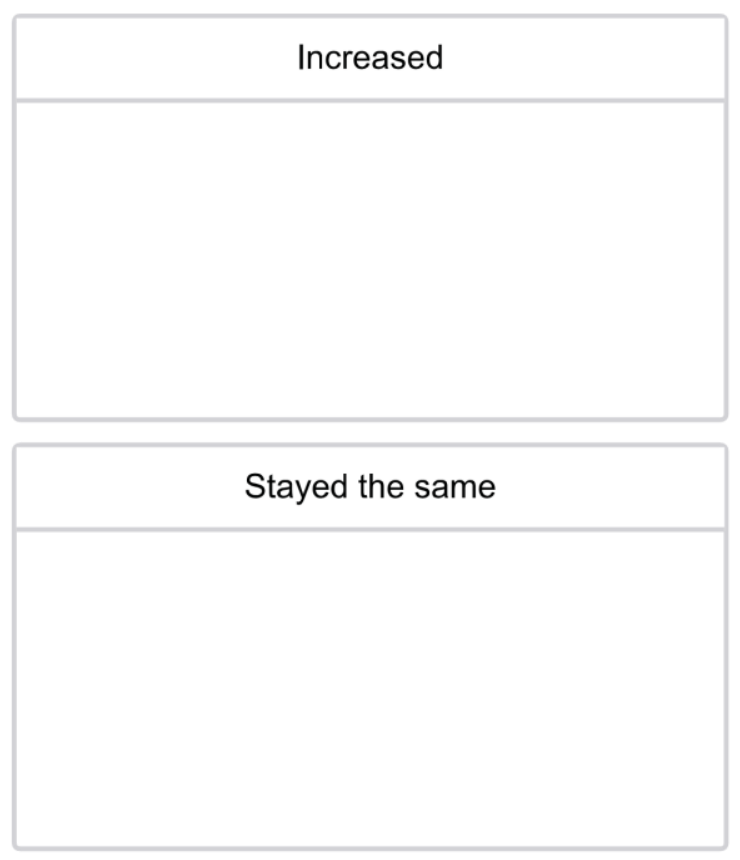
Commuting time

Amount of travel made by bicycling

Amount of travel made by transit

Amount of travel made by walking

Number of people in the household

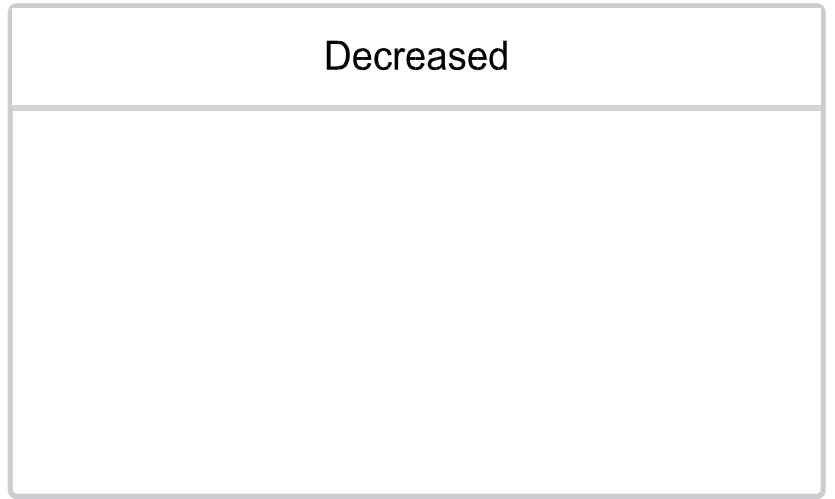

Not Applicable 
Please indicate how important the following items were when you were looking for your CURRENT residence. Please drag and drop each item into the appropriate box.

Items
Having dedicated parking
at your residence
Bike lanes and paths
nearby
Easy access to the
freeway
Good public transit
service
Access to carsharing
service
Access to bikeshare
Sidewalks throughout the
neighborhood
Shops, services and
restaurants within walking
distance
Multiple bedrooms
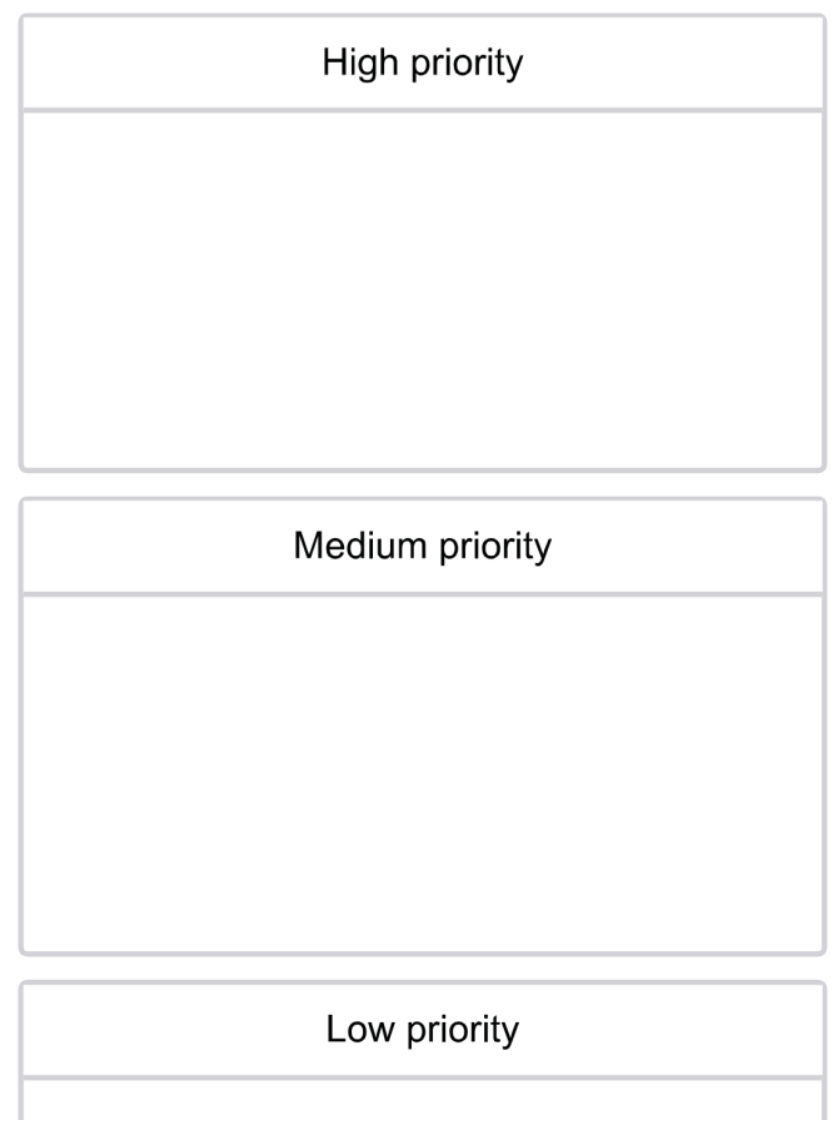
Availability of off-street

parking (garages or driveways)

High quality K-12 schools

Park and open spaces nearby

Easy access to downtown

Close to work or school

Low levels of car traffic on neighborhood streets

Lots of interaction between neighbors

Lots of people out and about in the neighborhood

Economic level of neighbors similar to my level

Living at the center of it all

Please note anything that you considered when you were looking for your CURRENT residence that was not included in the items above.

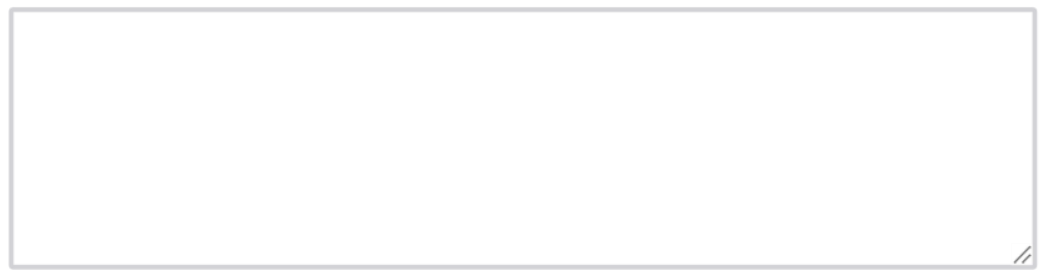

\section{Transportation Resources}

What is the total number of private vehicles (car, truck, van, etc.) that are owned or leased by EVERYONE living in your dwelling unit? 
Of these, how many do you PERSONALLY own or lease?

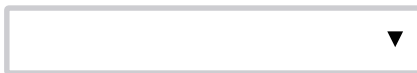

For each vehicle you PERSONALLY own or lease, please provide the following information:

\begin{tabular}{|c|c|c|c|c|c|}
\hline & Body Type & Year & Fuel Type & $\begin{array}{l}\text { Estimate Miles } \\
\text { Driven Per Week }\end{array}$ & $\begin{array}{c}\text { Year Purchased } \\
\text { Leased }\end{array}$ \\
\hline Vehicle 1 & $\checkmark$ & & $\checkmark$ & & \\
\hline Vehicle 2 & 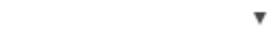 & & 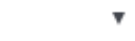 & & \\
\hline Vehicle 3 & $\checkmark$ & & $\checkmark$ & & \\
\hline Vehicle 4 & $\checkmark$ & & $\checkmark$ & & \\
\hline Vehicle 5 & 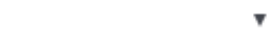 & & v & & \\
\hline
\end{tabular}

You responded that do not own or lease a vehicle, why? Select all that apply.

$\square$ Owning and maintaining a vehicle is too expensive

I prefer to bike

I prefer to walk

I prefer to take transit

I am purchasing a vehicle soon

Parking is too much of a hassle at home

Parking is too much of a hassle at my destinations (work, shopping, etc.) $\square$ I have access to a someone else's vehicle (roommate's, friend's, or family member's car)

$\square$ I belong to a carsharing service (ZipCar, Car2Go, Reach Now, etc.)

$\square$ I use rideshare (i.e. Uber, Lyft, taxi, etc.)

$\square$ Owning a car has negative environmental impacts

$\square$ Owning a car is inconvenient

I don't drive

Other, specify 
You responded that you currently own or lease a vehicle. Under what circumstances would you be willing to give up your ownership and/or lease and personally own no vehicles? Select all that apply.

\begin{tabular}{|c|c|c|c|}
\hline $\begin{array}{l}\text { Under no } \\
\text { circumstances would } \\
\text { I willingly give up my } \\
\text { vehicle. }\end{array}$ & $\begin{array}{l}\square \text { Greater supply of } \\
\text { rideshare services } \\
\text { (such as Uber and } \\
\text { Lyft) }\end{array}$ & $\begin{array}{l}\square \text { More retail and } \\
\text { service } \\
\text { establishments in my } \\
\text { neighborhood }\end{array}$ & $\begin{array}{l}\square \text { My driving skill } \\
\text { levels become } \\
\text { inadequate due to } \\
\text { physical or mental } \\
\text { abilities }\end{array}$ \\
\hline $\begin{array}{l}\text { The price of fuel } \\
\text { were to double }\end{array}$ & $\begin{array}{l}\square \text { Cheaper rideshare } \\
\text { services }\end{array}$ & $\begin{array}{l}\square \text { I could work from } \\
\text { home }\end{array}$ & $\begin{array}{l}\square \text { My children move } \\
\text { out of the house or } \\
\text { can get around on } \\
\text { their own }\end{array}$ \\
\hline $\begin{array}{l}\text { Transit service near } \\
\text { my home was more } \\
\text { frequent or went to } \\
\text { places I wanted to } \\
\text { go }\end{array}$ & $\begin{array}{l}\square \text { More options to use } \\
\text { carshare (Zipcar, } \\
\text { Car2Go, Reach } \\
\text { Now, e.g.) when I } \\
\text { need one }\end{array}$ & $\begin{array}{l}\square \text { Parking my car } \\
\text { became more } \\
\text { difficult or more } \\
\text { expensive }\end{array}$ & $\begin{array}{l}\square \text { I lived closer to my } \\
\text { work or school. }\end{array}$ \\
\hline $\begin{array}{l}\text { Transit service near } \\
\text { my work or school } \\
\text { was more frequent } \\
\text { or went to places I } \\
\text { wanted to go }\end{array}$ & $\begin{array}{l}\square \text { Better/safer } \\
\text { bicycling } \\
\text { infrastructure }\end{array}$ & $\begin{array}{l}\square \text { Traffic congestion } \\
\text { causes travel times } \\
\text { to be worse }\end{array}$ & $\begin{array}{l}\square \text { I felt safer (more } \\
\text { secure) traveling } \\
\text { alone. }\end{array}$ \\
\hline $\begin{array}{l}\text { Transit service were } \\
\text { free }\end{array}$ & $\begin{array}{l}\square \text { Better/safer } \\
\text { sidewalks and } \\
\text { pedestrian aids }\end{array}$ & $\begin{array}{l}\square \text { Ownership and } \\
\text { maintenance costs } \\
\text { of this vehicle } \\
\text { become too high }\end{array}$ & $\square$ Other \\
\hline
\end{tabular}

How many PERSONAL working bicycles do you own?

0 Total number of working bicycles

Do you have any of the following? Select all that apply.

$\square$ Carshare memberships (e.g., ZipCar, Car2Go)

Rideshare account (e.g., Uber, Lyft)

Bikeshare membership (e.g., BiketownPDX)

Transit pass (monthly or annually)

None of the above 
Which CARSHARING service do you participate in? Please check all that apply.

$\square$ ZipCar $\begin{aligned} & \square \text { Private carshare provided by your residence } \\ & \text { or work }\end{aligned}$
$\square$ Get Around
$\square$ Car2Go
$\square$ Rot a member of any carsharing service
Reach Now
How do you pay for the CARSHARING membership? Please check all that apply.
$\square$ Paid in full by you or someone in your
household
$\square$ Paid in full through work or school $\quad \square$ It is paid in full by my place of residence
$\square$ Paid in part/Discounted through work or $\quad \square$ Other, specify
school

How do you access this CARSHARE? Please check all that apply.

$\square$ Carshare is available on-site at your apartment

Carshare is located in your neighborhood

$\square$ Carshare is located near your work

$\square$ Other location, specify

Which BIKESHARE service do you participate in? Please check all that apply.

$\square$ BikeTownPDX $\square$ Not a member of any bikesharing service
$\square$ Go by Bike (OHSU bike share) $\square$ Other, specify
$\square$ Private bikeshare provided by residence or
work


How is your BIKESHARE membership paid for? Please check all that apply.

Paid in full by you or someone in your household

Paid in full through work or school

Paid in part/Discounted through work or school
It is paid in full by by my place of residence

It is paid in part/Discounted by my place of residence

Other, specify

Do you have a monthly or annual TRANSIT pass? If so, how do you pay for it?

No, I do not have a transit pass.

Yes and my place of residence provides my transit pass at no cost.

Yes and I pay the full cost of this transit pass. Yes and my place of residence pays part of the cost of my transit pass.

Yes and an employer or school provides my transit pass at no cost to me.

Yes and an employer or school pays part of the costs of my transit pass.

Other, specify

\section{Transportation Use}

What is your current employment status? Please check all that apply.

$\square$ Employed full-time

Not currently employed

$\square$ Employed part-time

$\square$ Not currently employed, but looking for work

\section{Student}

Retired

$\square$ Other, specify 
Please tell us how often you work at each of the following locations:

\begin{tabular}{l|l|l|l|} 
& $\begin{array}{c}\text { How often do you } \\
\text { work from: }\end{array}$ & $\begin{array}{c}\text { Approximate } \\
\text { Distance from } \\
\text { Home } \\
\text { (times per week) }\end{array}$ \\
\hline $\begin{array}{l}\text { A workplace provided by my employer } \\
\text { (office, restaurant, etc.) }\end{array}$ \\
$\begin{array}{l}\text { Shared or collective workspace } \\
\text { At my clients' location }\end{array}$ \\
$\begin{array}{l}\text { Coffee shop, bar, restaurants or other } \\
\text { public space }\end{array}$ \\
My home
\end{tabular}

Please tell us about your school:

\begin{tabular}{l|c|c|c|} 
& $\begin{array}{c}\text { How often do you go to school: } \\
\text { (times per week) }\end{array}$ & $\begin{array}{c}\text { Approximate Distance from Home } \\
\text { (miles) }\end{array}$ & How do you usually get there? \\
\hline School & - & & \\
\hline
\end{tabular}

Approximately how many TIMES PER MONTH do you get or use....

0 Groceries delivered from a supermarket or grocery store (Fred Meyer, New Seasons, Safeway, etc.)

0 Prepackaged food deliveries (Blue Apron, Hello Fresh, etc.)

0 Food deliveries from local restaurants (pizza, Chinese food, etc.)

0 Packages from online shopping (Amazon, etc.)

0 Deliveries from other local stores (furniture, hardware etc.)

0 Rideshare service (Uber, Lyft, etc.)

0 Carshare service (Car2Go, Zipcar, etc.) 
Approximately how many MILES PER WEEK do you drive? Please include the vehicles you own or lease, vehicle share services (i.e. ZipCar, Car2Go, Reach Now and Get Around) and/or borrowing a friend's vehicle.

$0 \quad$ Weekly miles driven

On an average weekday, how many TIMES PER DAY do you leave and return to your home?

0 Leave home

0 Return home

How many TIMES PER WEEK do you frequent your neighborhood or local businesses (restaurants, bars, shops, etc). by WALKING AND/OR BICYCLING?

I never walk or bicycle to neighborhood destinations

Less than once per week

1 to 3 times per week

3 to 5 times per week

Most days

Multiple times per day

\section{Parking}

Is there parking available at the building you live in?

\section{No, there is not parking available}

\section{Yes, there is parking availble}

\section{I don't know}

How many parking spaces are available for your DWELLING UNIT (regardless of whether you personally use them)?

Number of free parking spaces

Number of paid parking spaces

Total 
Of these parking spaces available for your dwelling unit, how many of these do you use PERSONALLY?

Number of free parking spaces

Number of paid parking spaces

Total

Of the parking spaces you pay for, how much do you pay?

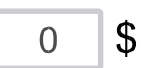

We'd like to know more about parking the vehicles you lease or own in spaces other than at your apartment building:

\begin{tabular}{l|l|l|} 
& $\begin{array}{c}\text { In a typical week, about how many } \\
\text { nights do you PERSONALLY park a } \\
\text { vehicle at each type of parking? }\end{array}$ & $\begin{array}{c}\text { Approximately, how } \\
\text { much do you pay for } \\
\text { each type of parking? } \\
\text { (dollars per months) }\end{array}$ \\
\hline $\begin{array}{l}\text { Off-street parking near your } \\
\text { place of residence (e.g., } \\
\text { parking garage or parking lot) }\end{array}$ & & \\
$\begin{array}{l}\text { On-street parking near your } \\
\text { place of residence (e.g., } \\
\text { curbside) }\end{array}$ & & \\
\hline
\end{tabular}




\section{Preferences}

Please indicate how well each item matches your personality by dragging and dropping into the appropriate box.

Items

Adventurous

Like a routine

Spontaneous

Likes being outdoors

Risk taking

Ambitous

Like to stay close to home

Efficient

Variety seeking

On time

Like being alone

Independent

Aggressive

Patient

Restless

Like being in charge
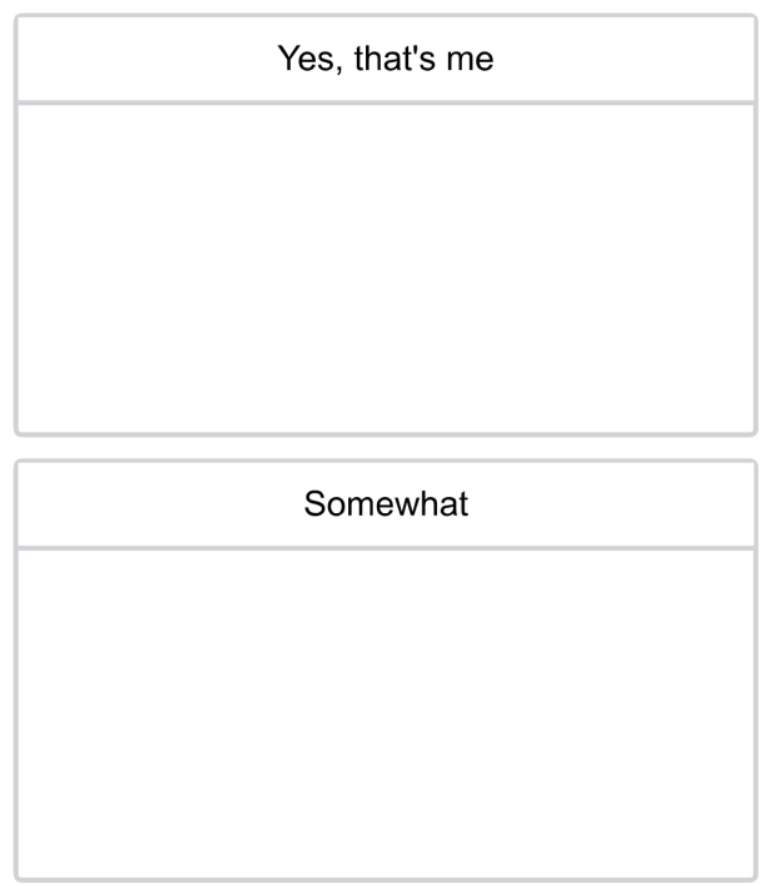

No, not at all 
Indicate the degree to which you agree with each of the following statements.

\begin{tabular}{|c|c|c|c|c|c|}
\hline & $\begin{array}{l}\text { Strongly } \\
\text { disagree }\end{array}$ & Disagree & Neutral & Agree & $\begin{array}{c}\text { Strongly } \\
\text { agree }\end{array}$ \\
\hline & 1 & 2 & 3 & 4 & 5 \\
\hline $\begin{array}{l}\text { I could manage } \\
\text { without a car }\end{array}$ & 0 & 0 & 0 & 0 & 0 \\
\hline $\begin{array}{r}\text { Traveling by car is } \\
\text { safe }\end{array}$ & 0 & 0 & 0 & 0 & 0 \\
\hline $\begin{array}{l}\text { Driving a car makes } \\
\text { all things accessible }\end{array}$ & 0 & 0 & 0 & 0 & 0 \\
\hline $\begin{array}{l}\text { I try to limit my } \\
\text { driving to help } \\
\text { improve air quality }\end{array}$ & 0 & 0 & 0 & 0 & 0 \\
\hline $\begin{array}{r}\text { Parking a car in my } \\
\text { neighborhood is a } \\
\text { hassle }\end{array}$ & 0 & 0 & 0 & 0 & $\mathrm{O}$ \\
\hline $\begin{array}{l}\text { I like to bike and } \\
\text { walk around the city }\end{array}$ & 0 & 0 & 0 & 0 & 0 \\
\hline
\end{tabular}

\section{Personal Information}

Select the category to which you most identify with:
Male
Female
Other, specify

What is your age?

Age in years:

Prefer not to say 
What is the highest grade or year of school you completed?

Less than a high school graduate

High school graduate or equivalent

Some college, vocational training, or associates degree

Bachelor's degree

Graduate or professional degree

What was your approximate income before taxes last year?

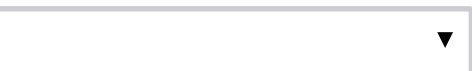

Thank you! You will automatically be directed to a Google Form. Here you can submit your contact information if you would like to be entered into a drawing for a gift of $\$ 50$.

We would value any additional comments you may have on this survey. Please write them in the space below. 


\section{Appendix C. Data Manipulation}

Variables were manipulated after data were gathered from intercept surveys. This appendix describes the recoding and classification of the webbased survey data for input into the multinomial models of Chapter 4.

The respondent could choose between 18 levels of income, including Don't Know and Refuse to Answer. Because the categories were not evenly spaced-i.e., one category was $\$ 25,000$ to $\$ 49,000$, and another was $\$ 50,000$ to $\$ 99,999$-the midpoints of the categories were used and treated as continuous values to calculate Table 3-3. However, for use in the models, we kept the discrete nature of the data. We reduced the number of income levels to five, based on the number of respondents for each category. These five levels were used in the early models of chapter 4 . In this test, the income levels with similar coefficients were collapsed, as long as they were contiguous, and we came up with the four levels of income as can be seen in Table 4-2.

A similar procedure was used for education. There were initially five categories of educational level: less than high school graduate, high school graduate, some college or associates degree, bachelor's degree, and graduate or professional degree. First, we collapsed less than high school, high school graduate and some college because these categories did not have sufficient respondents. We then used the three categories in the models of chapter 4 and 
comparing the coefficients of the three categories, found that the categories bachelor's degree and graduate or professional degree could be joined, as their coefficients were similar.

Household size was collected as a continuous variable; however, as there were only 30 respondents living in a three or more person household, we collapsed the data in three categories.

The age category consists of two bins: individuals under 35 and individuals 35 or older. The survey instrument collected age as a continuous variable. We chose these two bins to control explicitly for Millennials. Although the elderly may exhibit travel behavior different from other population groups, the sample had 35 observations of age above 65 , so these respondents are included in the 35 or older group.

Distance to work was collected as a continuous variable. We then divided into four categories: not working / unknown, based on the respondents that do not work, are looking for work or did not answer; more than 10 miles based on a distance usually covered by auto trips; between 2 and 10 miles, a typical distance for bike commuters; less than 2 miles and telecommute, a common distance for bike and walk commuters. 